\title{
COMPARISON OF HEATING METHODS FOR IN-SITU OIL SHALE EXTRACTION
}

\author{
A Thesis \\ by \\ KAUSHIK GAURAV HAZRA \\ Submitted to the Office of Graduate and Professional Studies of \\ Texas A\&M University \\ in partial fulfillment of the requirements for the degree of \\ MASTER OF SCIENCE
}

Chair of Committee, Christine Ehlig-Economides

Co-Chair of Committee, George J. Moridis

Committee Member, Yuefeng Sun

Head of Department, A. Daniel Hill

May 2014

Major Subject: Petroleum Engineering

Copyright 2014 Kaushik Gaurav Hazra 


\begin{abstract}
Oil shales are lamellar, non-porous, impermeable hydrocarbon bearing rocks that contain organic matter called kerogen which, when heated at pyrolysis temperature of approximately $600-800{ }^{\circ} \mathrm{F}$, thermo-chemically decomposes to liberate hydrocarbons. They are at the base of the resource triangle because cutting edge technology and higher fuel prices are required to economically produce them.

Technologies for oil shale production include surface and in-situ retorting. This study focusses on in-situ oil shale production methodologies. The process of heating oil shale to the pyrolysis temperature can be achieved by direct or indirect heating. Direct heating geometries include the Shell in-situ conversion process (ICP) using downhole electric heaters in vertical holes and the ExxonMobil Electrofrac (EF) approach using longitudinal vertical fractures created from horizontal wells and propped with electrically conductive material such as calcined coke. Indirect heating approaches propose injection and circulation of steam or a non-condensable gas like $\mathrm{CO}_{2}$. These include the Chevron CRUSH concept of creating horizontal fractures from vertical wells or the Texas A\&M University (TAMU) concept using multiple vertical transverse fractures penetrated by horizontal wells (MTFH).

The objective of this study is to compare energy efficiency of various in-situ retorting technologies for different heating schemes and well configurations using the commercial adaptive-implicit thermal simulator, STARS of Computer Modelling Group Ltd. (CMG). STARS is a three phase multi-component thermal simulator and is based on
\end{abstract}


vapor-liquid distribution ratio of a component, $K$ values to perform phase equilibrium calculation instead of using the Equation of state (EOS). Shell has applied CMG STARS to model its in-situ upgrading project, but is yet to publish details on the input parameters used for modeling. As such, the various thermo-physical parameters like thermal conductivity, specific heat capacity, porosity, permeability needed for the numerical simulation are obtained by extensive literature survey of various oil shale deposits in Green river formation of USA.

Using CMG -STARS, we have built and validated simulation model to replicate Shell's in-situ Conversion Process (ICP) in the Mahogany Demonstration Project South (MDPS). A sensitivity analysis of direct heating pattern and spacing reproduces previous work. Then the validated model is used to evaluate the size and fracture spacing sufficient to heat the oil shale in other direct and indirect heating approaches and to compare pressurized hot fluid circulation to heating elements on terms of hydrocarbon production and energy efficiency while keeping all the model inputs similar for each method. This research also enables oil shale well design recommendations for direct and indirect heating methodologies considering the depth of the reservoir and, for indirect heating, the pressure and temperature for the circulation fluid. 


\section{DEDICATION}

To my parents and gurus 


\section{ACKNOWLEDGEMENTS}

I would like to express my deepest appreciation to Dr. Christine EhligEconomides and Dr. George Moridis, of the Petroleum Engineering Department at Texas A\&M University for invaluable guidance and persistent help to realize this study.

I would extend my sincerest gratitude to Crisman Institute for funding my research. I must acknowledge Mr. K. Patel of Computer Modeling Group (CMG) for his immense technical support during the research. I would like to also single out Kyung Jae Lee, $\mathrm{PhD}$ student, for her valuable input regarding the literature survey.

I am immensely thankful to Jennifer for buying me the coffee-maker that saved me a lot of time from running to Starbucks as well as Ashwin for his incredible formatting tips that helped a lot to come up with a better presentation of my research. Finally, I am always indebted to my parents and teachers whose blessings and values have always inspired me to achieve well in life. 


\section{NOMENCLATURE}

$b$

BHP

BOE

Btu

c

$c_{p}$

C

$\mathrm{Ea}$

$E_{\text {in }}$

$E_{\text {out }}$

$\mathrm{h}_{f}$

$k$

K

K

MMBTU

MSCF

STB

$S$

$T$

$\mathrm{X}_{f}$

$\rho_{\mathrm{R}}$
Viscosity coefficient

Bottom-hole Pressure, psi

Barrel of oil equivalent

British thermal units

Viscosity coefficient

Specific heat capacity, Btu $/ \mathrm{lbm} /{ }^{0} \mathrm{~F}$

Concentration, $1 \mathrm{bmol} / \mathrm{ft}^{3}$

Activation energy, kJ/mol

Thermal energy input (heaters, hot fluid circulation), Btu

Chemical energy output, Btu

Fracture height, $\mathrm{ft}$

First order reaction rate constant, sec-1

Vapor-liquid distribution ratio of a component

Permeability, md

Million metric British thermal units

Thousand standard cubic feet

Stock tank barrels

Viscosity coefficient

Temperature $\left({ }^{0} \mathrm{~F},{ }^{0} \mathrm{C},{ }^{0} \mathrm{~K}\right)$

Fracture half length, $\mathrm{ft}$

Rock density, lbm/ft3 
Greek variables and operators

$\begin{array}{ll}\alpha & \text { Thermal diffusivity, } \mathrm{ft}^{2} / \mathrm{day} \\ \kappa & \text { Energy efficiency } \\ \mu & \text { Thermal conductivity, Btu/ft/Day/ }{ }^{0} \mathrm{~F} \\ \Phi & \text { Viscosity, (cp, Pa.sec) } \\ & \text { Porosity }\end{array}$

\section{Subscripts}

c

Critical

hyd

Hydrostatic

in

Input

$f$

Fracture

out

Output

$R$

Rock

Abbreviations

\section{CAPEX Capital expenditure}

$\mathrm{CF}$

Critical fluid

CMG

Computer Modelling Group Ltd.

CRUSH Chevron's technology for the recovery and in-situ upgrading of oil shale

Cum Cumulative 


\begin{tabular}{ll} 
CWE & Cold water equivalent \\
EF & Electrofrac \\
EOS & Equation of state \\
GCR & Gas combustion retort \\
GFC & Geothermic fuel cell \\
GPRS & Stanford's general purpose research simulator \\
HZ & Horizontal heater well \\
IC & Lumped components \\
ICP & In-situ conversion process \\
Inj & Injected \\
HZI & Horizontal injector well \\
HZP & Horizontal producer well \\
KER & Kerogen \\
LGR & Local grid refinement \\
LPG & Liquified petroleum gas \\
MDPO & Mahogany Demonstration Project Original \\
MDPS & Mahogany Demonstration Project South \\
MTFH & Multistage transverse fractured horizontal \\
OB & Overburden \\
OPEX & Oertical producer well \\
Prod & Produced \\
\hline
\end{tabular}




$\begin{array}{ll}\text { RF } & \text { Radio frequencies } \\ \text { sat } & \text { Saturated steam } \\ \text { sc } & \text { Supercritical } \\ \text { SMR } & \text { Small modular reactor } \\ \text { TAMU } & \text { Texas A\&M University } \\ \text { UB } & \text { Underburden } \\ \text { v } & \text { Vapor }\end{array}$




\section{TABLE OF CONTENTS}

Page

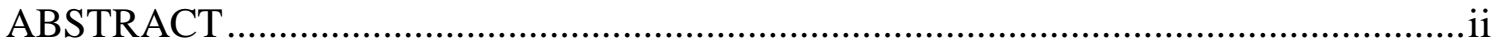



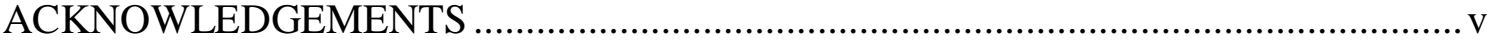

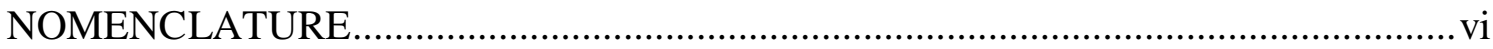

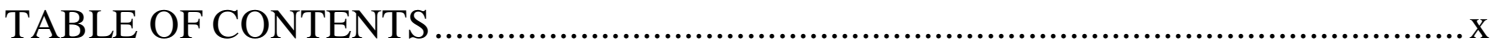

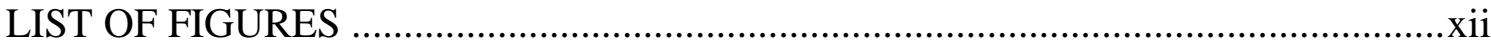

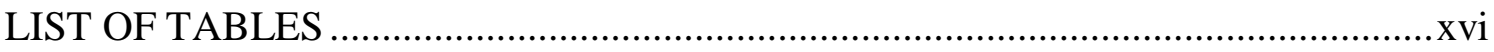

CHAPTER I INTRODUCTION AND BACKGROUND ...................................... 1

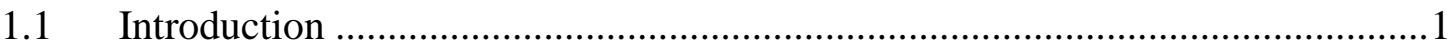

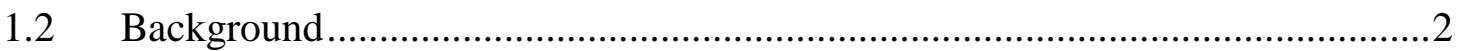

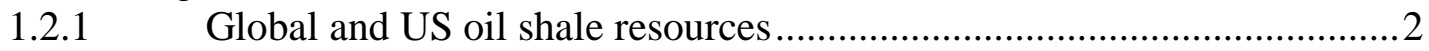

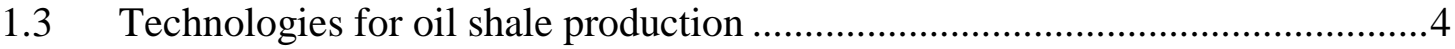

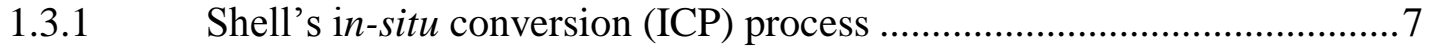

1.3.2 ExxonMobil's' electrofrac ${ }^{\mathrm{TM}}$ process..................................................

1.3.3 Chevron CRUSH technology …................................................. 9

1.3.4 Petroprobe (subsidiary of earth search sciences, Inc.) ...........................10

1.3.5 Schlumberger /Raytheon-CF radio-frequency technology ..................... 11

1.3.6 Independent Energy Partners (IEP)'s geothermic fuel cell (GFC) ......... 12

1.3.7 TAMU MTFH approach............................................................. 13

1.3.8 Petrobras' Petrosix gas combustion retort (GCR) used in Brazil ..........15

1.3.9 Fushun retorts used in China .....................................................16

1.3.10 Kiviter and Galoter retorts used in Estonia ...................................... 17

1.4 Economics of oil shale development in USA ...............................................19

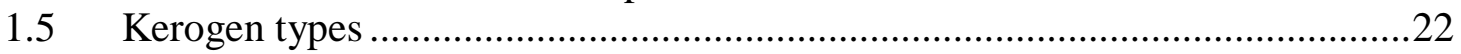

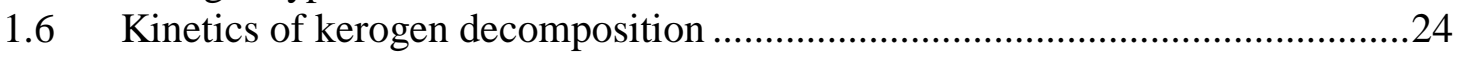

CHAPTER II SHELL IN-SITU CONVERSION PROCESS (ICP) ............................26

2.1 Simulation model description .................................................................2

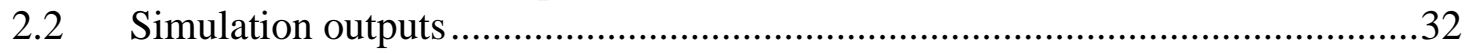




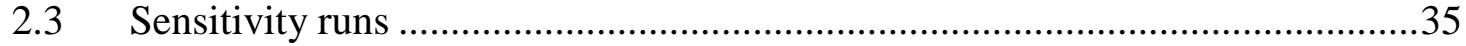

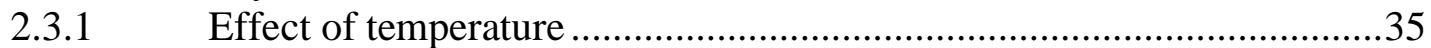

2.3.2 Effect of number of heaters ........................................................... 38

2.3.3 Effect of heater spacing .............................................................. 40

2.4 Shell ICP energy efficiency comparison for various cases ............................43

CHAPTER III EXXONMOBIL ELECTROFRAC (EF) PROCESS ............................ 46

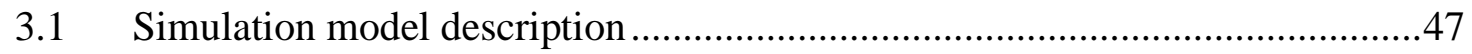

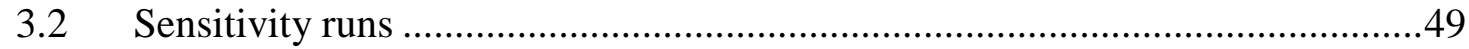

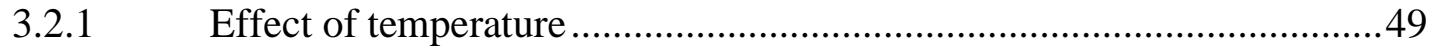

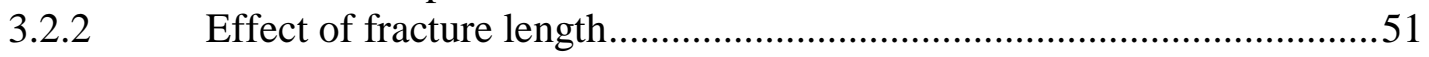

3.3 ExxonMobil electrofrac energy efficiency comparison for various cases.........53

CHAPTER IV TAMU APPROACH (MULTISTAGE TRANSVERSE FRACTURED

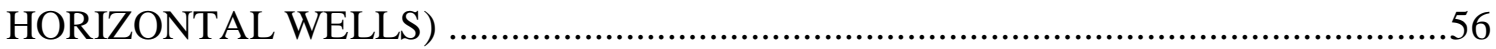

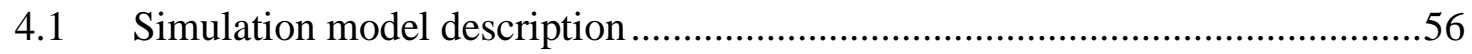

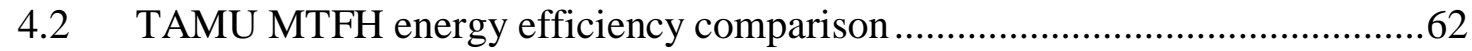

CHAPTER V CHEVRON CRUSH TECHNOLOGY ........................................... 65

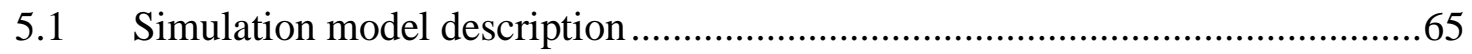

5.2 Chevron CRUSH energy efficiency comparison........................................69

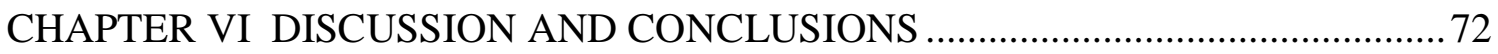

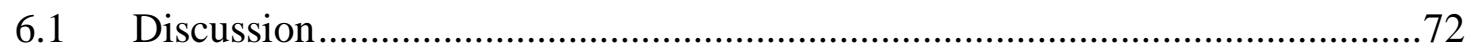

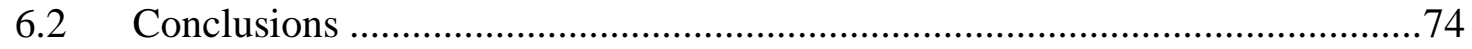

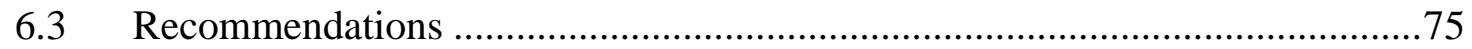

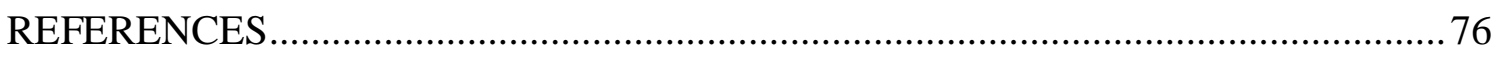




\section{LIST OF FIGURES}

Page

Figure 1: Countries with oil shale deposits (Biglarbigi et al. 2007) ................................3

Figure 2: Oil shale development technologies .........................................................

Figure 3: Shell's in-situ conversion process (Crawford, P. et al. 2008) ........................... 8

Figure 4: Electrofrac ${ }^{\mathrm{TM}}$ process (Crawford, P. et al. 2008)........................................

Figure 5: Chevron CRUSH process (Biglarbigi et al. 2007) ..................................... 10

Figure 6: PetroProbe process (Crawford, P. et al. 2008) ........................................... 11

Figure 7: RF/Critical fluid oil extraction technology (Crawford, P. et al. 2008) .............12

Figure 8: IEP's Geothermic fuels cells process (Crawford, P. et al. 2008) .....................13

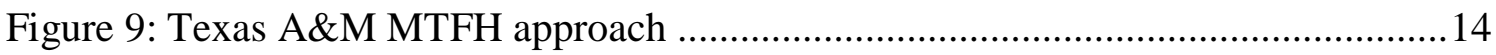

Figure 10: Petrosix gas combustion retort (Crawford, P. et al. 2008)............................ 16

Figure 11: Fushun vertical retort (Crawford, P. et al. 2008) ...................................... 17

Figure 12: Galoter lateral retort (Crawford, P. et al. 2008) ..................................... 18

Figure 13: Kiviter vertical retort (Crawford, P. et al. 2008) …....................................... 18

Figure 14: Minimum economic price for oil shale technology ..................................21

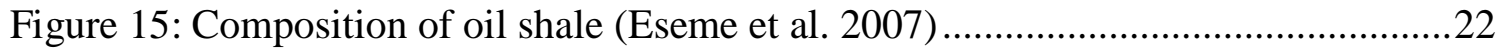

Figure 16: Van Krevlen diagram for kerogen types (Das 1989) .................................24

Figure 17: Shell ICP (a) Top view of heaters (b) Side view of heaters ........................27

Figure 18: Shell ICP cumulative oil and gas production ..........................................33

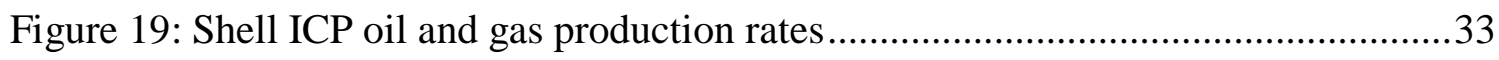




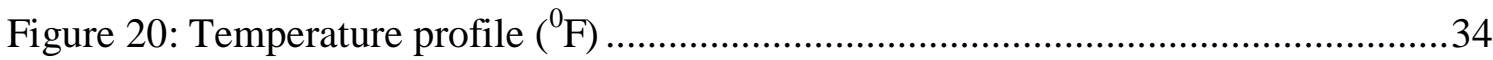

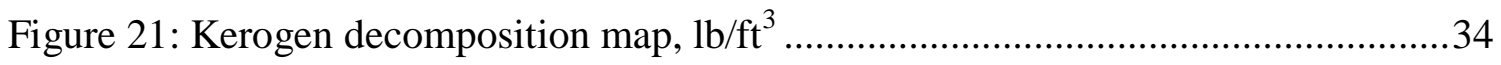

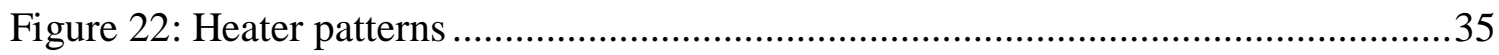

Figure 23: Effect of temperature on cumulative oil and gas production...........................36

Figure 24: Effect of temperature on oil and gas production rates ...................................37

Figure 25: Formation temperature profile for hexagonal pattern at heater

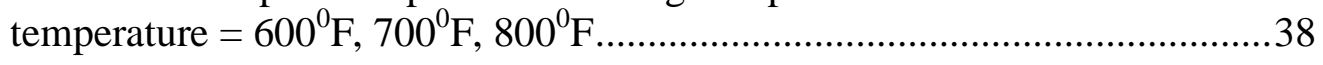

Figure 26: Effect of number of heaters on cumulative oil and gas production .................39

Figure 27: Effect of number of heaters on oil and gas production rates ..........................39

Figure 28: Formation temperature profile for number of heaters (triangular, square

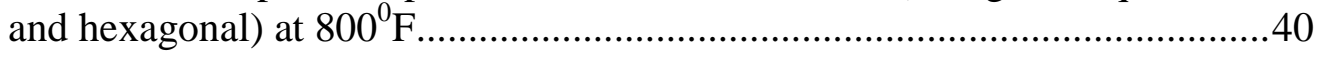

Figure 29: Effect of heater spacing on cumulative oil and gas production.......................41

Figure 30: Effect of heater spacing on oil and gas production rates ...............................42

Figure 31: Formation temperature profile of hexagonal pattern for heater

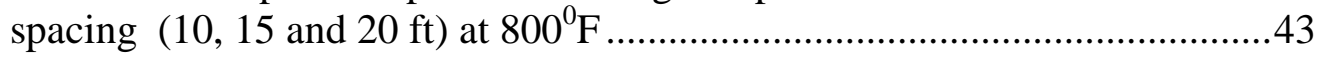

Figure 32: Energy ratio comparison for various sensitivity runs ………………...........45

Figure 33:ExxonMobil EF simulation model developed using CMG .............................46

Figure 34: Comparison of Shell ICP and ExxonMobil EF: cumulative oil and gas production

Figure 35: Comparison of Shell ICP and ExxonMobil EF: oil and gas production rates

Figure 36: Effect of Temperature on ExxonMobil EF process: cumulative oil and gas production 
Figure 37: Effect of Temperature on ExxonMobil EF process: oil and gas production rates

Figure 38: Formation temperature profile for heater temperature $=600^{0} \mathrm{~F}, 700^{0} \mathrm{~F}$, $800^{0} \mathrm{~F}$

Figure 39: Effect of heater spacing on cumulative oil and gas production

Figure 40: Effect of heater spacing on oil and gas production rates

Figure 41: Formation temperature profile for fracture lengths $=35 \mathrm{ft}, 45 \mathrm{ft}, 55 \mathrm{ft}$

Figure 42: ExxonMobil EF energy ratio comparison for temperatures $=600^{\circ} \mathrm{F}$, $700^{0} \mathrm{~F}, 800^{\circ} \mathrm{F}$.

Figure 43: ExxonMobil EF energy ratio comparison of for fracture lengths $=35 \mathrm{ft}$, $45 \mathrm{ft}, 55 \mathrm{ft}$.

Figure 44: TAMU MTFH simulation model developed using CMG

Figure 45: Comparison of Shell ICP and TAMU MTFH STEAM: cumulative oil and gas production

Figure 46: Comparison of Shell ICP and TAMU MTFH STEAM: oil and gas production rates

Figure 47: Comparison of EF and TAMU MTFH STEAM \& $\mathrm{CO}_{2}$ : cumulative oil and gas production

Figure 48: Comparison of EF and TAMU MTFH STEAM \& $\mathrm{CO}_{2}$ : oil and gas production rates

Figure 49: Formation temperature profile for TAMU MTFH STEAM \& $\mathrm{CO}_{2}$ injection 61

Figure 50: Electrofrac and TAMU MTFH Steam \& $\mathrm{CO}_{2}$ injection energy ratio comparison at temperature $=600^{\circ} \mathrm{F}$

Figure 51: Chevron CRUSH simulation model developed using CMG 66

Figure 52: Comparison of Shell ICP and Chevron CRUSH STEAM \& $\mathrm{CO}_{2}$ : cumulative oil and gas production 
Figure 53: Comparison of Shell ICP and Chevron CRUSH STEAM \& $\mathrm{CO}_{2}$ : oil and gas production rates

Figure 54: Formation temperature profile for Chevron CRUSH STEAM and $\mathrm{CO}_{2}$ injection

Figure 55: Shell ICP and Chevron CRUSH STEAM \& $\mathrm{CO}_{2}$ injection energy ratio comparison at temperature $=600^{\circ} \mathrm{F}$. .70

Figure 56: Depth of application of in-situ techniques @ $600{ }^{0} \mathrm{~F}$. .73 


\section{LIST OF TABLES}

Page

Table 1: Top 10 oil shale resources countries (Biglarbigi et al. 2007) ..........................4

Table 2: Companies with different oil shale extraction methodologies

(Biglarbigi et al. 2007) .........................................................................

Table 3: Minimum economic price for oil shale technology .....................................20

Table 4: Kinetic reactions for Shell ICP model ......................................................29

Table 5: Properties of chemical components of oil shale .........................................29

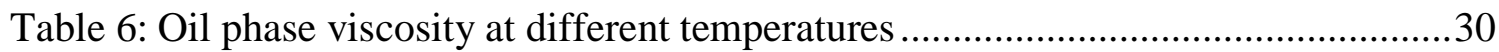

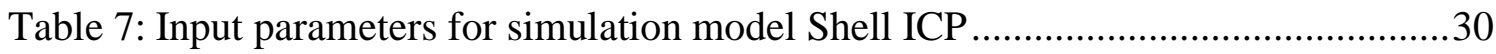




\section{CHAPTER I}

\section{INTRODUCTION AND BACKGROUND}

\subsection{Introduction}

Oil shale is a lamellar, non-porous and impermeable sedimentary rock, rich in organic matter kerogen that thermo-kinetically decomposes to yield oil, gas and water when heated at pyrolysis temperatures of $600-800{ }^{\circ} \mathrm{F}$. United States has the largest oil shale deposit in the world with an estimated reserve of approximately 3 trillion barrels of oil with 1.5 trillion barrels located in the Green River basin in Wyoming (Dyni 2006). Oil shale resources dwarf conventional oil reserves and can be a profitable venture, given the rising crude prices and an even increasing need of alternative fuel. According to Biglarbigi et al. (2007) the key concerns associated with development of oil shale resources are resource access, technological enhancements, economics and environmental issues.

The organic matter kerogen falls in Type I or II in Van Krevelen diagram (Das 1989), is insoluble in organic solvents; and has high molecular weight and polymeric nature. The matrix composition is dominated by clay minerals, marls and carbonates. There are four major oil shale processes: surface mining with a surface retort, underground mining with a surface retort, in-situ retorting and modified in-situ retorting (Crawford, P. et al. 2008) . In-situ technology is applicable for deeper and thicker deposits which are not as amenable to surface or deep-mining methods. In the recent years, there has been a tremendous development in oil shale technologies for recovery of 
hydrocarbon with emphasis on being economically viable, environmentally responsible and socially sustainable.

\subsection{Background}

This section contains the extensive literature review of global and United States oil shale resources potential and various surface and in-situ retorting technologies for production of hydrocarbons from oil shale. It also discusses the economics for oil shale development in US along with composition and chemical kinetics of kerogen decomposition, the primary component and the parent hydrocarbon material in oil shale.

\subsubsection{Global and US oil shale resources}

Oil shale resources are extremely large in comparison to conventional oil reserves, making it one of the largest known energy resources. There are nearly 100 major oil shale deposits worldwide, the major countries with vast oil shale deposits are shown in Figure 1. According to US Geological Survey estimates in 2010, the total world resource estimate for oil shale is 2.8 trillion barrels and might be more than 2.5 times this value based on quality of the deposits considered (Biglarbigi et al. 2010). 

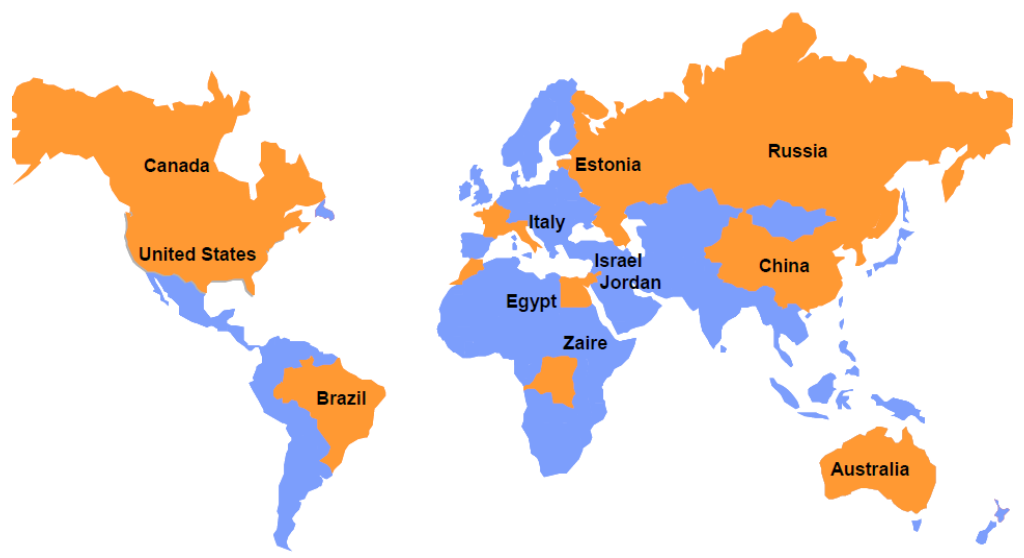

\section{Countries With Oil Shale Deposits}

Figure 1: Countries with oil shale deposits (Biglarbigi et al. 2007)

The worldwide oil shale resource is estimated to be about 10 trillion barrels with USA at the top of the pyramid, having nearly $60 \%$ of the total resources (Biglarbigi et al. 2007). The western oil shale resources in the United States are estimated to be 6 trillion barrels of oil equivalent and are considered as one of the largest hydrocarbon resources on the planet. Of this vast chunk, 2 trillion barrels of oil shale have high rich organic matter and is mostly trapped in Green River formation; in the states of Colorado, Utah and Wyoming in the western United States. Table 1 shows the top ten countries with oil shale resources. 
Table 1: Top 10 oil shale resources countries (Biglarbigi et al. 2007)

\begin{tabular}{|lr|}
\hline \multicolumn{2}{|c|}{ Oil Shale Resources in } \\
\hline China & 16 Billion \\
Estonia & 16 Billion \\
Australia & 32 Billion \\
Jordan & 34 Billion \\
Morocco & 53 Billion \\
Italy & 73 Billion \\
Brazil & 82 Billion \\
Zaire & 100 Billion \\
Russia & 248 Billion \\
United States & 6,000 Billion \\
\hline
\end{tabular}

Currently four major technologies are used for production of hydrocarbon from oil shale i.e. Surface mining/surface retort, Underground mining/surface retort, True insitu technology and Modified in-situ technology. The following section focusses on different oil shale extraction technologies with a brief review of both surface and in-situ retorting technologies.

\subsection{Technologies for oil shale production}

According to a report published by US Department of Energy, atleast 24 companies are engaged in research \& development of the oil shale resources in the United States that is summarized in Table 2 (Biglarbigi et al. 2007). 
Table 2: Companies with different oil shale extraction methodologies (Biglarbigi et al. 2007)

\begin{tabular}{|l|c|l|c|}
\hline \multicolumn{1}{|c|}{ Company } & $\begin{array}{c}\text { Technology } \\
\text { Type }\end{array}$ & \multicolumn{1}{|c|}{ Company } & $\begin{array}{c}\text { Technology } \\
\text { Type }\end{array}$ \\
\hline $\begin{array}{l}\text { Anadarko Petroleum } \\
\text { Corporation }\end{array}$ & N/A & $\begin{array}{l}\text { James A. Maguire, } \\
\text { Inc. }\end{array}$ & In-Situ \\
\hline $\begin{array}{l}\text { Chattanooga } \\
\text { Corporation }\end{array}$ & Surface & $\begin{array}{l}\text { Millennium Synthetic } \\
\text { Fuels, Inc. }\end{array}$ & Surface \\
\hline Chevron USA & In-Situ & $\begin{array}{l}\text { Mountain West } \\
\text { Energy Company }\end{array}$ & In-Situ \\
\hline E.G.L. Resources & In-Situ & Natural Soda, Inc. & N/A \\
\hline $\begin{array}{l}\text { Electro-Petroleum } \\
\text { Exploration } \\
\text { Corporation (OSEC) }\end{array}$ & In-Situ & $\begin{array}{l}\text { Phoenix-Wyoming, } \\
\text { Inc. }\end{array}$ & In-Situ \\
\hline $\begin{array}{l}\text { Earth Search } \\
\text { Pciences / Petro- } \\
\text { Probe, Inc. }\end{array}$ & In-Situ \\
\hline $\begin{array}{l}\text { ExxonMobil } \\
\text { Corporation }\end{array}$ & In-Situ & Red Leaf Resources & Surface \\
\hline Brent Fryer, Sc.D. & Surf/In-Situ & $\begin{array}{l}\text { Raytheon } \\
\text { Corporation }\end{array}$ & In-Situ \\
\hline $\begin{array}{l}\text { Global Resource } \\
\text { Corporation }\end{array}$ & In-Situ & $\begin{array}{l}\text { Shell Frontier Oil } \\
\text { and Gas, Inc. }\end{array}$ & In-Situ \\
\hline $\begin{array}{l}\text { Imperial Petroleum } \\
\text { Recovery Corp. }\end{array}$ & Upgrading & Syntec, Inc. & Surface \\
\hline $\begin{array}{l}\text { Independent Energy } \\
\text { Partners }\end{array}$ & In-Situ & $\begin{array}{l}\text { Western Energy } \\
\text { Partners }\end{array}$ & Surface \\
\hline $\begin{array}{l}\text { J.W. Bunger and } \\
\text { Associates, Inc. }\end{array}$ & Surface \\
\hline
\end{tabular}

Crawford et al. conducted an analysis on various oil shale technologies that can be implemented on commercial scale with improved performance (Crawford, P.M. et al. 2008). There are four major types of oil shale processes categorized in a Tree diagram as shown in Figure 2 and discussed below. In-situ technology is applicable for deeper, thicker deposits which are not as amenable to surface or deep-mining methods. In-situ processes heat the resource in natural depositional setting and thus minimize or eliminate the need for mining and surface pyrolysis.

A. Surface mining with surface retorting: In this process, the ore is produced from open cast surface mines, crushed, and processed in surface retorts 
B. Underground mining with surface retorting: In this process shale ore is mined, transported to the surface, crushed, and then heated in surface vessels to produce liquids and gases, after which the processed shale is disposed of in the mine and other disposal areas.

C. Modified In-situ: Modified in-situ approaches have improved the pyrolysis and recovery efficiency of in- situ combustion processes by fracturing the resource to improve heat transfer and fluid flows through the shale.

D. True In-situ: In the true in-situ process, heat is applied to the subsurface oil shale resource without mining. Recent approaches are focused on applying heat without any combustion of the resource as earlier some of the shale was combusted at one end of the deposit to generate heat at pyrolysis temperatures to produce liquids and gases. 


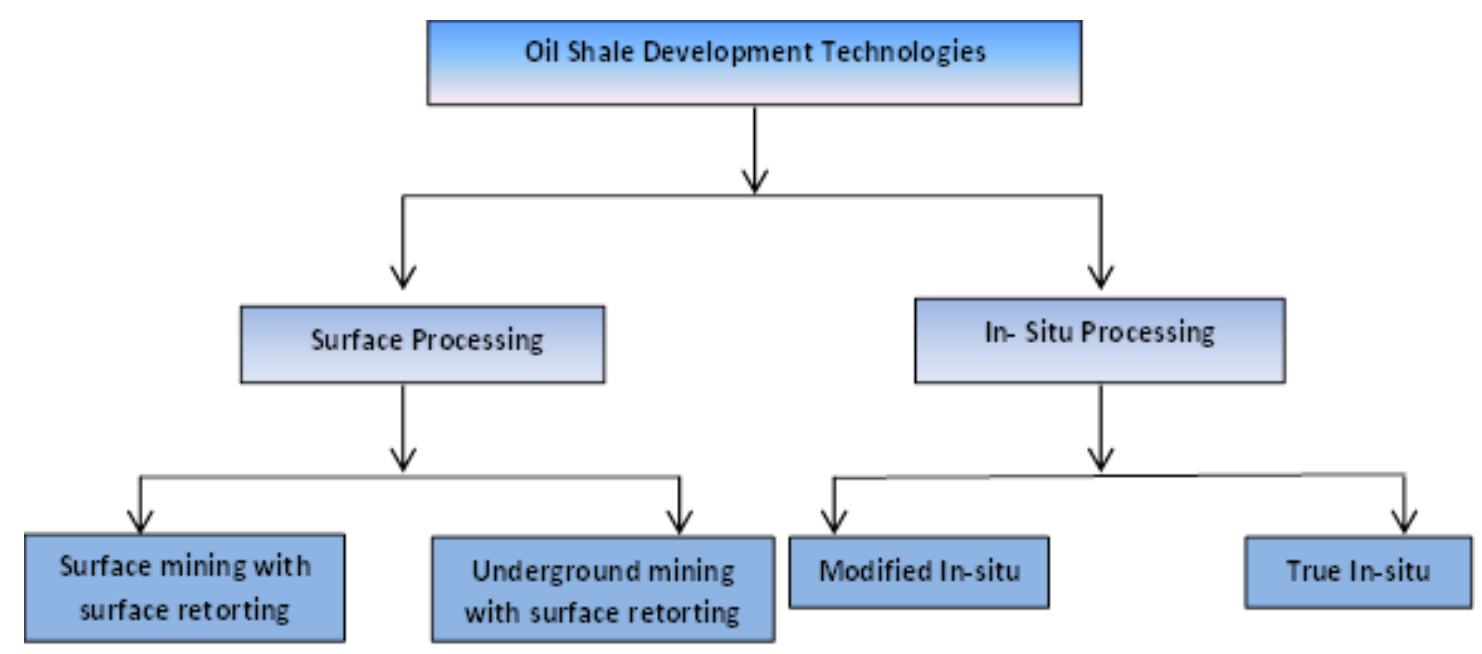

Figure 2: Oil shale development technologies

In the recent years, there has been tremendous advancement in Oil Shale technologies. The new variations on the traditional approaches described above have resulted in improvements in efficiencies, reductions in energy use, reductions in net water use, effective carbon management, higher production yields, and/or increased product quality as measured by API gravity and other standard measures.

Few of the newly developed technologies (esp. in-situ) to recover oil and gas from oil shale in a way that is economically viable, environmentally responsible are mentioned below (Crawford, P.M. et al. 2008).

\subsubsection{Shell's in-situ conversion (ICP) process}

Shell's Mahogany research project has conducted research on in-situ (in-ground) conversion process (ICP) as shown in Figure 3 to recover oil and gas from oil shale in Colorado. The rock formation is heated slowly over time to 650 to $750^{\circ} \mathrm{F}$ by electric heaters, inserted in vertical heater wells, at a target depth zone 1000 to 2000 feet 
subsurface converting the kerogen in oil shale into oil and gas.

This heating technology generates significantly lower carbon emissions than traditional surface retorting processes due to the slow and lower temperature of the heating process. Shell is currently working on a freeze-wall technology to protect the heating zone from groundwater intrusion and to protect contamination of the groundwater; the freeze wall is terminated to resume unimpeded groundwater flow as the production area is cleaned.

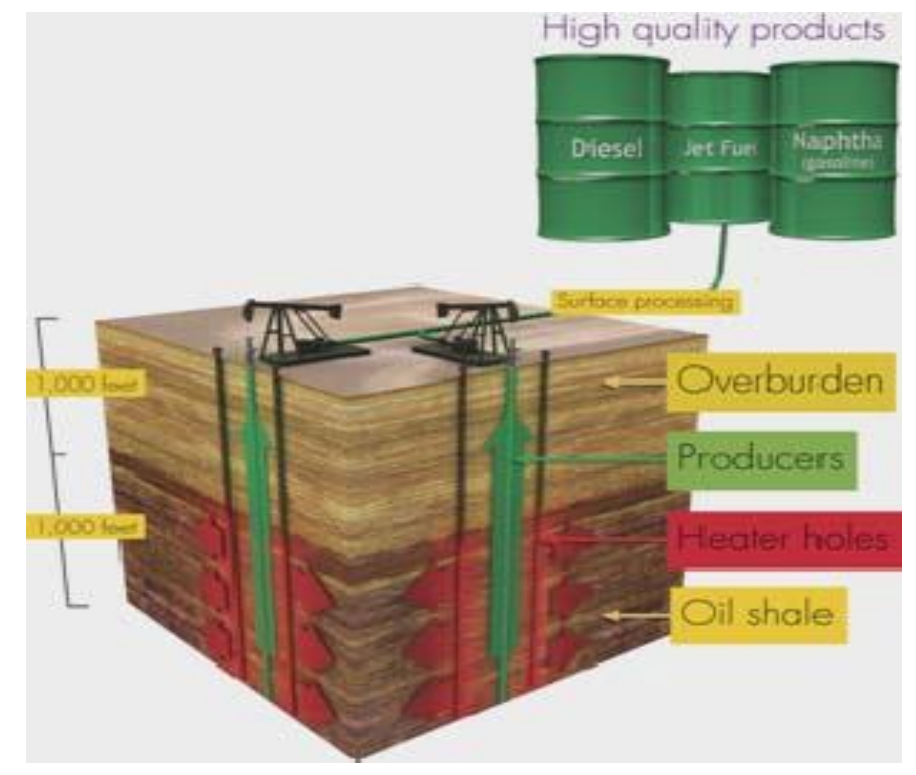

Figure 3: Shell's in-situ conversion process (Crawford, P. et al. 2008)

\subsubsection{ExxonMobil's' electrofrac ${ }^{\mathrm{TM}}$ process}

This technique for in-situ oil shale conversion involves hydraulically fracturing the oil shale and filling the fractures with an electrically conductive material, forming a 
heating element as shown in Figure 4.. Vertical fractures achieve a conductive zone that will heat the resources to pyrolysis temperature, producing liquids and gases that can be produced by conventional recovery technologies. ExxonMobil screened over thirty candidate technologies and concluded that linear heat conduction from planar heat sources is the most effective method for converting kerogen into oil and gas.

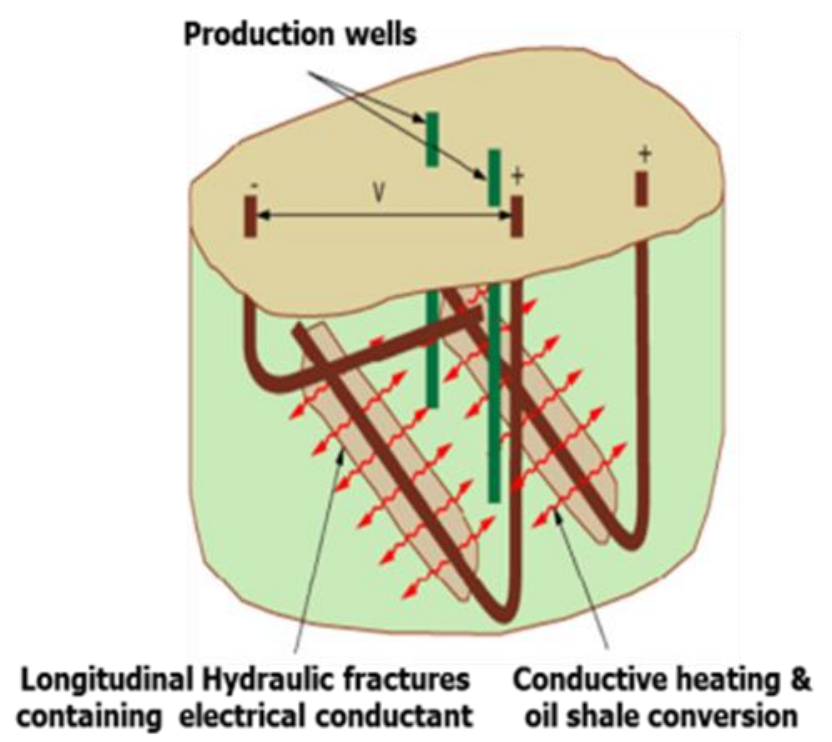

Figure 4: Electrofrac ${ }^{\mathrm{TM}}$ process (Crawford, P. et al. 2008)

\subsubsection{Chevron CRUSH technology}

Chevron proposes an in-situ conversion technology of oil shale known as CRUSH as shown in Figure 5. It involves creation of controlled horizontal fractures at shallow depth through vertical wells and circulation of hot $\mathrm{CO}_{2}$ gas through the fractured formation to convert solid kerogen into oil and gas products. The circulated $\mathrm{CO}_{2}$ is recycled and reheated to be used further for heating the fractured formation. 


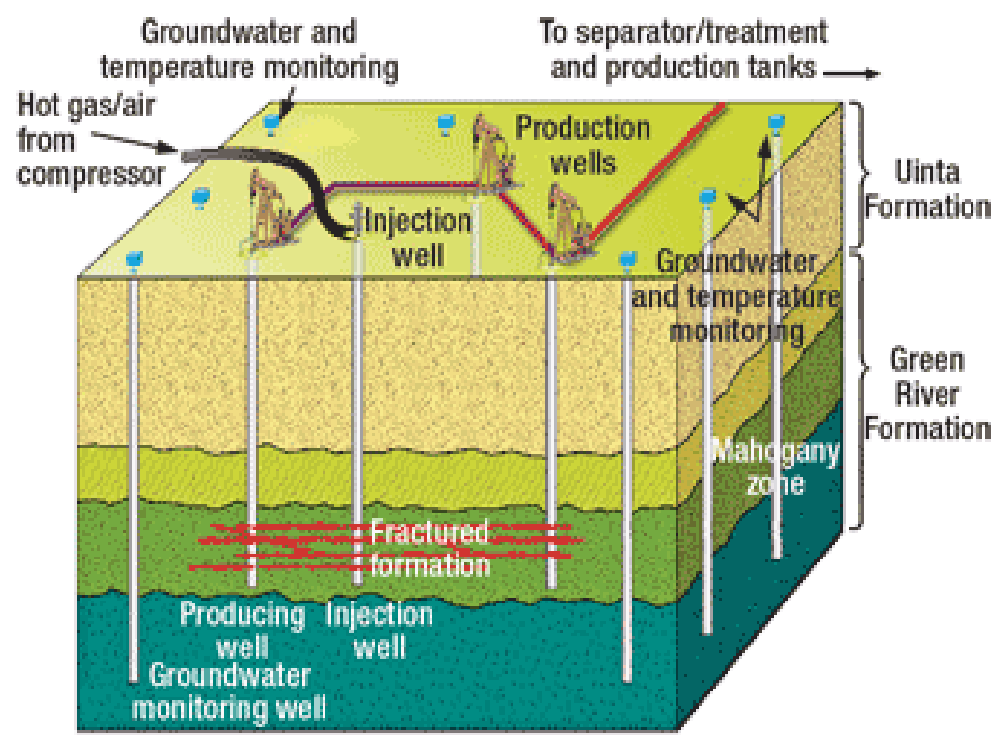

Figure 5: Chevron CRUSH process (Biglarbigi et al. 2007)

\subsubsection{Petroprobe (subsidiary of earth search sciences, Inc.)}

In this technology, air is super-heated in a burner on the surface that moves down the borehole; interacts with the organic rich rock and brings hydrocarbons to the surface with minimal surface footprint. Drilling is done into oil shale deposits as deep as 3000 or more feet and super-heated air is injected through a processing inlet conduit within the hole that heats the rock and converts the kerogen to a gaseous state as shown in Figure 6. The portable design of surface plant allows it to be dismantled easily and moved to the next site. 


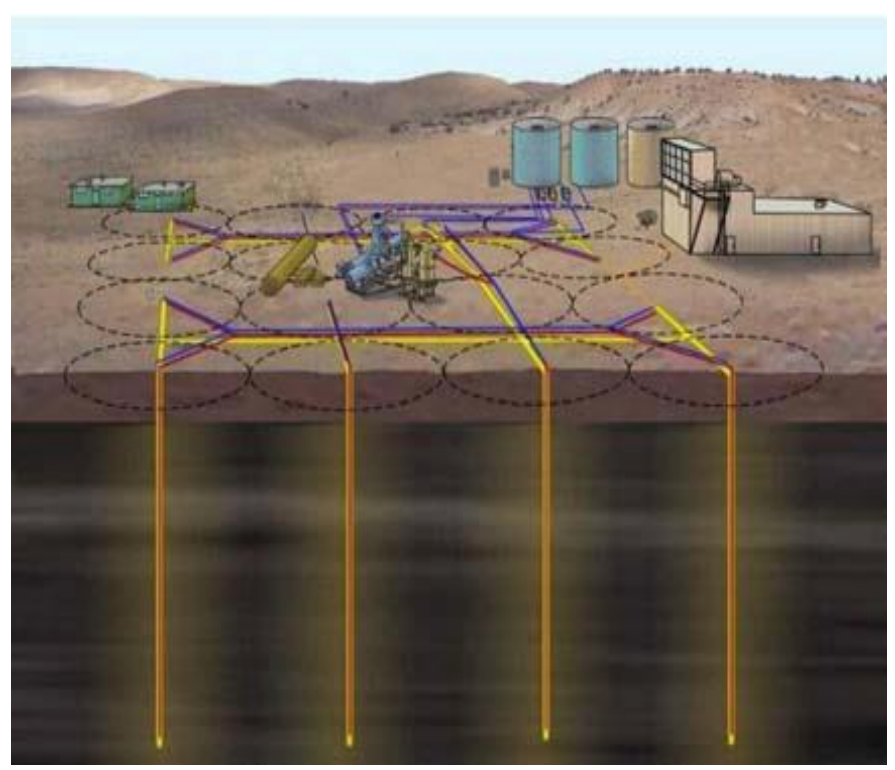

Figure 6: PetroProbe process (Crawford, P. et al. 2008)

\subsubsection{Schlumberger /Raytheon-CF radio-frequency technology}

This in-situ method is based on the application of radio frequencies (RF) to heat the buried shale to high temperatures (pyrolysis) and then hydrocarbon is extracted from production wells by pumping supercritical fluid (CF) carbon-dioxide into the shale formations as shown in Figure 7. One of the advantages of this process is that it can yield quick production of oil and gas in terms of months whereas other methods take longer time; may years to heat the shale in-situ. Due to lower heating requirements, this in-situ process is very much applicable in recovery of tar sands and heavy oil and the yield will be in order of $10-15$ barrels of oil equivalent per barrel consumed. 


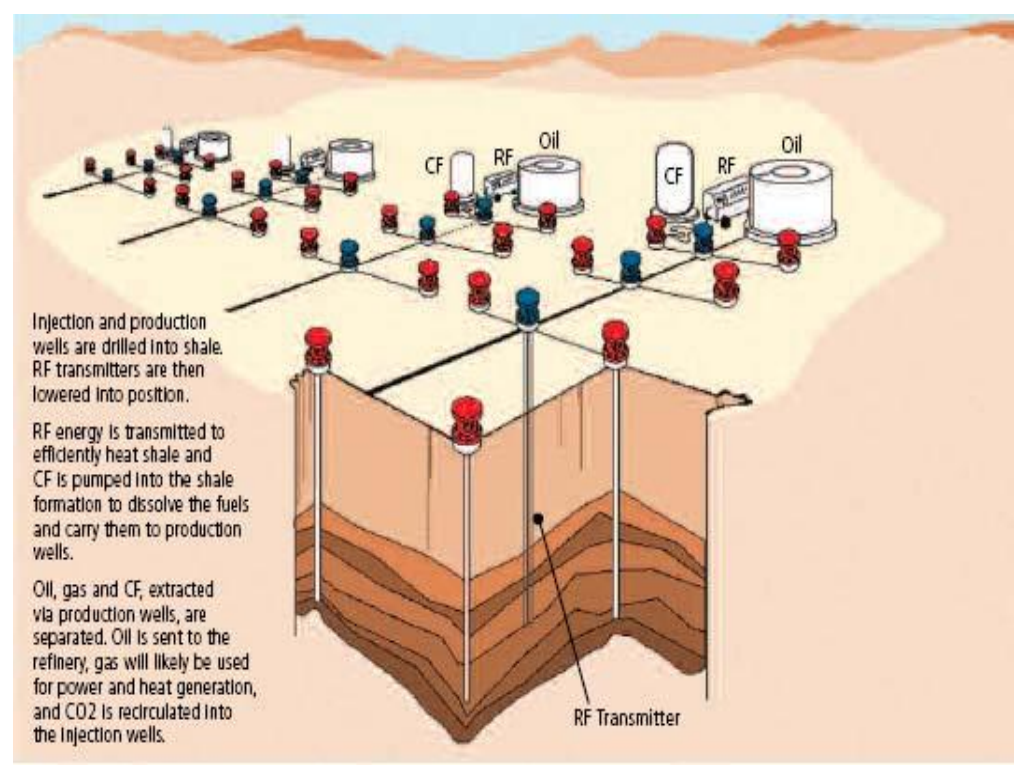

Figure 7: RF/Critical fluid oil extraction technology (Crawford, P. et al. 2008)

\subsubsection{Independent Energy Partners (IEP)'s geothermic fuel cell (GFC)}

This technique involves placement of high temperature fuel cells in the oil shale formation to convert kerogen to shale oil as shown in Figure 8. The formation is heated by GFCs from top to bottom at a uniform rate due to solid to solid conduction which is more effective than other non-conductive applications. The increase in formation temperature raises the formation pressure of the heated zone by $100-200$ psi which is enough to fracture the oil shale and thus establishes communication between heating and producing wells.

One of the biggest advantages of this method is that it does not consume large amount of external energy and becomes self-fueling due to the gases generated from its own heat. It also yields approximately $174 \mathrm{Kwh}$ per barrel recovered instead of consuming large amount of electricity When compared to mining and retorting 
operations, GFCs cause minimal surface impact and waste disposal problems are too eliminated.

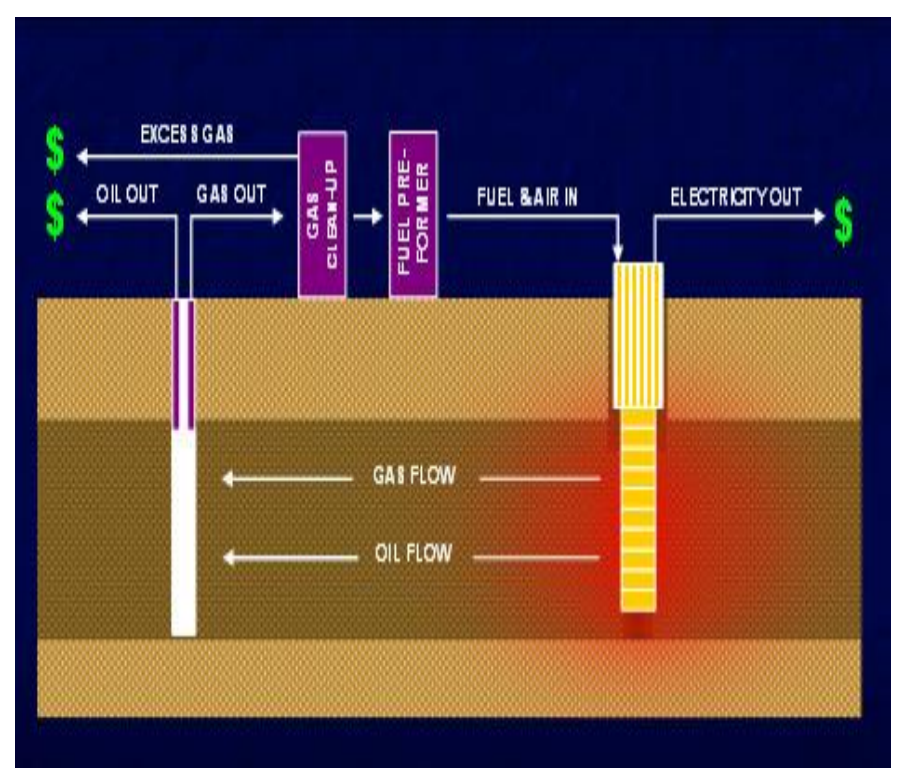

Figure 8: IEP's Geothermic fuels cells process (Crawford, P. et al. 2008)

\subsubsection{TAMU MTFH approach}

Thoram and Ehlig-Economides 2011 investigated the feasibility of steam injection through transverse vertical fractures created from a horizontal well to heat the oil shale to pyrolysis temperatures as shown in Figure 9. Their numerical studies revealed that injection of super-heated steam through vertical fractures can raise the formation temperatures to $550-700{ }^{0} \mathrm{~F}$ within a period of two years, after which the converted hydrocarbons would be produced from the same fractures. They proposed the use of small modular reactor (SMR) to produce super-heated steam at $750^{\circ} \mathrm{F}$ because 
conventional steam generators cannot produce steam at such high temperature. They concluded that rate of thermal front propagation occurs faster at fractures at initial stage which gradually moves into the matrix with time.

Chevron proposes a similar approach CRUSH but with non-condensable gas like hot $\mathrm{CO}_{2}$ circulation through a network of horizontal hydraulic fractures created from vertical wells (Biglarbigi et al. 2007). But the creation of transverse or horizontal fractures are determined by local in-situ stresses and will be a matter of investigation to choose between these two indirect heating approaches depending upon the depth of the oil shale.

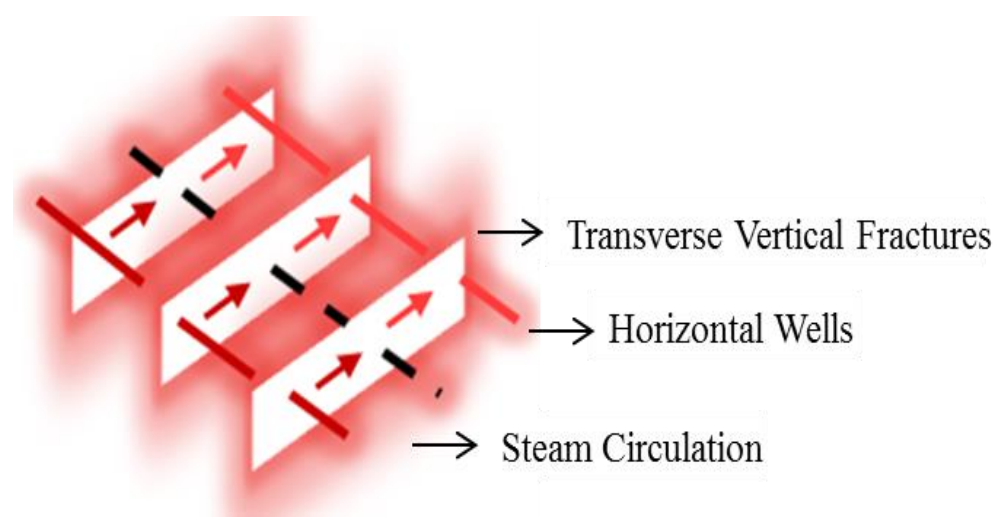

Figure 9: Texas A\&M MTFH approach

Three oil shale surface retorting technologies, currently being utilized worldwide are mentioned below. 


\subsubsection{Petrobras' Petrosix gas combustion retort (GCR) used in Brazil}

This process (PETROSIX) was initiated in 1960s to extract oil from pyrobituminous shale. GCR is world's largest operational surface oil shale pyrolysis reactor with a production value of $3870 \mathrm{Bpd}$ of shale oil, 120 tonnes of fuel gas and 45 tonnes of LPG which are generated from 7800 tonnes of shale that are processed daily.

The retort is consisting of two sections as shown in Figure 10; upper one is for pyrolysis and the lower section for coke cooling. First of all, mined shale is crushed into fragments in a crusher and then sent to the retort where it is heated to higher temperatures. The organic matter in form of oil and gas is released which is cooled in the lower section allowing the oil vapor to condensate to form a product which is transported from the retort by the gases. Gases released are further cleaned for light oil extraction. The rest of the products are sent to gas treatment unit where liquefied petroleum gas (LPG) is produced along with other fuels.

Some of the attracting features of Petrosix process are:

- Simplicity of design with high operational factor (about 94\%).

- High thermal efficiency and recovery efficiency.

- Minimum environmental and health related impacts. 


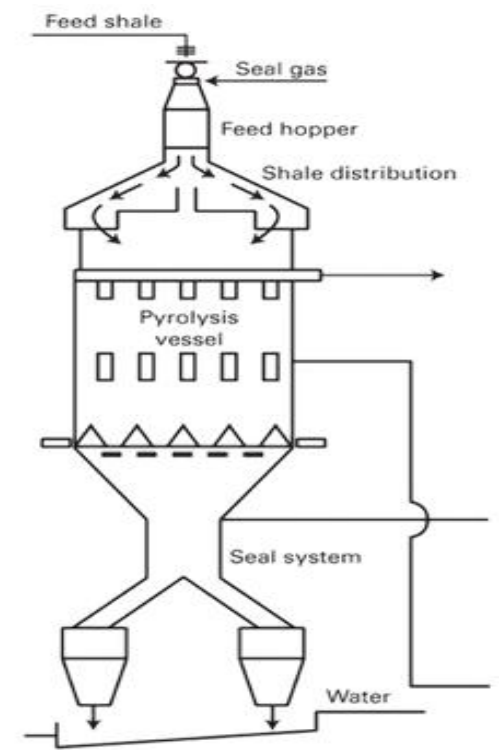

Figure 10: Petrosix gas combustion retort (Crawford, P. et al. 2008)

\subsubsection{Fushun retorts used in China}

In China, Fushun Retorts as shown in Figure 11 are being used in greater numbers to achieve high volumes of shale oil production. In 2005, more than 120 retort units were employed; each having a capacity of 100 tonnes of oil shale. The advantage of having low capacity retorts is that it allows 20 of them to be grouped together to share a single condenser system.

Disadvantages of Fushun Retorts:

- Low calorific value of gas due to introduction of nitrogen in pyrolysis.

- Low oil yields due to less efficient pyrolysis because of introduction of oxygen in the upper chamber.

- To increase production rate, construction of additional batteries of Fushun retorts is required which is quite expensive. 


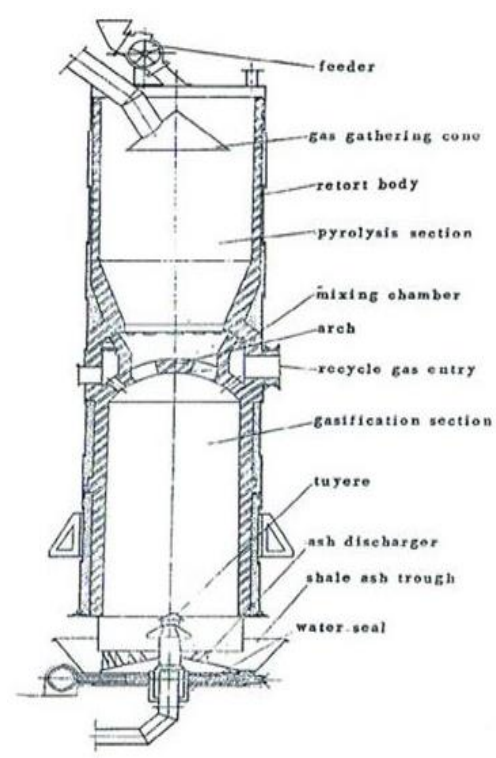

Figure 11: Fushun vertical retort (Crawford, P. et al. 2008)

\subsubsection{Kiviter and Galoter retorts used in Estonia}

The Galoter retorts are horizontal fluidized bed retorts with processing capacity of 3000 tonnes oil shale per day. The Kiviter retorts are lump shale, gas combustion processors and vertical in design with a medium scale production capacity of 1000 tonnes oil shale per day which is one-third the capacity of the Galoter retorts. If compared to Petrosix process, the production capacity of Galoter retort as shown in Figure 12 is almost half of the former. The main features of the Galoter retort are its higher thermal efficiency, higher yield, better quality of produced gases and reduced energy inputs as compared to Kiviter retort; shown in Figure 13. But on the other hand, the process involved in Galoter retort is more complex and requires high operating time as compared to Kiviter retort. 


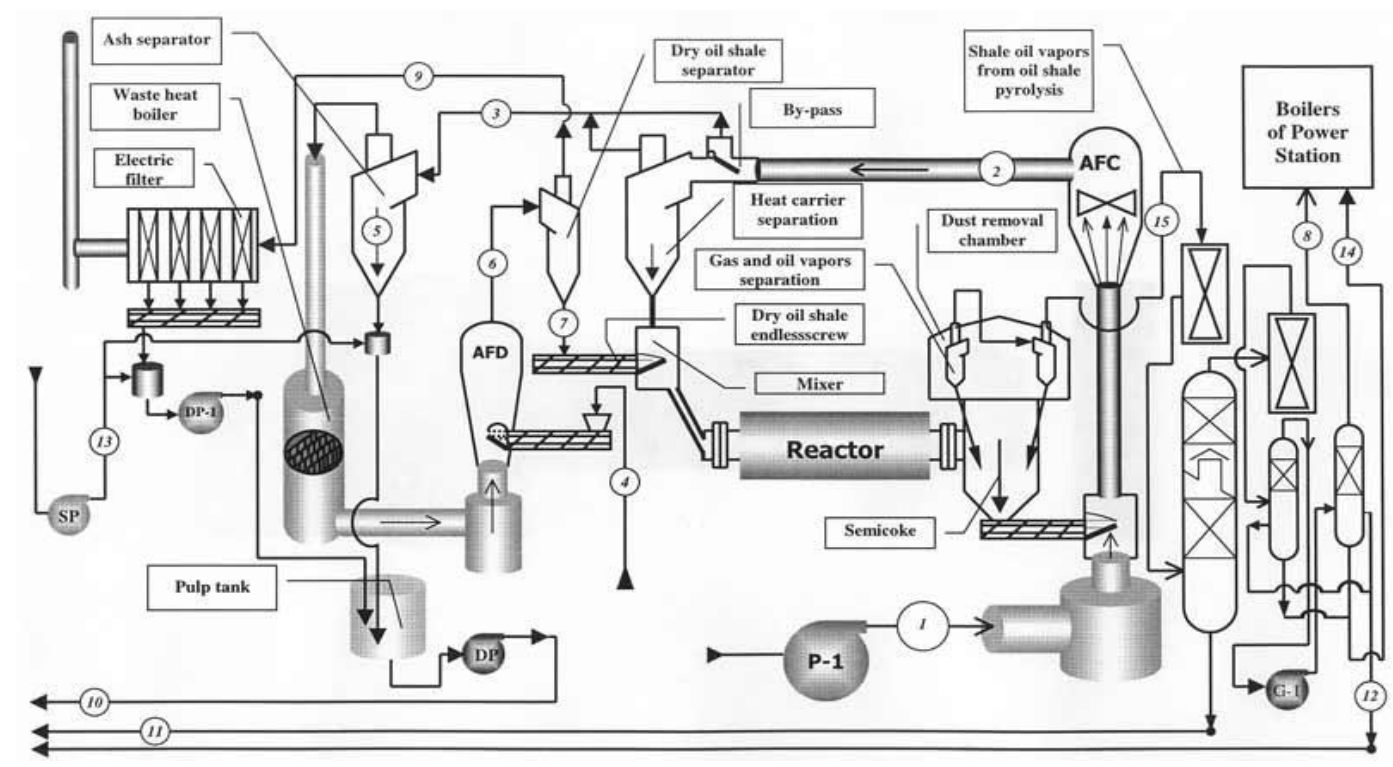

Figure 12: Galoter lateral retort (Crawford, P. et al. 2008)

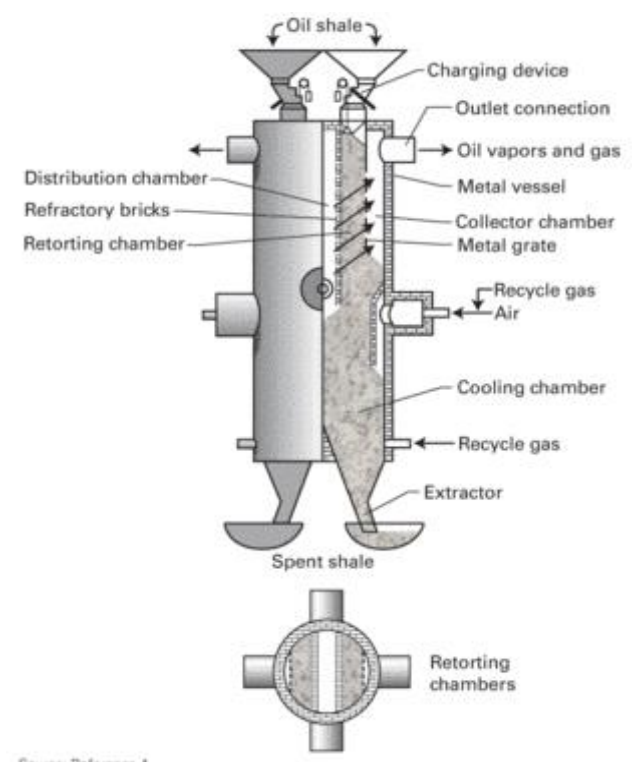

Figure 13: Kiviter vertical retort (Crawford, P. et al. 2008) 
There is significant research going in order to improve Oil Shale technologies. Building on the experiences gained from earlier methodologies, new approaches are being developed to deal with past challenges related to energy use, thermal efficiency, oil yield, and emission related issues and prevention ground water contamination. The new technologies to be developed will assure better yield, improved operability and reliability and at the same time will keep capital investments and operating costs competitive with conventional hydrocarbon production.

The following section outlines the economical viability of different oil shale extraction methodologies. Figure 14 shows minimum economic price for oil shale technology and breakdown price for generic surface project. It can be seen that capital and operating costs are the largest components. The taxes and transfer payments comprising of royalty and severance payments account for one third of the price requirement.

\subsection{Economics of oil shale development in USA}

United States have more than 1.8 trillion barrels of oil trapped in the oil shale in Federal lands of western region comprising of Colarado, Utah and Wyoming states. Nearly 800 billion of trapped oil can be recovered which is atleast three times the proven reserves of Saudi Arabia (Biglarbigi et al. 2008). With oil prices staying well above 60 $\$ / b b l$ along with advancing extraction technologies in recent years have made the development of oil shale a profitable venture. This in turn will lead to increase in domestic oil production, creation of employment, increased contribution to GDP, reduced imports and increase in the direct federal and state revenues. 
The economic validity of the project depends mainly on two parameters.

- Operating costs and investments: These depend upon the type of technology employed and the quality of the resource. The production capacity can vary from 10000 to100000 barrels per day for surface retort to as much as 300000 barrels per day for full scale in-situ projects.For operating costs, the model estimates in the range of of $\$ 12$ to $\$ 20$ per barrel whereas the capital costs fall in the range of $\$ 40,000$ to $\$ 55,000$ per barrel of daily (stream day) capacity.

- Minimum Economic Price: It is defined as the world crude oil price needed to yield a $15 \%$ rate of return on the project which covers for the capital and technical risks involved in the project. It varies for the type of technology applied as shown in Table 3 below.

Table 3: Minimum economic price for oil shale technology

\begin{tabular}{|l|c|}
\hline Technology & $\begin{array}{c}\text { Average Minimum Economic Price } \\
(\mathbf{\$} / \mathbf{b b l})\end{array}$ \\
\hline Surface Mining & 47 \\
\hline Underground Mining & 57 \\
\hline True In-Situ & 38 \\
\hline Modified In-situ & 62 \\
\hline
\end{tabular}




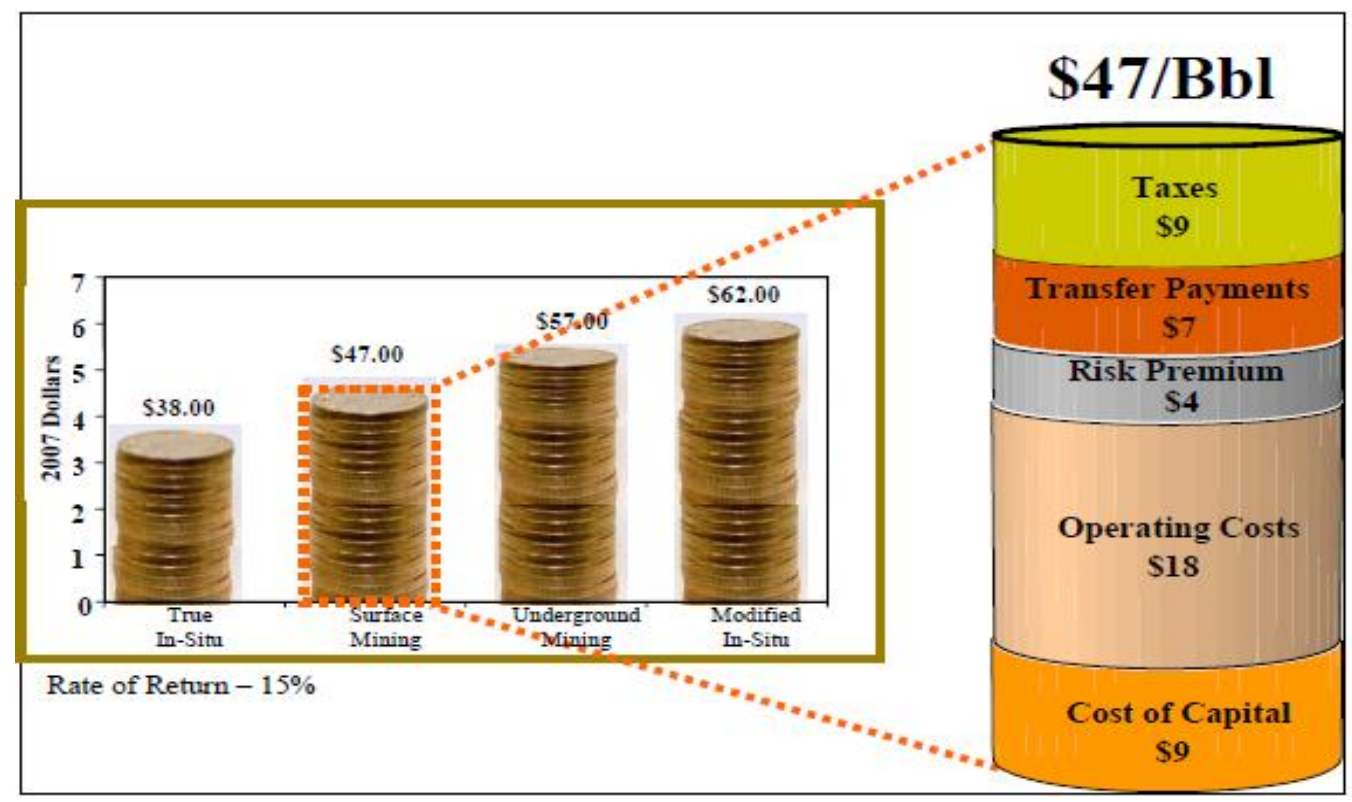

Figure 14: Minimum economic price for oil shale technology (Biglarbigi et al. 2008)

Oil shale is a fine grained sedimentary rock consisting of solid and insoluble organic matter Kerogen, inorganic mineral matrix mainly composed of clay, quartz, pyrite and feldspar with minor amount of uranium, iron, vanadium and nickel and pores that are either moisture or air filled (Eseme et al. 2007) as shown in Figure 15. The following section describes different types of kerogen and kinetics of kerogen decomposition that occurs when subjected to pyrolysis temperature in the range of $600-800{ }^{0} \mathrm{~F}$; expediting the process of conversion of kerogen to oil and gas that would have otherwise taken million of years under natural conditions of high temperature and pressure. 


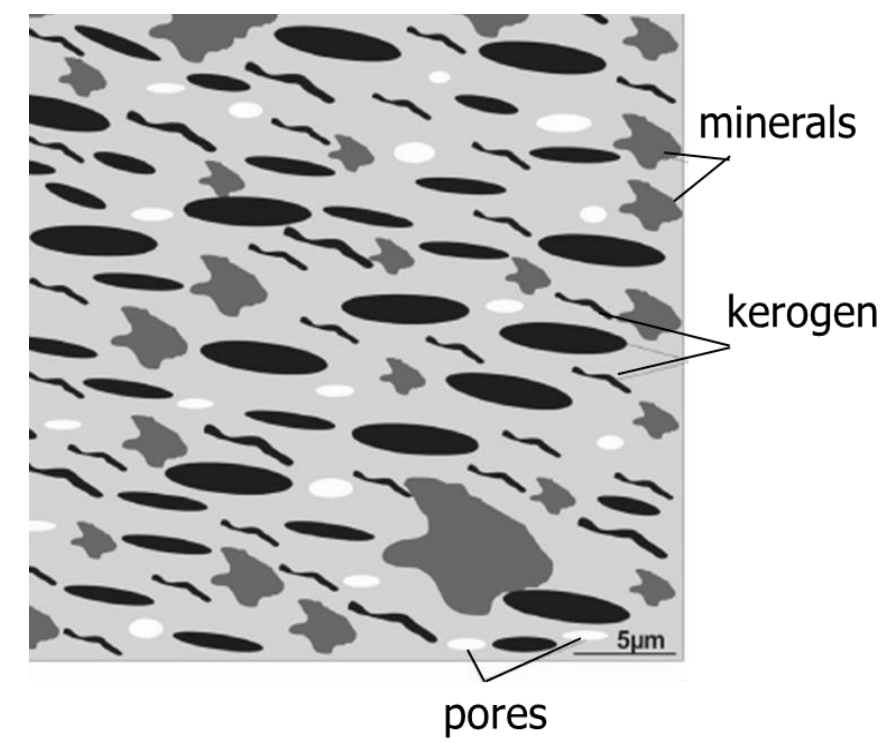

Figure 15: Composition of oil shale (Eseme et al. 2007)

\subsection{Kerogen types}

Petroleum (oil and gas) is generated from organic matter in sedimentary rocks through a series of complex, predominantly first-order thermo-chemical reactions under the influence of temperature, pressure and time. Organic matter mainly comprises of lipids, proteins, carbohydrates and lignin-humic compounds and goes under diagenetic processes to form soluble bitumen and insoluble kerogen in organic solvents (Dow 1977). Kerogen has a high molecular weight and is complex mixture of organic material constituting carbon, hydrogen and oxygen with traces of nitrogen and sulfur.

Kerogen is classified into three groups based on Van Krevelen diagram (Das 1989) as shown in Figure 16.

- Type I Kerogen (Sapropelic): They are derived from lacustrine algae and are formed in anoxic lakes from lipids and proteins with few cyclic or aromatic 
structures. They have the highest oil yield with high hydrogen to carbon ratio (>) 1.5 and low oxygen to carbon ratio $(<)$ 0.1. The western oil shale deposits (tertiary Eocene age) of Green River formation in Colorado, Utah and Wyoming are prominent examples of Type I Kerogen.

- Type II Kerogen (Planktonic): They are formed from lipids in a marine depositional environment under reducing conditions and have higher aromaticity and sulfur content. They yield lesser amount of oil than Type I Kerogen with hydrogen to carbon ratio lesser than 1.25 and oxygen to carbon ratio of $0.1-$ 0.2. Devonian oil shales in eastern part of the United States are the primary examples of Type II Kerogen.

- Type III Kerogen (Humic): They are composed of terrestrial organic matter, mainly cellulose and lignin and have broader ring and aromatic structure. They yield mostly gas and least amount of oil on pyrolysis with hydrogen to carbon ratio lesser than 1 and oxygen to carbon ratio of 0.03- 0.02. Humic coal is an example of Type III Kerogen. 


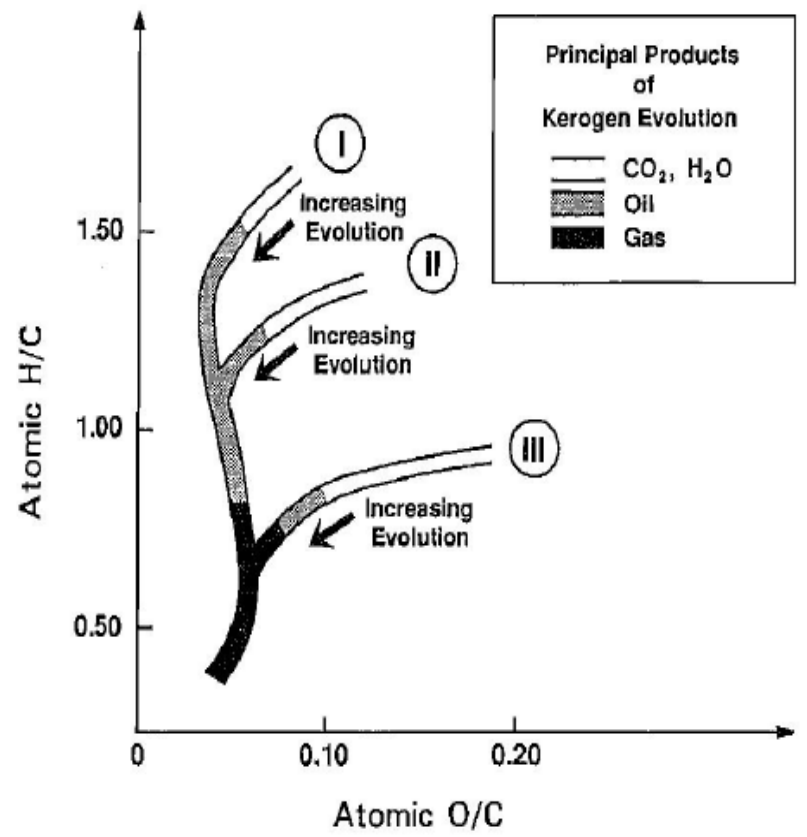

Figure 16: Van Krevlen diagram for kerogen types (Das 1989)

\subsection{Kinetics of kerogen decomposition}

Decomposition of kerogen to bitumen and hydrocarbon on application of heat takes place through series of complex chemical reactions, predominantly first order kinetic reactions and can be simplified into two step mechanism as shown below (Campbell et al. 1978).

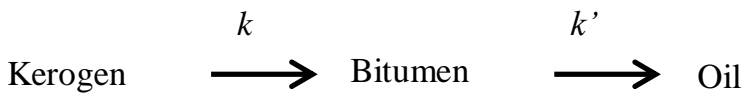

Where $k \& k^{\prime}$ are reaction rate constants, $k>k^{\prime}$ at $T<300{ }^{\circ} \mathrm{C}$

Two different mechanisms, low temperature and high temperature kerogen conversion are proposed for production of hydrocarbon from oil shales (Hill and Dougan 1967). In the lower temperature range of $500-700{ }^{0} \mathrm{~F}$, kerogen decomposes to 
bitumen, which then finally decomposes to form oil, gas and carbonaceous residue with a pour point in the range of $-20{ }^{\circ} \mathrm{C}$ and an API gravity of about $40^{\circ}$. When heated at higher temperatures $\left(>800{ }^{0} \mathrm{~F}\right)$, bitumen produces a stabilized polymer product that thermally decomposes to yield different type of oil, gas and residue with pour point of $80{ }^{\circ} \mathrm{F}$ and API gravity of $20^{\circ}$. Low temperature oil shale conversion results in liquids with lesser aromatic and polar compounds and also has insignificant nitrogen content because of low polymerization of nitrogen containing compounds (Wen and Kobylinski 1983). Almost $95 \%$ of the kerogen in oil shale deposits of Green River formation is decomposed to bitumen by two parallel competing first order kinetic reactions, one at higher temperature $\left(>350{ }^{\circ} \mathrm{C}\right)$ with an activation energy of $45.7 \mathrm{kcal} / \mathrm{mol}$ and another at lower temperature $\left(<350{ }^{\circ} \mathrm{C}\right.$ ) with an activation energy of $20.8 \mathrm{kcal} / \mathrm{mol}$ (Leavitt et al. 1987). 


\section{CHAPTER II}

\section{SHELL IN-SITU CONVERSION PROCESS (ICP)}

This chapter describes Shell's Mahogany Demonstration Project South (MDPS) pilot field project along with the input parameters for simulation and the results. Shell followed up its Mahogany Demonstration Project Original (MDPO) with the south field pilot project MDPS to overcome the limitations of the former in terms of effective heating and hydrocarbon recovery. Sixteen vertical heater wells were drilled in three concentric rings with two producer wells at the centre as shown in Figure 17. Six heaters are each placed at the two outer rings with a spacing of $19.5 \mathrm{ft}$ and $14 \mathrm{ft}$, respectively, whereas the inner-most ring has four heaters with a spacing of $10 \mathrm{ft}$. There are two producer wells, $5 \mathrm{ft}$ apart in the central part. The formation depth was $400 \mathrm{ft}$ with the targeted heated interval of $110 \mathrm{ft}$ approximately (Fowler and Vinegar 2009). The top of the heated interval was at $280 \mathrm{ft}$ depth.

This chapter summarized some of the current surface and in-situ oil shale heating technologies along with economics of hydrocarbon extraction from oil shale. It also provides an overview of chemical kinetics for oil shale conversion at lower and higher temperatures which are detailed in the following chapter. The next chapter outlines one of the direct heating methods i.e. Shell ICP which is based on heating the formations with downhole electrical heaters from vertical wells. A validated simulation model is built for Shell's one of the field projects with thorough kinetic reactions and sensitivity analyses on the effect of heater temperature, heater spacing and number of heaters on 
hydrocarbon production are performed and their implications on energy efficiency are determined.

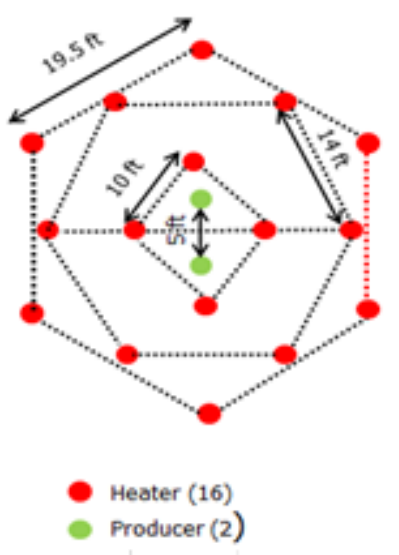

(a)

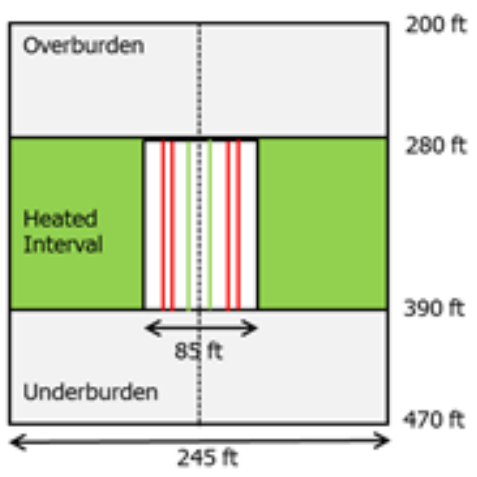

(b)

Figure 17: Shell ICP (a) Top view of heaters (b) Side view of heaters

\subsection{Simulation model description}

Kinetic reactions involved in thermal decomposition of kerogen and the generated components are adapted from Wellington et al. (2005) and Fan et al. (2010) respectively. Pyrolysis experiments on Green River oil shale yield several oil and gas species as investigated by Braun and Burnham (1990). Fan et al. (2010) applied lumping procedures on these species to determine the properties and pseudo components listed in Table 4. The pseudo species $\mathrm{IC}_{37}, \mathrm{IC}_{13}, \mathrm{IC}_{2}$ represent heavy oil, light oil and hydrocarbon gas respectively and their chemical properties are listed in Table 5. The API gravity of light oil and heavy oil is taken as 45 and 10 respectively as reported by Wellington et al. (2005). Stone's model has been used for the three phase relative permeability calculations. The gas phase viscosity is obtained using the built-in 
correlations in STARS and the oil phase viscosity is calculated using the equation 1 as given by Miadonye et al. (1994) and is reported in Table 6.

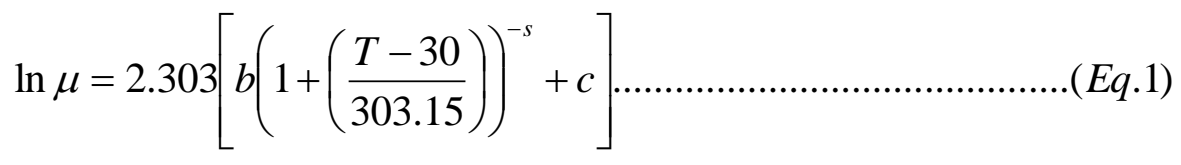

Where $\mu$ is in Pa.s, $T$ is in ${ }^{0} \mathrm{~K}$

$b, c \& s$ are parameters calculated for the oil under study

For simulations presented in this study, $b=4.1228 ; s=3.5640 ; c=-3.002$

Data for reservoir parameters are obtained from the work done by (Fan et al. 2010) who modelled Shell's in-situ upgrading project using Stanford's general purpose research simulator (GPRS) which is a thermal/compositional simulator based on EOS and is coupled with chemical kinetics and are reported in Table 7.

Due to thermal-kinetic reactions, as kerogen decomposes; both porosity and permeability will increase in the heated interval but here we are not modeling evolution of any of these parameters and rather assigning averaged values. The effective porosity $(\Phi)$ for the heated interval is taken as 0.05 though half of the pore space created due to kerogen decomposition will end up to be filled with solid prechar. The permeability for the heated interval is assigned a value of $300 \mathrm{md}$ as reported in the work of Fan et al. (2010) that is in accordance with the value calculated using Carman-Kozeny equation provided in Wellington et al. (2005).. The overburden (OB) and underburden (UB) have very less or no kerogen and thus have been assigned very low porosity and permeability 
values as we assume that their matrix remain unaffected during heating of the target interval.

Table 4: Kinetic reactions for Shell ICP model

\begin{tabular}{|c|c|c|}
\hline Reactions & $\begin{array}{l}\text { Frequency } \\
\text { Factor }(\mathbf{A})\end{array}$ & $\begin{array}{c}\text { Ea } \\
(\mathrm{kJ} / \mathrm{mol})\end{array}$ \\
\hline $\begin{array}{l}\mathrm{KER}(\mathrm{s})-->0.02691 \mathrm{H}_{2} \mathrm{O}+0.009588 \mathrm{IC}_{37}+0.0178 \mathrm{IC}_{13}+ \\
0.04475 \mathrm{IC}_{2}+0.01049 \mathrm{H}_{2}+0.00541 \mathrm{CO}_{2}+0.5827 \\
\text { PRECHAR }\end{array}$ & $3.74 \mathrm{E}+12$ & 161.6 \\
\hline $\mathrm{IC}_{37}(\mathrm{~g})-->1.853 \mathrm{IC}_{13}+0.045 \mathrm{IC}_{2}+2.4515$ PRECHAR & $6.25 \mathrm{E}+16$ & 206.034 \\
\hline $\mathrm{IC}_{37}(\mathrm{o})-->0.2063 \mathrm{IC}_{13}+2.365 \mathrm{IC}_{2}+17.497$ PRECHAR & $2.65 \mathrm{E}+20$ & 206.034 \\
\hline $\mathrm{IC}_{13}(\mathrm{~g})-->5.73 \mathrm{IC}_{2}$ & $9.85 \mathrm{E}+16$ & 219.328 \\
\hline $\mathrm{IC}_{13}(\mathrm{o})-->0.573 \mathrm{IC}_{2}+10.904$ PRECHAR & $3.82 \mathrm{E}+20$ & 219.328 \\
\hline
\end{tabular}

Table 5: Properties of chemical components of oil shale

\begin{tabular}{|c|c|c|c|}
\hline Component & $\begin{array}{c}\text { Molecular Weight } \\
(\mathbf{l b} / \mathbf{l b m o l})\end{array}$ & $\begin{array}{c}\text { Critical Pressure } \\
\text { (psia) }\end{array}$ & $\begin{array}{c}\text { Critical Temperature } \\
(\mathbf{0} \mathbf{F})\end{array}$ \\
\hline Kerogen & 15.15 & & \\
\hline Prechar & 12.72 & & 1135.13 \\
\hline $\mathrm{IC}_{37}$ & 317.96 & 213.21 & 827.65 \\
\hline $\mathrm{IC}_{13}$ & 169.52 & 348.82 & 60.07 \\
\hline $\mathrm{IC}_{2}$ & 26.89 & 668.48 & 87.89 \\
\hline $\mathrm{CO}_{2}$ & 44.01 & 1069.8 & 705.2 \\
\hline $\mathrm{H}_{2} \mathrm{O}$ & 18.02 & 3206.2 & \\
\hline
\end{tabular}


Table 6: Oil phase viscosity at different temperatures

\begin{tabular}{|c|c|}
\hline Temperature $\left({ }^{\mathbf{0}} \mathbf{F}\right)$ & Viscosity $(\mathbf{c p})$ \\
\hline 70 & 38204.91 \\
\hline 100 & 5819.37 \\
\hline 150 & 595.29 \\
\hline 200 & 124.36 \\
\hline 250 & 41.12 \\
\hline 300 & 18.44 \\
\hline 350 & 10.19 \\
\hline 400 & 6.52 \\
\hline 500 & 3.54 \\
\hline 600 & 2.43 \\
\hline 700 & 1.9 \\
\hline 800 & 1.61 \\
\hline
\end{tabular}

Table 7: Input parameters for simulation model Shell ICP

\begin{tabular}{|l|l|l|l|}
\hline \multicolumn{1}{|c|}{ Parameters } & \multicolumn{1}{|c|}{ value } & \multicolumn{1}{c|}{ Parameters } & \multicolumn{1}{c|}{ value } \\
\hline Grid (Cartesian) & $49 * 49 * 15$ & Porosity (OB/UB) & 0.0001 \\
\hline Grid Dimensions & $\begin{array}{l}\Delta \mathrm{x}=\Delta \mathrm{y}=5 \\
\mathrm{ft} ; \Delta \mathrm{z}=10 \mathrm{ft}\end{array}$ & Permeability (OB/UB) & $\begin{array}{l}\mathrm{K}_{\mathrm{x}}=\mathrm{K}_{\mathrm{y}}=\mathrm{K}_{\mathrm{z}}=1 \mathrm{E}-04 \\
\mathrm{md}\end{array}$ \\
\hline Overburden thickness & $80 \mathrm{ft}$ & Porosity (heated interval) & 0.05 \\
\hline Heated interval & $110 \mathrm{ft}$ & $\begin{array}{l}\text { Permeability (heated } \\
\text { interval) }\end{array}$ & $\mathrm{k}_{\mathrm{x}}=\mathrm{k}_{\mathrm{y}}=\mathrm{k}_{\mathrm{z}}=300 \mathrm{md}$ \\
\hline $\begin{array}{l}\text { Underburden } \\
\text { thickness }\end{array}$ & $80 \mathrm{ft}$ & Thermal conductivity & $15 \mathrm{Btu} / \mathrm{ft} / \mathrm{Day} /{ }^{0} \mathrm{~F}$ \\
\hline Initial temperature & $107^{0} \mathrm{~F}$ & Heater temperature & $800{ }^{0} \mathrm{~F}$ \\
\hline Initial pressure & $120 \mathrm{psi}$ & Producer BHP & $30 \mathrm{psi}$ \\
\hline Initial kerogen & $\begin{array}{l}3.8 \\
\mathrm{lbmol} / \mathrm{ft}^{3}\end{array}$ & $\begin{array}{l}\text { Rock volumetric heat } \\
\text { capacity }\end{array}$ & $25 \mathrm{Btu} / \mathrm{ft}^{3} /{ }^{0} \mathrm{~F}$ \\
\hline Rock compressibility & $3 \mathrm{E}-06 \mathrm{psi}^{-1}$ & & \\
\hline
\end{tabular}


We have built the simulation model with a Cartesian grid system. The overall model is $245 \mathrm{ft}$ in both length and width and $270 \mathrm{ft}$ in depth. The initial pore space is assumed to be saturated with free carbon dioxide and solid kerogen. Dyni (2006) reported that commercially feasible oil shale deposits have more than $10 \%$ organic matter by weight. As Green River oil shale is highly rich in organic matter kerogen, we assume it to be in the range of $30-40 \%$ by weight. The oil shale density is around 2.5 $\mathrm{g} / \mathrm{cc}$, and Wellington et al. (2005) reported that the molecular weight of kerogen is approximately $15.153 \mathrm{lb} / \mathrm{lbmol}$. The recommended parameters above correspond to initial kerogen concentration $(C)$ in the range of $3.1-3.8 \mathrm{lbmol} / \mathrm{ft}^{3}$. Thermal conductivity $(\kappa)$ of Green River oil shale varies over a wide range of temperature and kerogen content and is reported in between 6.3-25 Btu/ft/Day/ ${ }^{0} \mathrm{~F}$ (Prats and $\mathrm{O}^{\prime} \mathrm{Brien} 1975$ ). We have assumed constant values for rock density $\left(\rho_{R}\right)$ and specific heat $\left(c_{P}\right)$ though the former decreases with the increase in temperature whereas the latter one increases with the increase in kerogen content and temperature (Wang et al. 1979). In a way, the product of both these is assumed to be constant so that thermal diffusivity $(\alpha)$ which is a critical parameter for diffusion of heat into the formation is only governed by variation in thermal conductivity as it is defined as the ratio of thermal conductivity over the product of specific heat and density. Therefore, initial kerogen content and thermal conductivity have been used as the tuning parameters for a model match. 


\subsection{Simulation outputs}

Sixteen vertical heater wells are heated to a constant temperature of $800{ }^{0} \mathrm{~F}$ in the heated interval. The final input for kerogen concentration and thermal conductivity are chosen as $3.8 \mathrm{lbmol} / \mathrm{ft}^{3}$ and $15 \mathrm{Btu} / \mathrm{ft} / \mathrm{Day} /{ }^{0} \mathrm{~F}$ respectively to arrive at a closer match to Shell's reported field results. The model predicts cumulative hydrocarbon production of 1885 STB of oil and 2540 MSCF of gas with total of 2350 barrel of oil equivalent (BOE) in 500 days assuming $1 \mathrm{BOE}$ is equal to $5.478 \mathrm{MSCF}$ of gas and is shown in Figure 18. The reported field value for Shell MDPS hydrocarbon production is 1860 barrel of oil (Fowler and Vinegar 2009).

Thus, results of our simulation model are in conformance to the reported field values justifying the validity of input parameters for an excellent match. However, rigorous tuning of other properties as well as employing their dependence on temperature and organic matter content would provide more accurate results and can be a great scope for future work. The production profile for the Shell ICP validated simulation model is shown in Figure 18 and Figure 19. It can be observed from Figure 19 that initial rate of hydrocarbon recovery is very higher due to thermal decomposition of kerogen in the vicinity of the heaters as the pyrolysis temperature window is achieved very soon. Gradually with increasing time, as the thermal front propagates into the formation, the rates go down due to depletion of kerogen into oil and gas products. 


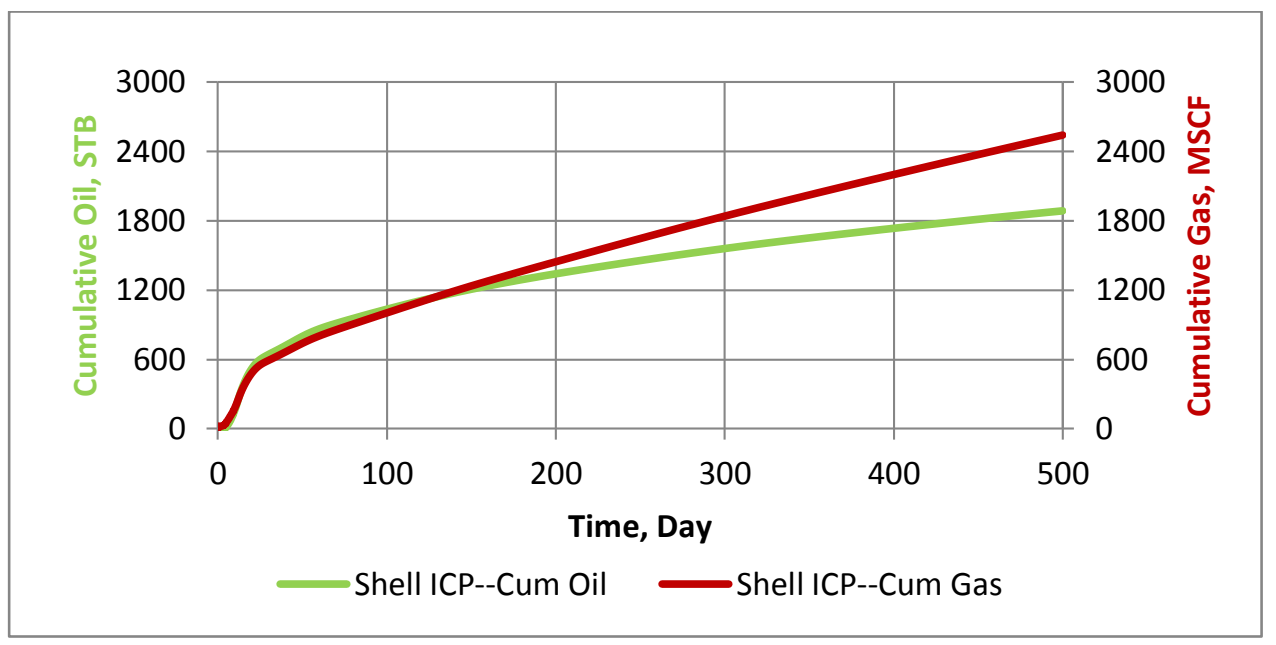

Figure 18: Shell ICP cumulative oil and gas production

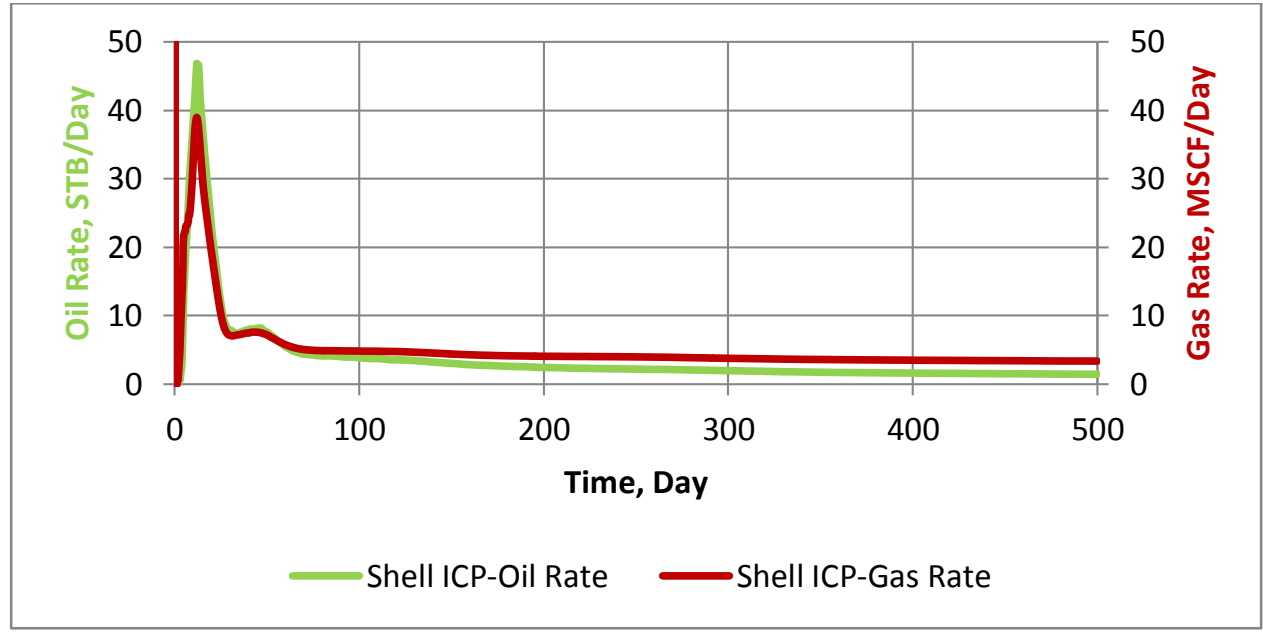

Figure 19: Shell ICP oil and gas production rates

Figure 20 shows the temperature profile in the formation when heaters are operated for 500 days at $800{ }^{0} \mathrm{~F}$. At the end of 500 days, almost laterally $85 \mathrm{ft}$ of formation attains the pyrolysis window of $500-700{ }^{0} \mathrm{~F}$ where kerogen decomposition takes place. Figure 21 shows the kerogen decomposition map in the heated interval over the duration of 500 
days of heating as the formation approaches pyrolysis temperature.
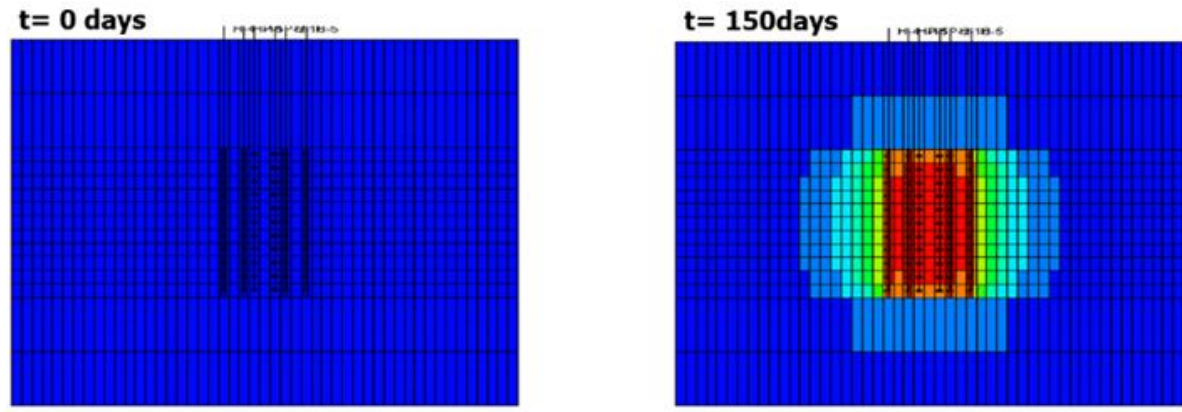

Temp (F)
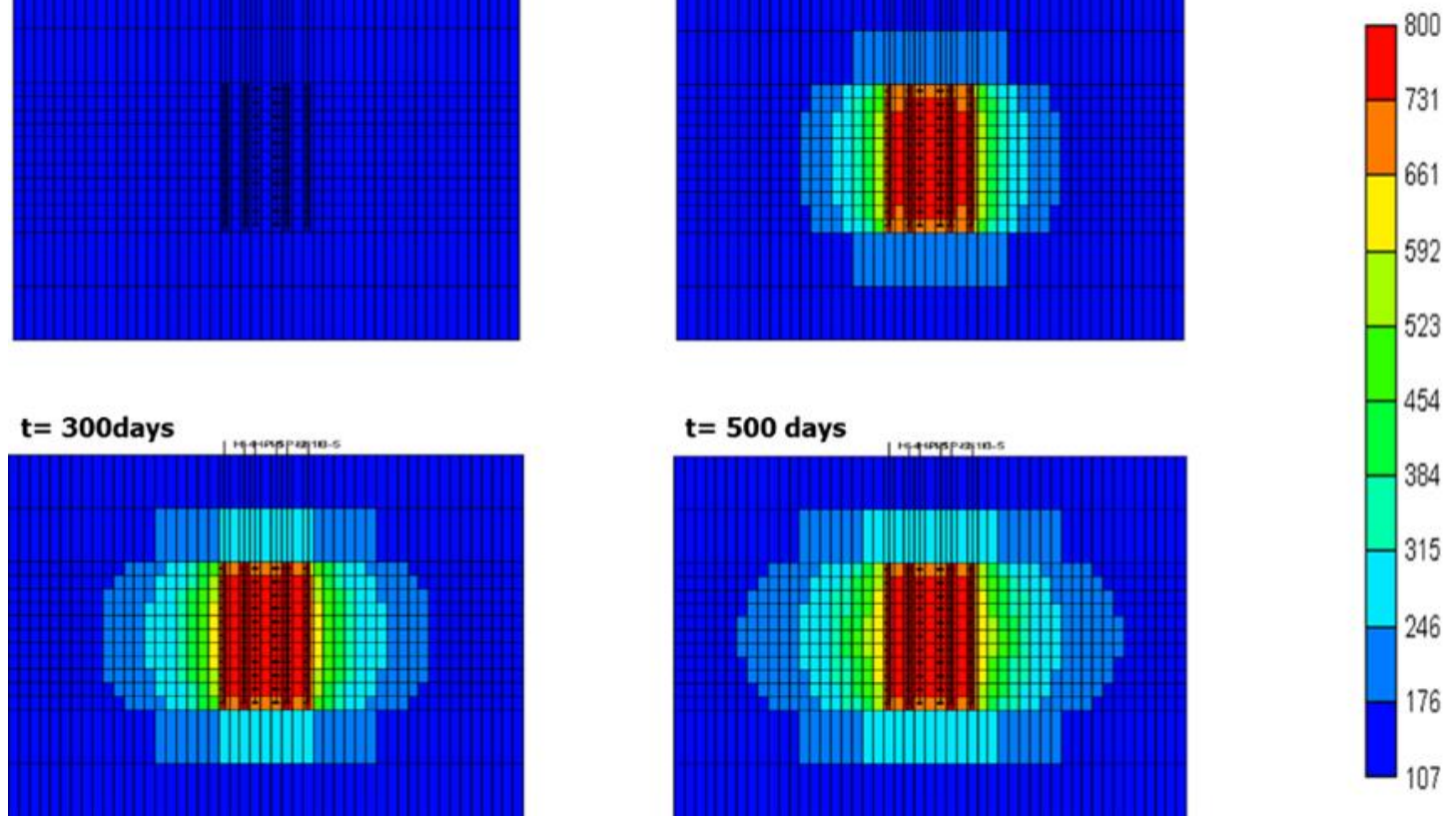

Figure 20: Temperature profile $\left({ }^{0} \mathrm{~F}\right)$
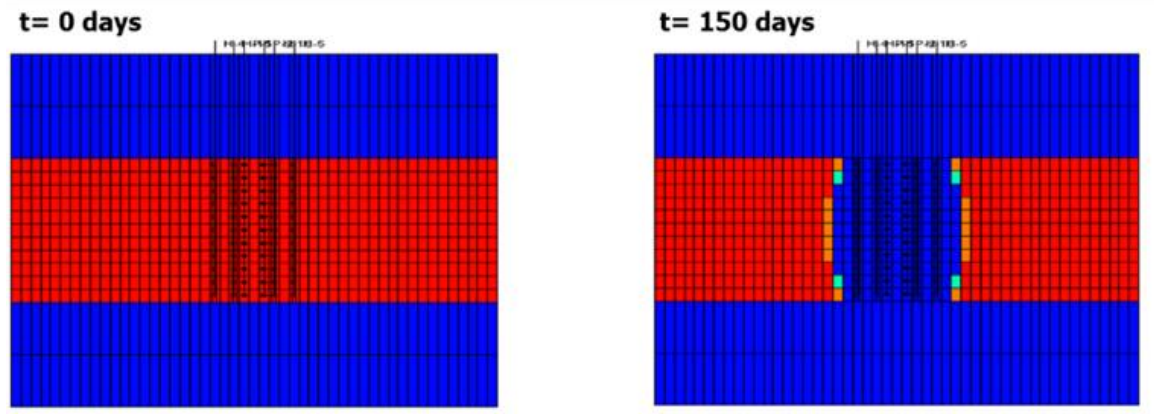

Conc $\left(\mathrm{lb} / \mathrm{ft}^{3}\right)$

$\mathbf{t}=\mathbf{3 0 0}$ days

$\mathbf{t}=\mathbf{5 0 0}$ days
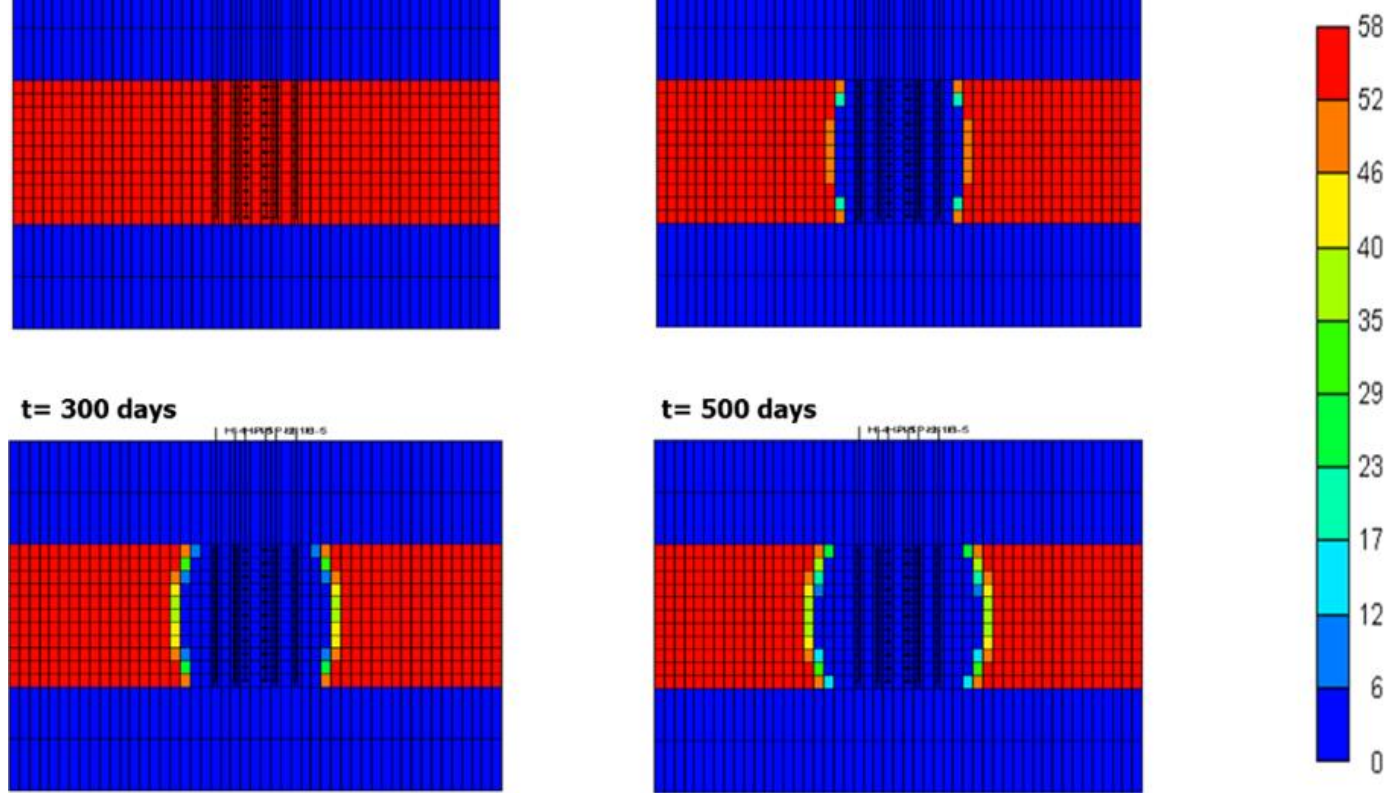

Figure 21: Kerogen decomposition map, $\mathrm{lb} / \mathrm{ft}^{3}$ 


\subsection{Sensitivity runs}

Various simulation runs revealed sensitivity to the effect of heater temperature, number of heaters and heater spacing on cumulative hydrocarbon production and production rates. These sensitivity runs can serve to optimize a field scale in-situ project and surface production facilities. We have used Cartesian grid system of $11 * 11 * 9$ grids along $\mathrm{x}, \mathrm{y}$ and $\mathrm{z}$ directions with local grid refinement (LGR) for thegrid blocks having heater wells. The various heater patterns are shown in Figure 22. We have taken a base case of heaters arranged in hexagon pattern with $20 \mathrm{ft}$ spacing and operating at $800{ }^{0} \mathrm{~F}$. The area under the pattern is approximately $1375 \mathrm{ft}^{2}$ and all the parameters for simulation are the same as that of the validated model for Shell ICP for MDPS project. Because the patterns are repeated, heat losses are only considered for overburden $(\mathrm{OB})$ and underburden (UB), and there is no peripheral heat loss.

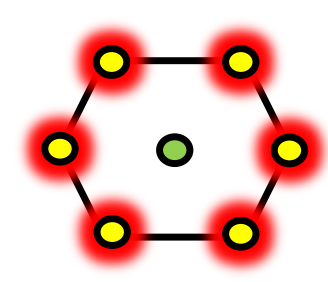

(a) Hexagon

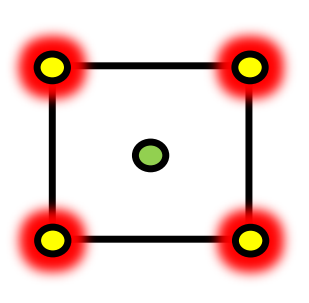

(b) Square



(c) Triangle

Figure 22: Heater patterns

\subsubsection{Effect of temperature}

Three heater operating temperatures of $600{ }^{0} \mathrm{~F}, 700{ }^{0} \mathrm{~F}$ and $800{ }^{0} \mathrm{~F}$ are 
considered. Since the kerogen decomposition is thermo-kinetically controlled mechanism, the higher the heater temperature; the more rapidly the formation approaches the pyrolysis temperature that results in faster recovery of hydrocarbons. However if simulation is run for a longer time, the cumulative oil and gas production curves approach asymptotical converging behaviour. Therefore, it can be inferred that downhole heaters operating at higher temperatures, accelerate the hydrocarbon production rates and expedite the initial cash flow to recover the cost of the project. In general, higher heating temperature result in greater gas production and lower liquid recovery but total barrel of oil equivalent (BOE) remains almost same and is equal to 660 BOE. Figure 23 and Figure 24 show the effect of heater temperature on the hydrocarbon production profile. It can be observed that peak production rates are greater for heaters operating at higher temperatures and also occur earlier in the operation period.

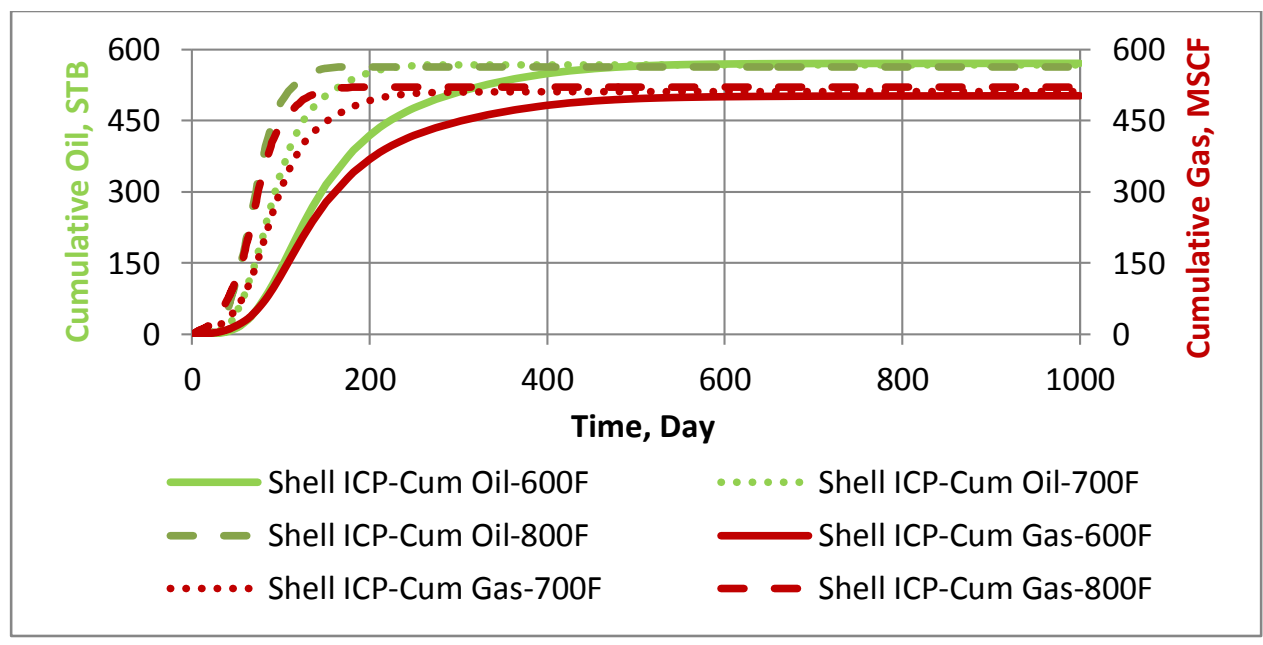

Figure 23: Effect of temperature on cumulative oil and gas production 


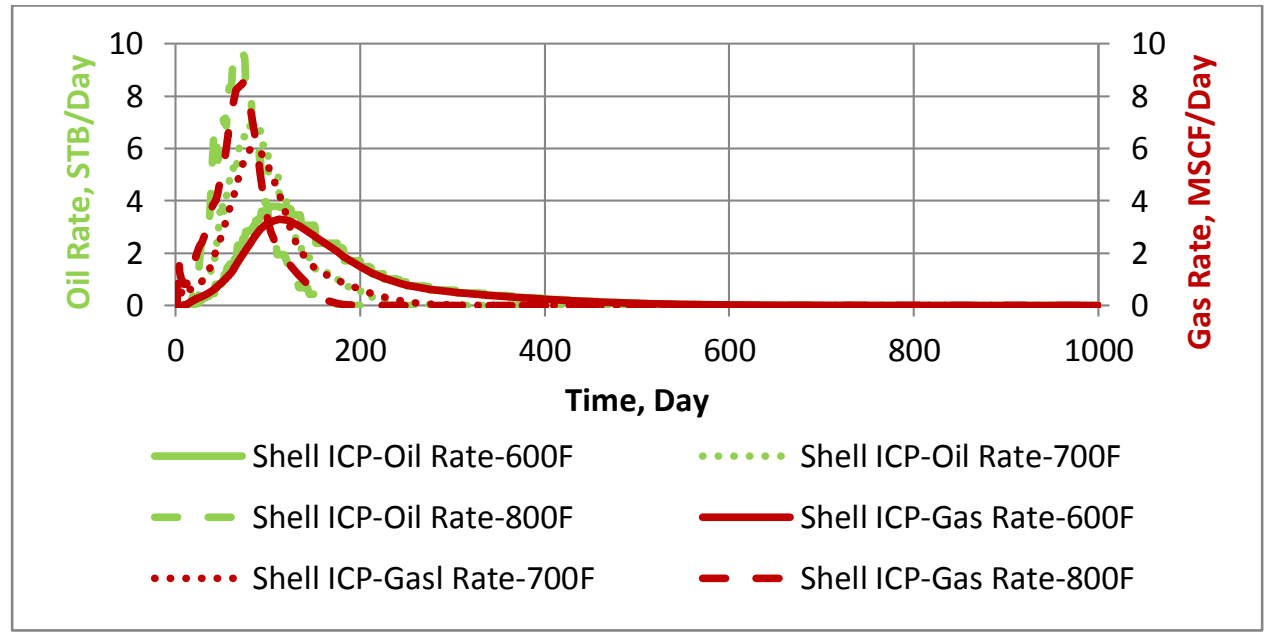

Figure 24: Effect of temperature on oil and gas production rates

Figure 25 shows the temperature profile of the heated formation when heaters are operated at the temperatures of $600{ }^{0} \mathrm{~F}, 700{ }^{0} \mathrm{~F}$ and $800{ }^{0} \mathrm{~F}$ for $100,200,300$ and 400 days respectively. It is vivid, higher the operating temperature of heater, faster the formation temperature rises and reaches the pyrolysis window. 


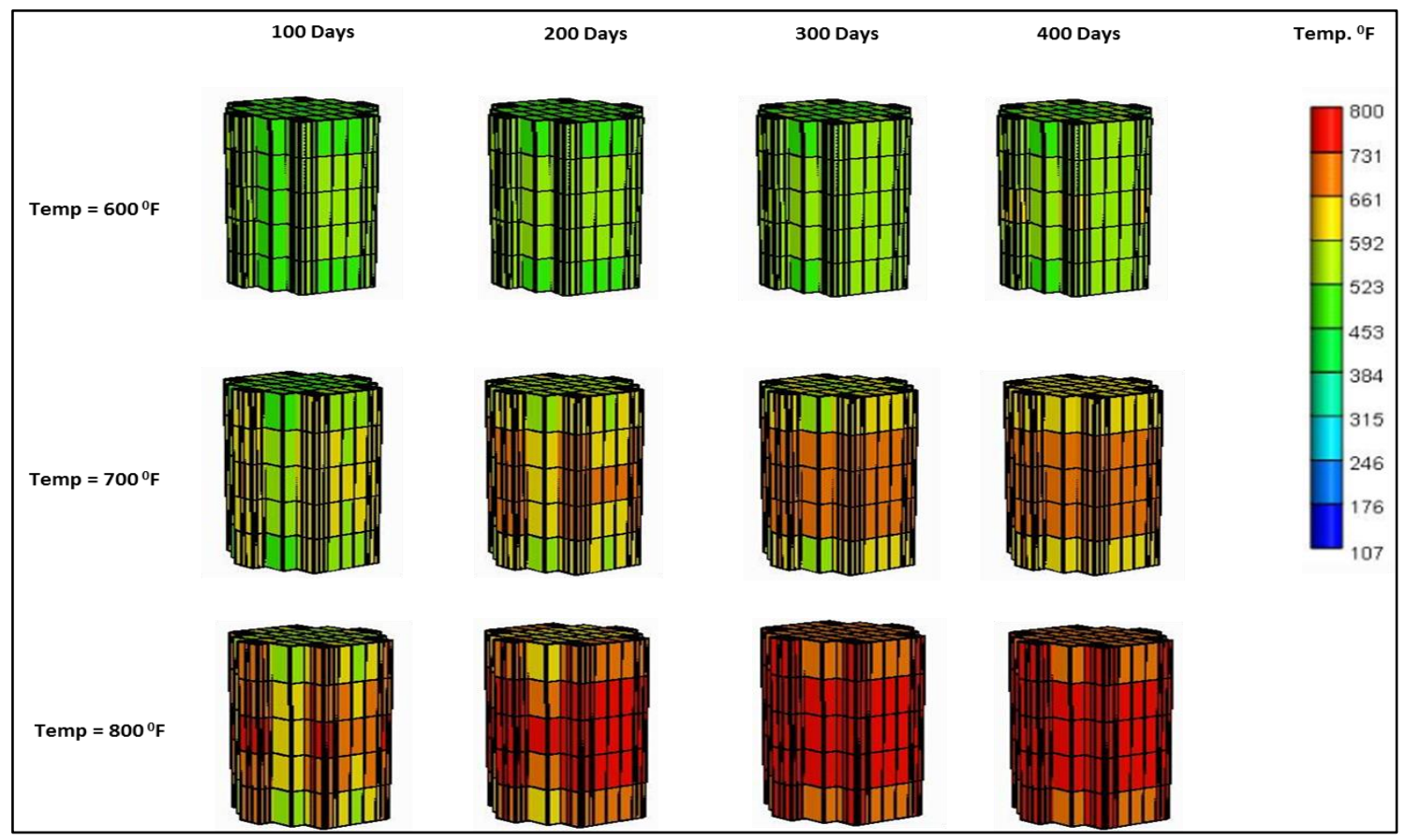

Figure 25: Formation temperature profile for hexagonal pattern at heater temperature $=600^{\circ} \mathrm{F}, 700^{\circ} \mathrm{F}, 800^{\circ} \mathrm{F}$

\subsubsection{Effect of number of heaters}

To analyze the sensitivity to the number of heaters, we have considered two additional cases of square and triangular heater patterns operating at $800{ }^{0} \mathrm{~F}$. The area under these patterns are the same as that of the hexagonal base case with heater spacing of approximately $33 \mathrm{ft}$ and $50 \mathrm{ft}$ for square and triangular patterns respectively. Since the number of heaters is reduced, the rate of heat diffusion into the formation is decreased that results in slower conversion rates of kerogen. The peak production times occur late for lesser number of heaters as the temperature is raised slowly to pyrolysis window. Also, the peak production rates are always lower than that of the hexagonal base case pattern. However, when operated for longer time, the cumulative hydrocarbon recovery 
is equal to that of the hexagonal pattern. Since fewer heaters imply less energy consumption and, more importantly few wells to drill, depending upon the technoeconomic considerations; optimization principles can be applied in these cases. Figure 26 and Figure 27 show the effect of the heating pattern on production as explained above.

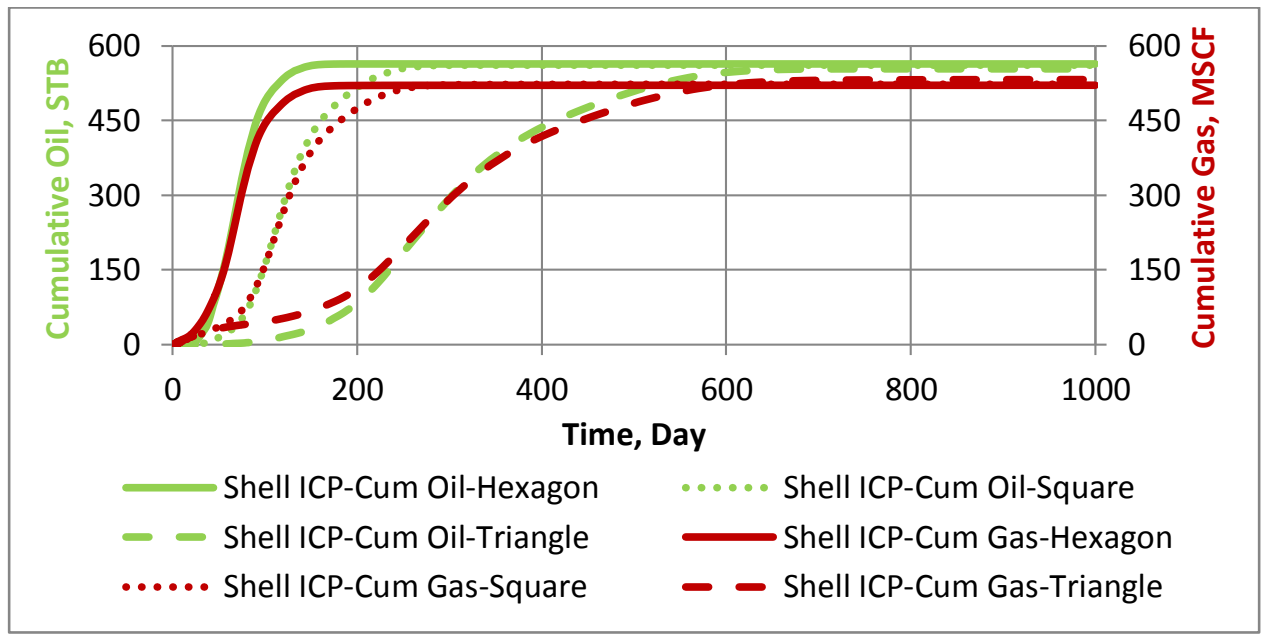

Figure 26: Effect of number of heaters on cumulative oil and gas production

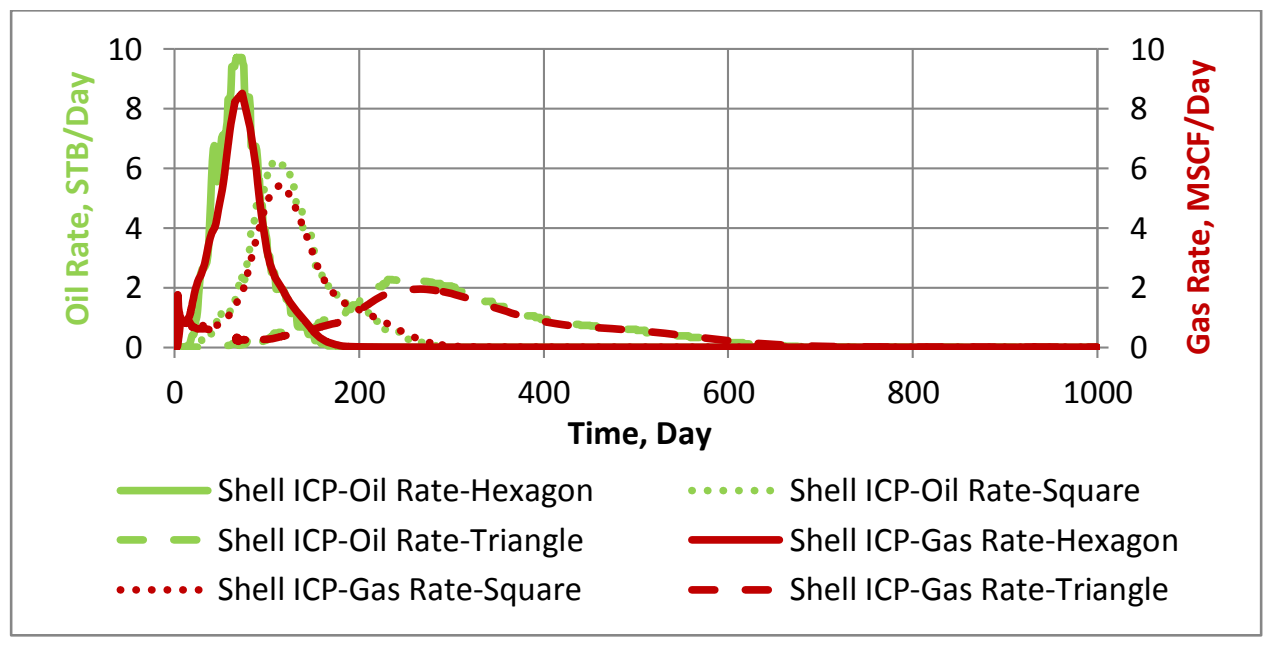

Figure 27: Effect of number of heaters on oil and gas production rates 
Figure 28 shows the temperature profile of the heated formation when heaters are operated in triangular, square and hexagonal arrangement at temperature of $800{ }^{0} \mathrm{~F}$ for 100, 200, 300 and 400 days respectively. It can be observed that higher the number of heaters, accelerated diffusion of heat occurs into the formation that rises the formation temperature rapidly for faster recovery of hydrocarbons as explained above.

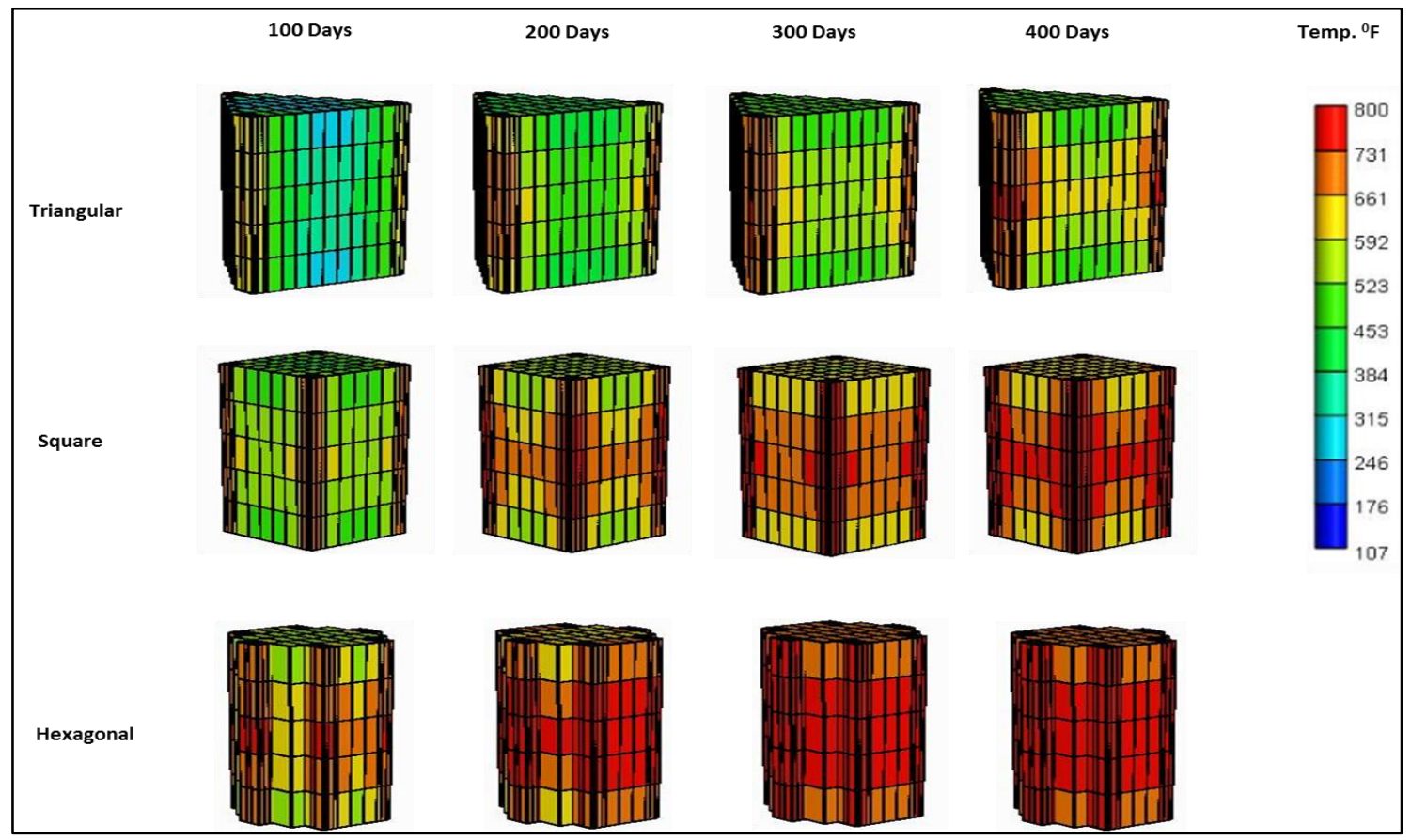

Figure 28: Formation temperature profile for number of heaters (triangular, square and hexagonal) at $800^{\circ} \mathrm{F}$

\subsubsection{Effect of heater spacing}

Two additional heater spacings of $15 \mathrm{ft}$ and $10 \mathrm{ft}$ are used for hexagonal heater pattern. In both cases, the simulation area decreases keeping other parameters same. 
However, we have assumed a reference area of 1 acre and upscaled the cumulative production for all the heater spacings. It can be inferred that as the heater spacing increases, the time to attain peak production rates also increases. Because of the larger area while keeping number of heaters constant, operating at $800^{\circ} \mathrm{F}$, it requires more time to heat the formation to higher temperatures, hence delaying peak production rates. Nonetheless, the cumulative hydrocarbon recovery remains almost same if they are operated for longer interval of time. The peak production is always higher for the smaller spacing since more heat is injected into the formation and increases the rate of recovery. Figure 29 and Figure 30 show the effect of heater spacing on hydrocarbon production profile.

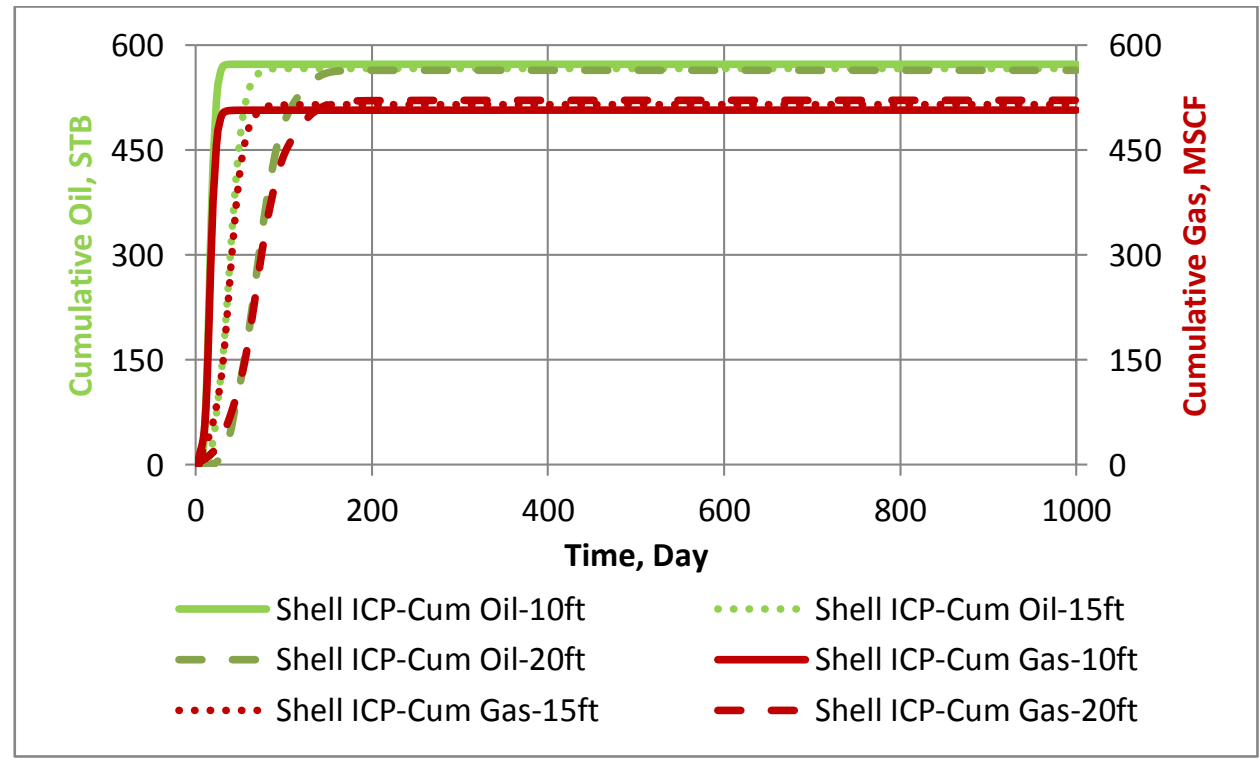

Figure 29: Effect of heater spacing on cumulative oil and gas production 


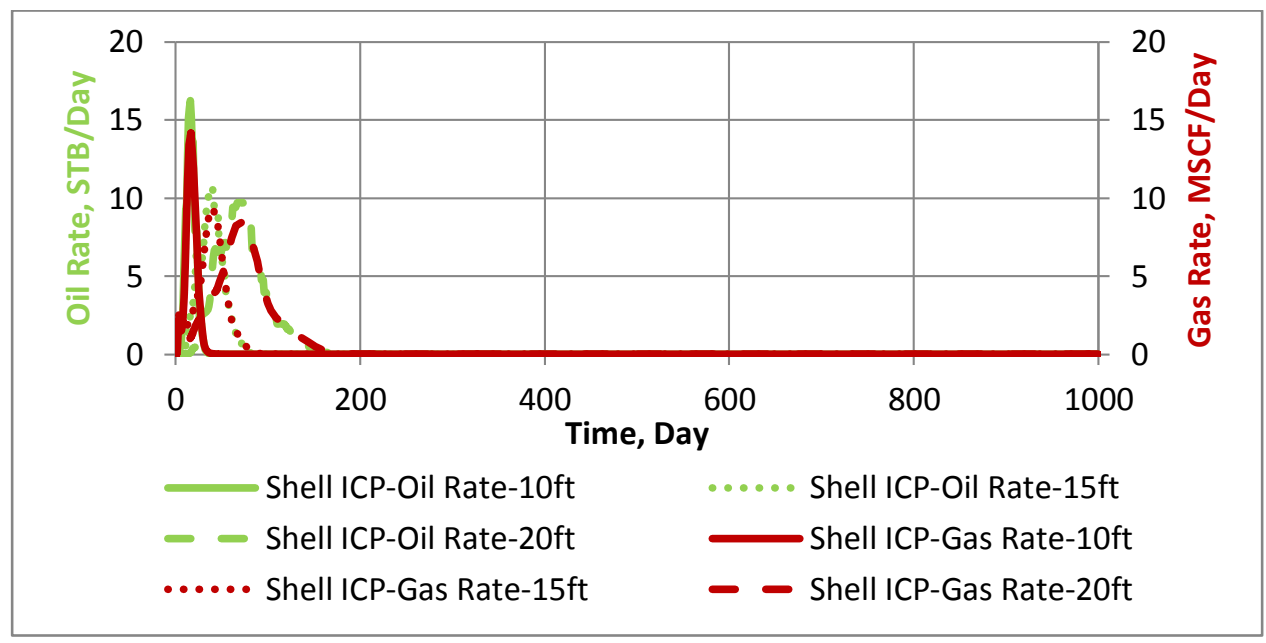

Figure 30: Effect of heater spacing on oil and gas production rates

Figure 31 shows the temperature profile of the heated formation for hexagonal arrangement of electric heaters operated with spacing of $10 \mathrm{ft}, 15 \mathrm{ft}$ and $20 \mathrm{ft}$ at temperature of $800^{\circ} \mathrm{F}$ for $100,200,300$ and 400 days respectively. Lesser spacing results in rapid rise in formation temperature as compared to larger spacing as the number of operating heaters is kept constant. This would result in faster recovery of hydrocarbons as thermo-kinetic reactions for kerogen decomposition start earlier. 


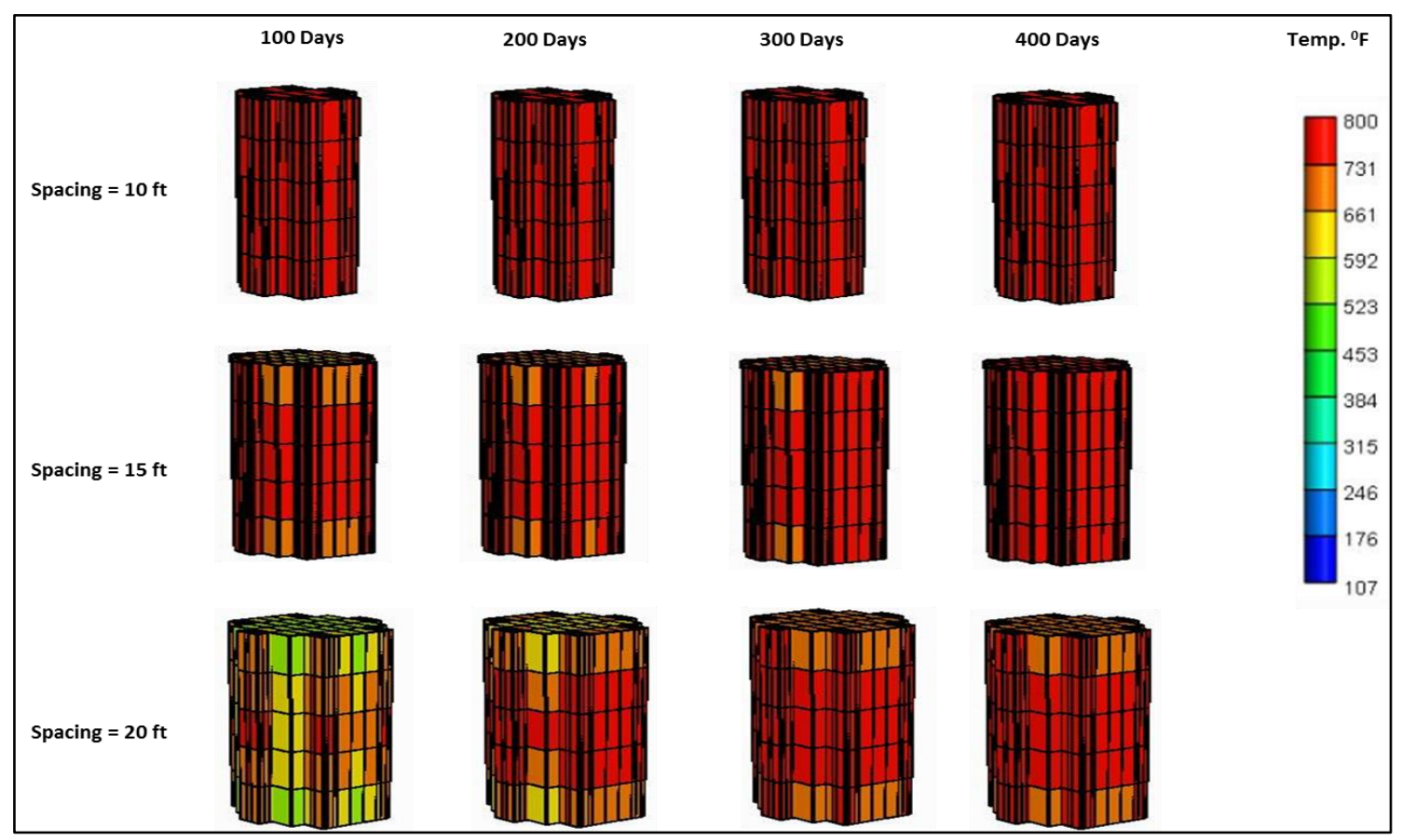

Figure 31: Formation temperature profile of hexagonal pattern for heater spacing $(10,15$ and $20 \mathrm{ft})$ at $800^{\circ} \mathrm{F}$

\subsection{Shell ICP energy efficiency comparison for various cases}

We have compared the results of sensitivity analysis on the basis of energy efficiency $(\eta)$ as it is the key parameter for designing an effective in-situ upgrading process. Energy efficiency is defined as the ratio of total chemical energy content of recovered hydrocarbons with each barrel of oil equivalent yield $5.6^{*} 10^{6}$ Btu and the total thermal energy input to attain it as given by equation 2 . However, we have not accounted for the external energy input required for the electricity generation required to operate the heaters. The maximum efficiency is obtained when the cumulative oil production reaches the final value after which it becomes constant with time. At this time the heaters could be turned off as all of the kerogen has been converted to oil and gas 
products, but the simulations actually kept the heaters on throughout. With continued heating, the efficiency actually drops, but this is not what we would expect the operator to do in practice. The maximum efficiency occurs when approximately $90 \%$ of the converted oil has been produced.

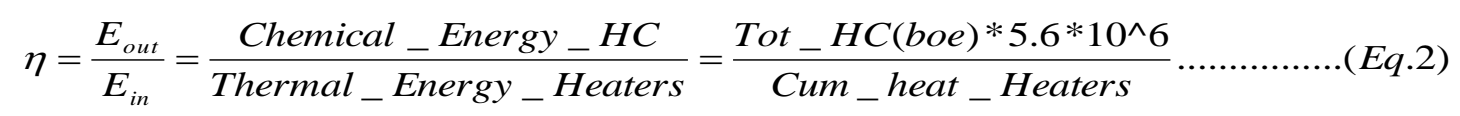

Figure 32 shows the energy efficiency comparison for the various heating patterns. The maximum efficiency of approximately $140 \%$ is obtained in case of hexagonal heater pattern operating at $800{ }^{0} \mathrm{~F}$ with $10 \mathrm{ft}$ spacing. The lowest efficiency is that of the triangular heater pattern operating at $800{ }^{0} \mathrm{~F}$ which is attributed to the fact that longer heating period would be required to convert a same volume of organic matter to hydrocarbons as compared to other cases that would result in increased overburden and underburden heat losses. It can be inferred that for a given spacing (e.g., $20 \mathrm{ft}$ ), the energy efficiency is almost similar for every case but the slope is always steeper for the highest temperature which indicates rapid hydrocarbon recovery. Also for a given heater temperature (e.g., $800{ }^{0} \mathrm{~F}$ ), highest energy efficiency is achieved for reduced heater spacing as it not only takes lesser time for formation to reach pyrolysis temperature but also reduced heat losses. 




Figure 32: Energy ratio comparison for various sensitivity runs

This chapter concluded one of the Shell's field projects for application of directly heating the formation by downhole electrical heaters from vertical wells along with the effect of heater temperature, heater spacing and number of heaters on hydrocarbon production and their implications on energy efficiency. Maximum energy efficiency is achieved for hexagonal heating pattern at $800{ }^{0} \mathrm{~F}$ with lowest spacing accompanied with rapid hydrocarbon production. The next chapter discusses another direct heating approach, ExxonMobil Electrofrac process in which vertical longitudinal fractures are created from horizontal wells in the deeper oil shale deposits to extract hydrocarbons. A sensitivity analyses on the effect of heater temperature and fracture length on hydrocarbon production are performed and their implications on energy efficiency are determined. 


\section{CHAPTER III}

\section{EXXONMOBIL ELECTROFRAC (EF) PROCESS}

This chapter describes simulation results of ExxonMobil's Electrofrac process, another approach of indirect heating using longitudinal vertical fractures created from horizontal wells and propped with electrically conductive material such as calcined coke which is a highly electrically conductive material and acts as a heating element (Symington et al. 2006). The in-situ conversion of organic matter is achieved by hydraulically fracturing the oil shale and filling it with calcined petroleum coke that has very high thermal conductivity in the range of 1000 to $2000 \mathrm{Btu} / \mathrm{ft} / \mathrm{Day} /{ }^{0} \mathrm{~F}$. This method can be aptly employed for Piceance basin oil shale as indicated by laboratory experiments and numerical modeling studies.

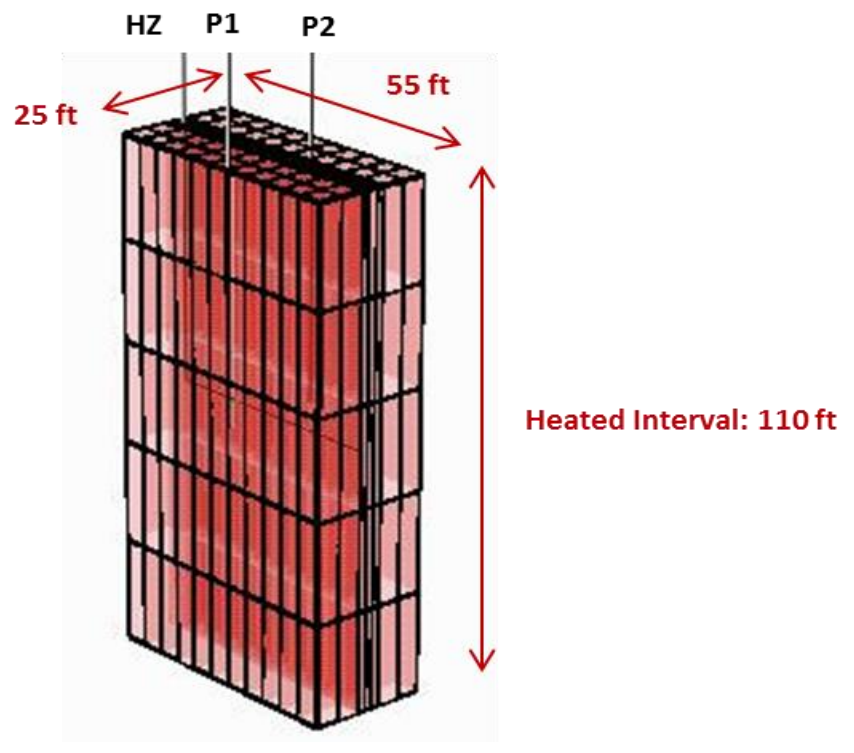

Figure 33:ExxonMobil EF simulation model developed using CMG 


\subsection{Simulation model description}

We have used Cartesian grid system of $11 * 11 * 9$ grids along $\mathrm{x}, \mathrm{y}$ and $\mathrm{z}$ directions with local grid refinement (LGR) for the grid bloacks containing the propped fracture as represented in Figure 33. The horizontal well (HZ) is drilled through the middle layer of oil shale deposit with a longitudinal fracture length $\left(2 x_{f}\right)$ and height $\left(h_{f}\right)$ of $55 \mathrm{ft}$ and 110 $\mathrm{ft}$ respectively and spacing of $25 \mathrm{ft}$. Both overburden and underburden thickness are taken as $80 \mathrm{ft}$ each. The simulation area is same as that Shell ICP case of hexagonal heater pattern with $20 \mathrm{ft}$ spacing. The propped fracture conductivity and thermal conductivity of value $2000 \mathrm{md}-\mathrm{ft}$ and $1600 \mathrm{Btu} / \mathrm{ft} / \mathrm{Day} /{ }^{0} \mathrm{~F}$ are assumed respectively for the fractured plane containing the electrically conductive material. The formation depth is $1970 \mathrm{ft}$ with the targeted heated interval of $110 \mathrm{ft}$ approximately. The top of the heated interval is at $1780 \mathrm{ft}$ depth. The horizontal well is being heated to a constant wellbore temperature of $800^{\circ} \mathrm{F}$ in the heated interval. Here we must note that in reality, vertical fractures cannot be created at shallow depth and the ExxonMobil approach is intended for formation depth sufficiently great to achieve vertical fractures. For heating and flow sensitivity, the total cumulative recovery and production rates are compared with that of Shell ICP case of hexagonal heater pattern operating at $600{ }^{0} \mathrm{~F}$ and $20 \mathrm{ft}$ spacing and are shown in Figure 34 and Figure 35. 


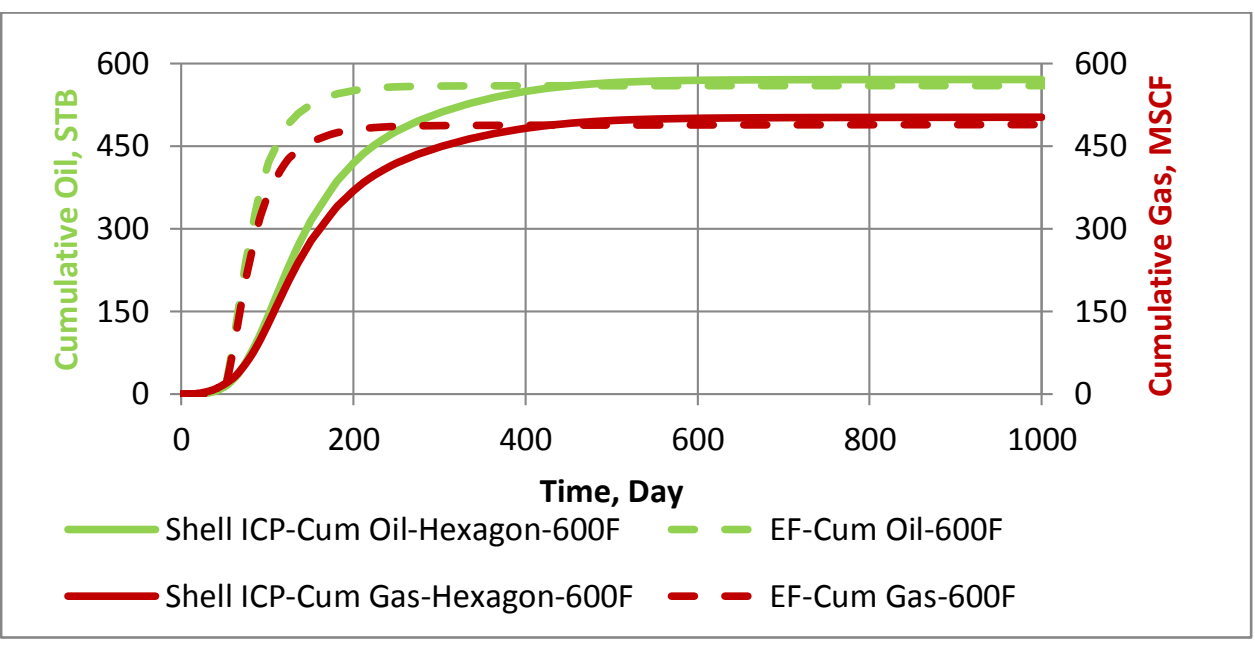

Figure 34: Comparison of Shell ICP and ExxonMobil EF: cumulative oil and gas production

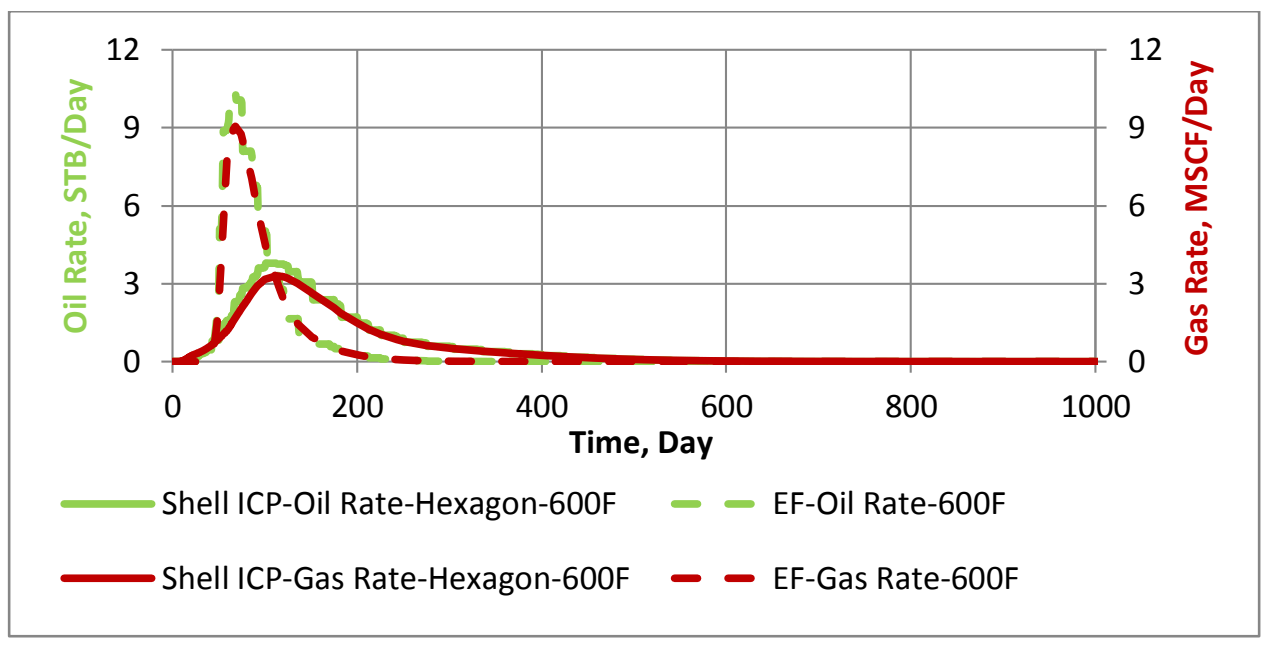

Figure 35: Comparison of Shell ICP and ExxonMobil EF: oil and gas production rates

It can be inferred from Figure 34 that though the ultimate recovery remains the same, the rate of recovery from Electrofrac process is higher than that of Shell ICP methodology. The peak oil production rate observed is 10 STB /Day as compared to 4 STB /Day of Shell ICP as shown in Figure 35. The maximum rate of gas production is 9 
MSCF /Day as compared to $3 \mathrm{MSCF} /$ Day of Shell ICP. These results are in conformance with the fact that linear conduction from planar fracture is more effective than the radial heat conduction from a wellbore.

\subsection{Sensitivity runs}

In this section, sensitivity analyses on the effect of heater temperature and longitudinal fracture length created from horizontal well on hydrocarbon production are performed.

\subsubsection{Effect of temperature}

We investigated the effect of temperature on production profile for the Electrofrac method when operated at temperatures of $600{ }^{0} \mathrm{~F}, 700{ }^{0} \mathrm{~F}$ and $800{ }^{0} \mathrm{~F}$. When heated for longer time at these temperatures, the ultimate recovery attains similar values as shown in Figure 36 but the peak production rates are greater for the higher temperatures as represented in Figure 37. Similar to Shell ICP method, higher heating temperature results in greater gas production and lower liquid recovery with total barrel of oil equivalent $(\mathrm{BOE})$ remains almost same and is equal to $660 \mathrm{BOE}$. It is because, at higher

temperatures, heavier components thermo-kinetically decompose to yield gaseous products and char. 


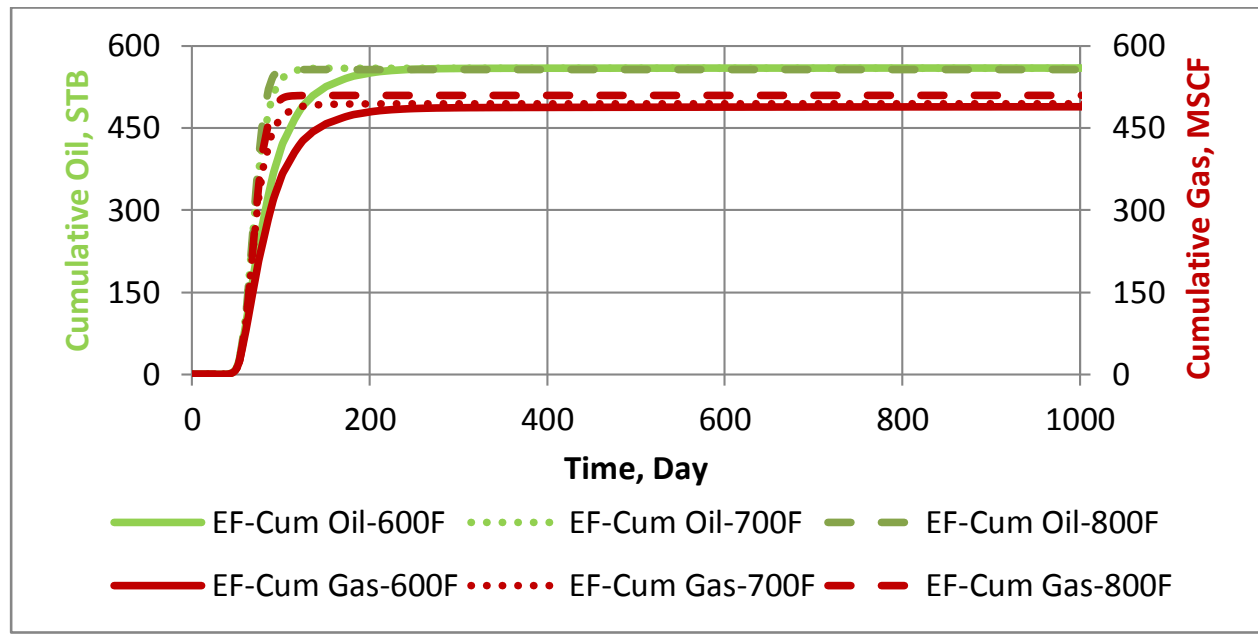

Figure 36: Effect of Temperature on ExxonMobil EF process: cumulative oil and gas production

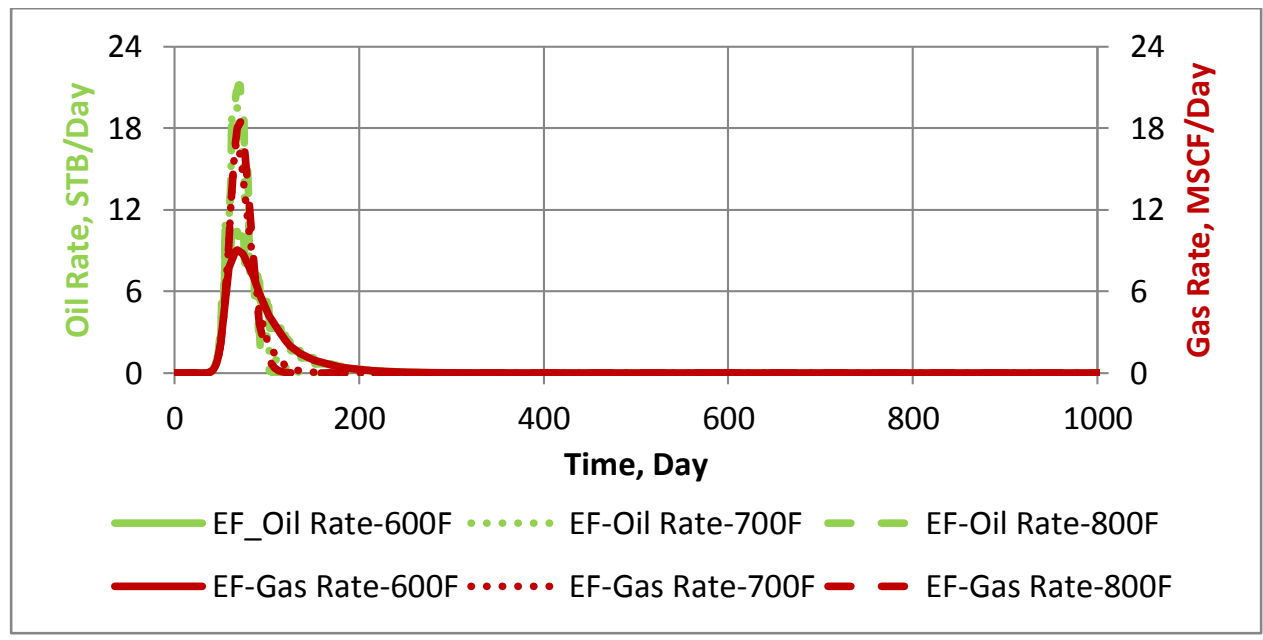

Figure 37: Effect of Temperature on ExxonMobil EF process: oil and gas production rates

Figure 38 shows the temperature profile of the heated formation when heaters are operated at the temperatures of $600{ }^{0} \mathrm{~F}, 700{ }^{\circ} \mathrm{F}$ and $800{ }^{0} \mathrm{~F}$ for $50,100,150$ and 200 days respectively and can be explained in the same manner as that of Shell ICP. 


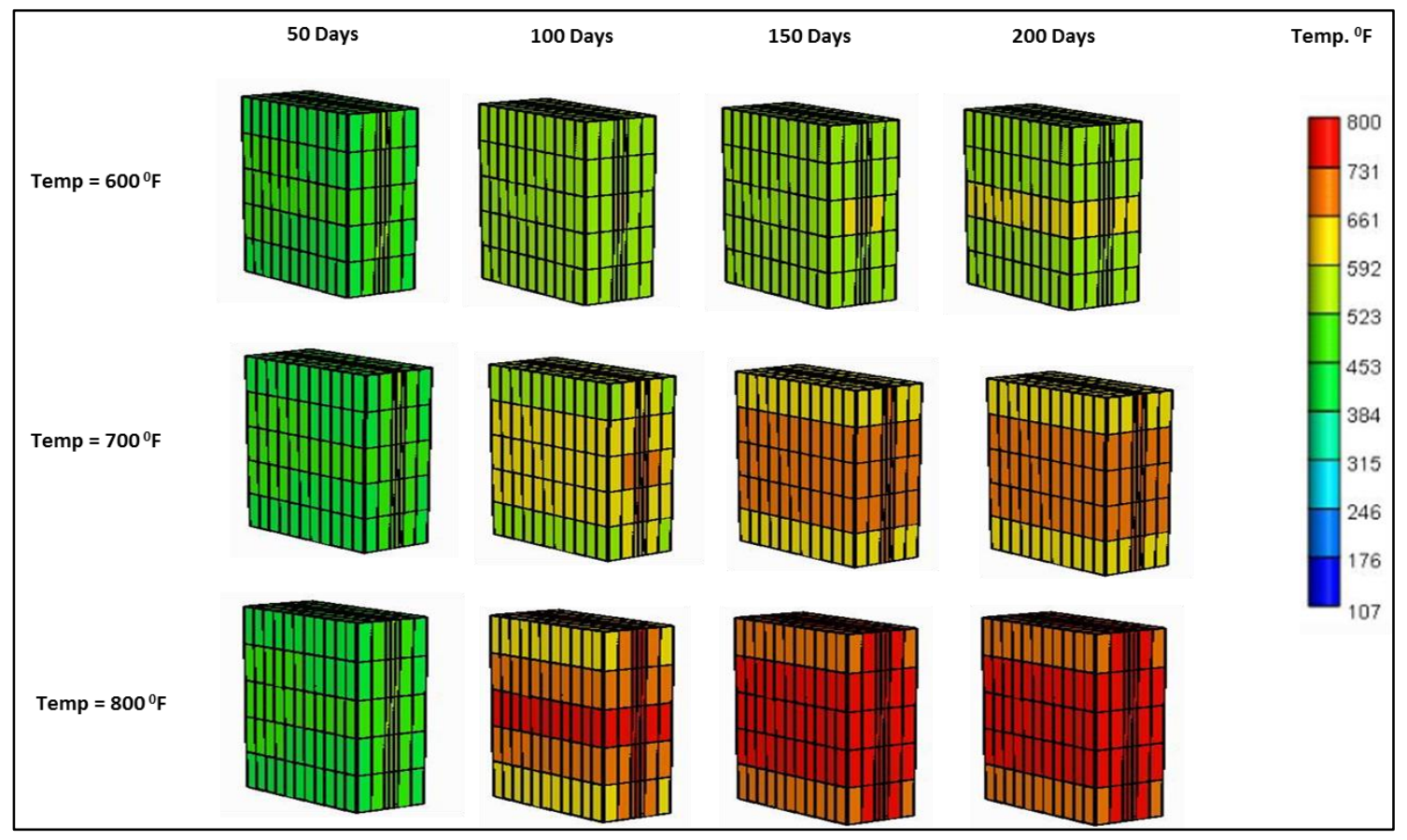

Figure 38: Formation temperature profile for heater temperature $=600^{\circ} \mathrm{F}, 700^{\circ} \mathrm{F}$, $800^{0} \mathrm{~F}$

\subsubsection{Effect of fracture length}

We also investigated the effect of fracture length on production profile for two additional fracture lengths of $35 \mathrm{ft}$ and $45 \mathrm{ft}$ when operated at temperature of $600{ }^{0} \mathrm{~F}$. As shown in Figure 39, when heated for longer time, the ultimate recovery attains similar values but the peak production rates are higher and occur earlier for greater fracture lengths as shown in Figure 40. The observed peak oil and gas production rates are 11 STB /Day and $10 \mathrm{MSCF} /$ Day respectively for fracture length of $55 \mathrm{ft}$ as compared to 10 STB /Day and $9 \mathrm{MSCF} /$ Day respectively for fracture length of $35 \mathrm{ft}$. This is due to the reason that greater the fracture length, bigger is the conduit through which the formation 
is being heated that expedites the conversion of kerogen into hydrocarbon.

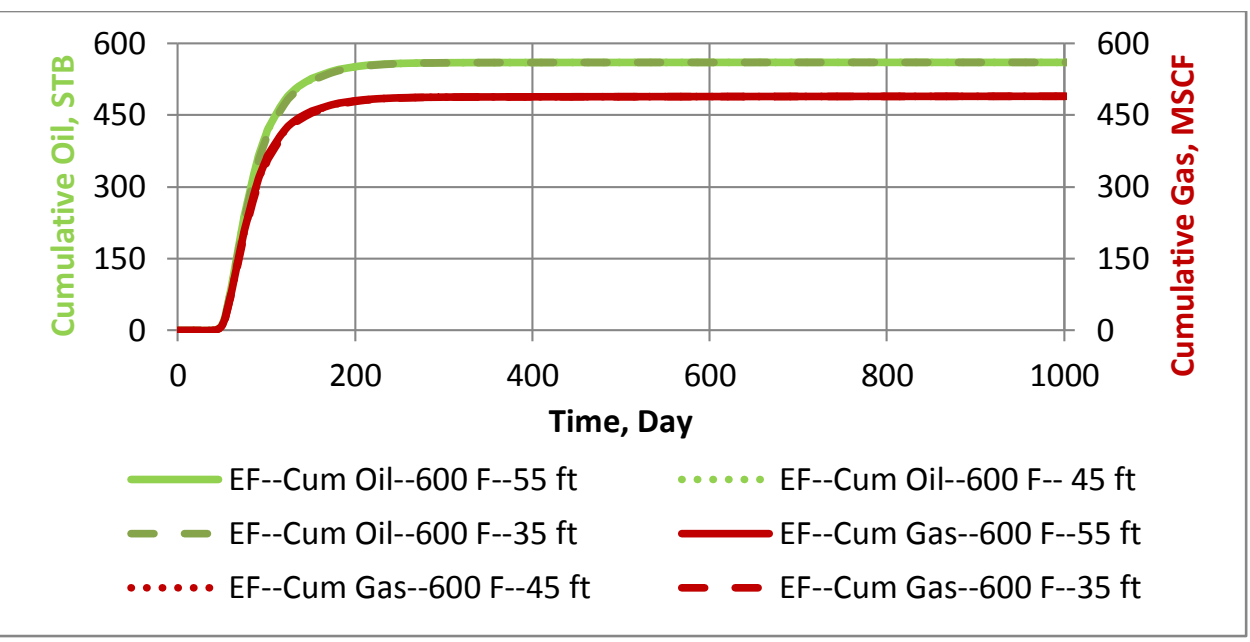

Figure 39: Effect of heater spacing on cumulative oil and gas production

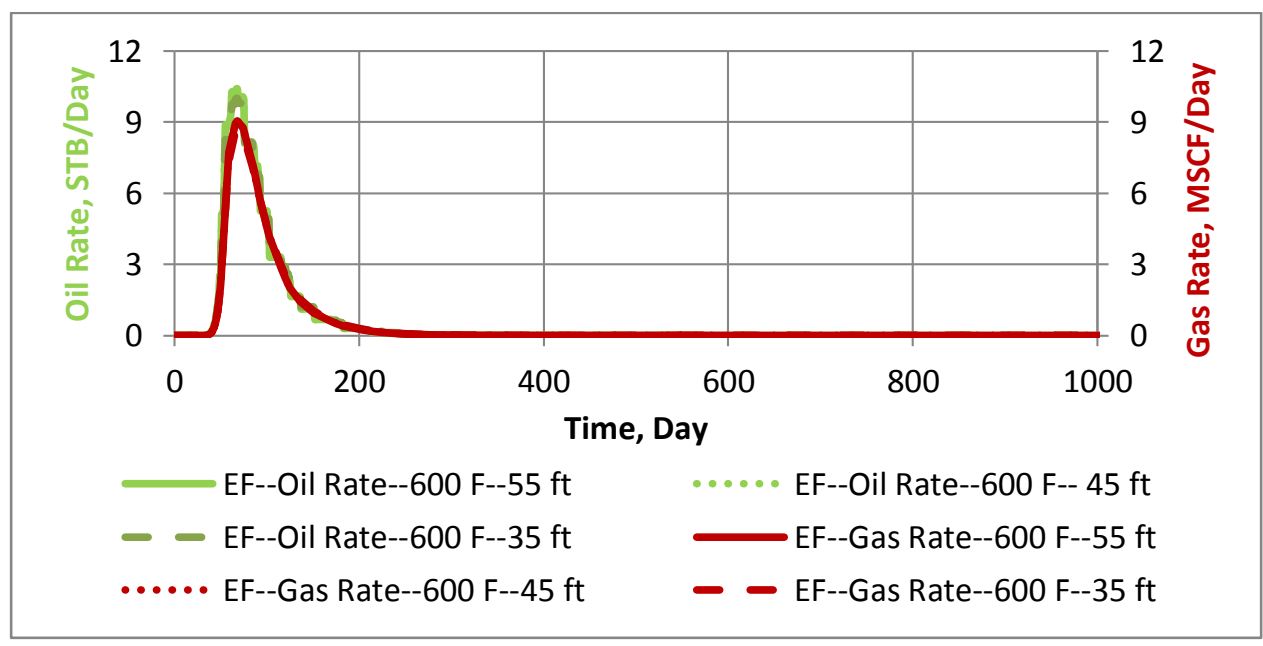

Figure 40: Effect of heater spacing on oil and gas production rates

Figure 41 shows the temperature profile of the heated formation for different fracture lengths at the heater temperature of $600{ }^{0} \mathrm{~F}$ for $50,100,150$ and 200 days 
respectively. Greater the fracture length, sooner the formation temperature reaches the pyrolysis window.

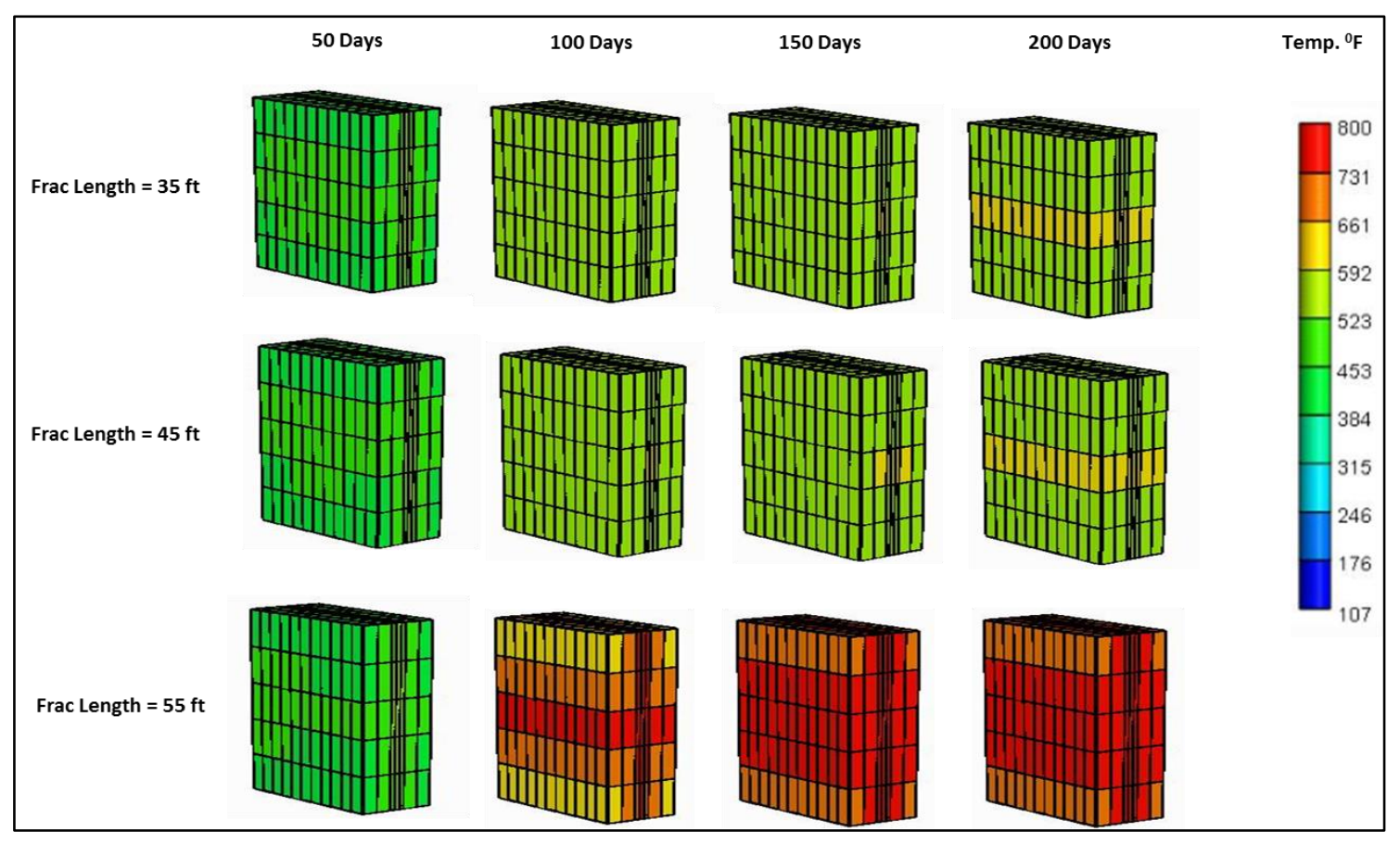

Figure 41: Formation temperature profile for fracture lengths $=35 \mathrm{ft}, 45 \mathrm{ft}, 55 \mathrm{ft}$

\subsection{ExxonMobil electrofrac energy efficiency comparison for various cases}

The energy efficiency of the Electrofrac method for $90 \%$ hydrocarbon recovery operated at different temperatures is shown in Figure 42. The largest efficiency obtained is approximately $140 \%$ at $600{ }^{0} \mathrm{~F}$. Since fracture acts as an efficient planar heat source, operating electrofrac process at lower temperatures curtails the need of higher energy input which in turn minimizes the overburden heat losses. This process is applicable with both vertical and horizontal fractures and can be a better option for deeper 
formations to avoid additional thermal losses incurred in case of downhole electric heaters. However, Shell ICP process can be applied in shallower formations as in-situ stresses may not favor the propagation of vertical fractures.

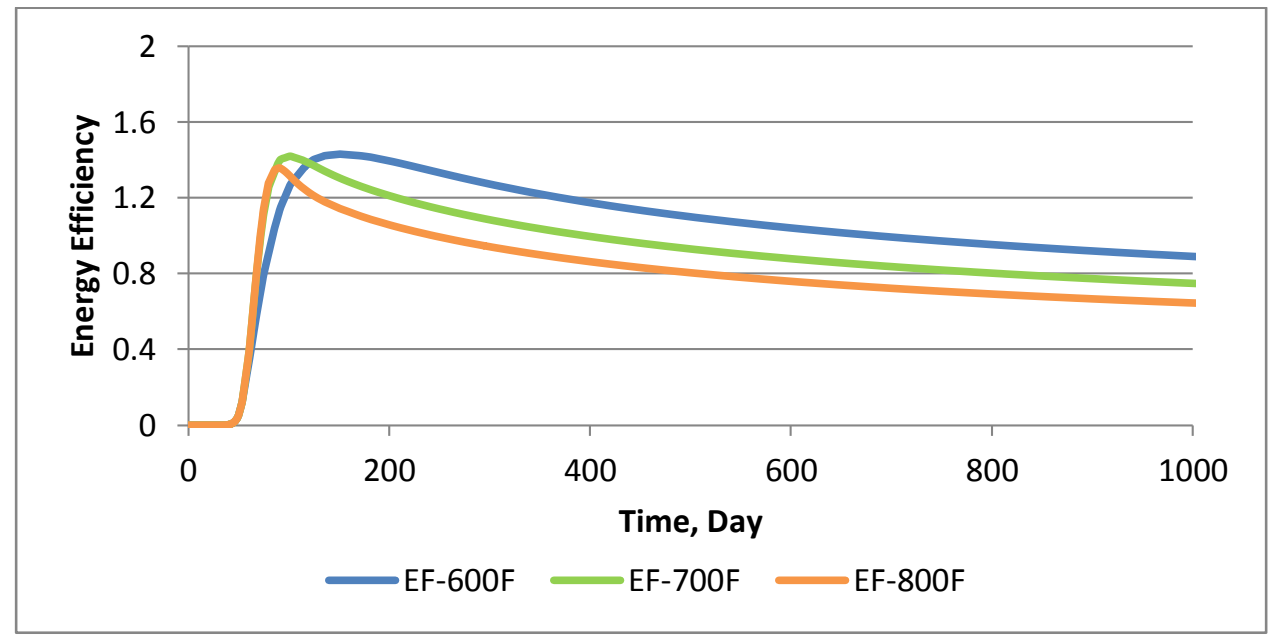

Figure 42: ExxonMobil EF energy ratio comparison for temperatures $=600^{\circ} \mathrm{F}$, $700^{\circ} \mathrm{F}, 800^{\circ} \mathrm{F}$

Figure 43 shows energy efficiency values for different fracture lengths of 35, 45 and $55 \mathrm{ft}$ respectively at $800{ }^{0} \mathrm{~F}$. The peak value is $140 \%$ for fracture length of $55 \mathrm{ft}$ for $90 \%$ of hydrocarbon recovery and is almost similar for other fracture lengths. It is because all these fracture lengths are considered in the same simulation box model, however if the hydrocarbon production is normalized based on the simulated area only containing the fracture length; lowest fracture length will have the highest efficiency, expedited hydrocarbon recovery with higher peak production rates similar to that of Shell ICP cases for different spacing of heater wells for hexagonal arrangement. 


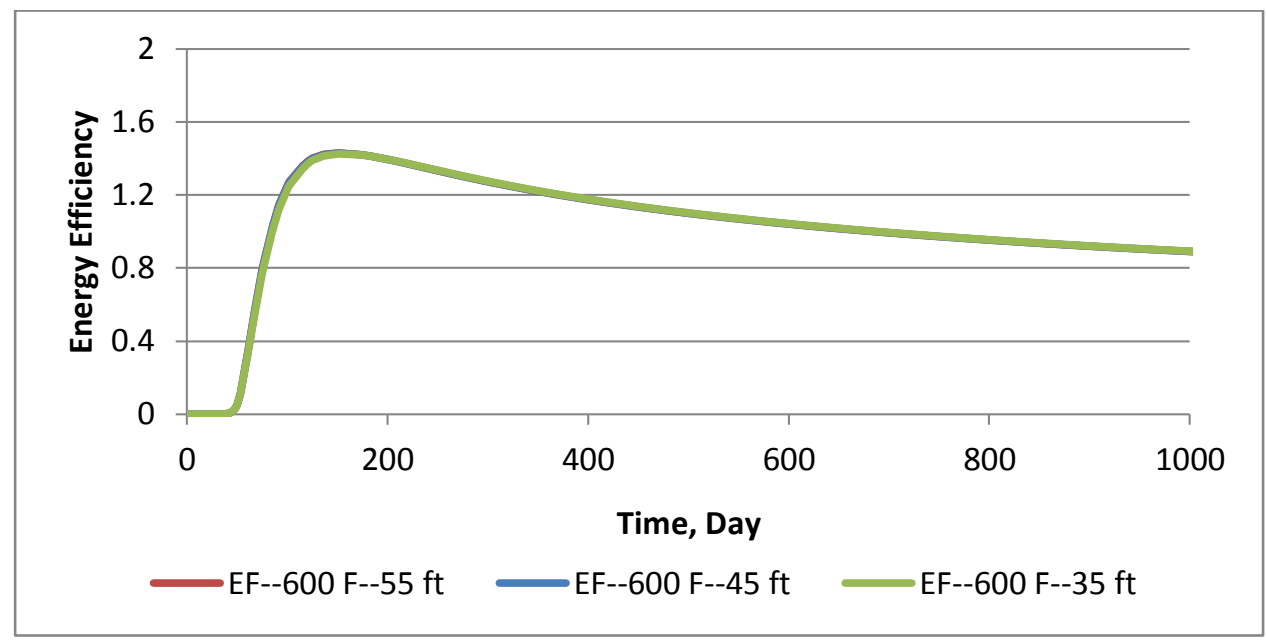

Figure 43: ExxonMobil EF energy ratio comparison of for fracture lengths $=35 \mathrm{ft}$, $45 \mathrm{ft}, 55 \mathrm{ft}$

This chapter described ExxonMobil Electrofrac (EF) technology for oil shale heating. Along with Shell ICP process, both these methodologies are based on direct heating of the formation from wellbore; either with downhole electrical heaters from vertical wells or electrically conducting material placed in the propped longitudinal fracture respectively. In case of ExxonMobil Electrofrac process, maximum energy efficiency is achieved at $600{ }^{0} \mathrm{~F}$. The following chapter illustrates application of one of the indirect heating approaches i.e. Texas A\&M University (TAMU) steam injection through multistage transverse fractured horizontal wells (MTFH) for heating oil shale deposits. A comparative study has been also conducted between direct heating approaches and TAMU MTFH for both steam and $\mathrm{CO}_{2}$ injection on oil and gas production performances accompanied with the effect of type of hot fluid on energy efficiency. 


\section{CHAPTER IV}

\section{TAMU APPROACH (MULTISTAGE TRANSVERSE FRACTURED HORIZONTAL WELLS)}

This chapter illustrates the concept of heating oil shale using hot fluid circulation like super-heated steam as investigated by Thoram and Ehlig-Economides (2011) or $\mathrm{CO}_{2}$ injection through transverse vertical fractures created from a horizontal well to heat the oil shale to pyrolysis temperatures. The transverse vertical fracture created from a horizontal well is intersected by two other parallelydrilled horizontal wells, injector and producer respectively for super heated steam circulation. All the horizontal wells are placed in the middle of the targeted oil shale formation within which the vertical fracture is contained. Chevron proposes a similar approach (Chevron CRUSH) but noncondensable gas like hot $\mathrm{CO}_{2}$ circulation through a network of horizontal hydraulic fractures created from vertical wells (Biglarbigi et al. 2007).

\subsection{Simulation model description}

Our simulation model for MTFH technology consists of modeling one fracture unit with cartesian gridding of $11 * 11 * 9$ grids along $\mathrm{x}, \mathrm{y}$ and $\mathrm{z}$ directions along with local logarithmic grid refinement (LGR) for the grid blocks containing fracture as represented in Figure 44. Fracture length $\left(2 x_{f}\right)$ and height $\left(h_{f}\right)$ are $37 \mathrm{ft}$ and $110 \mathrm{ft}$ respectively with spacing of $35 \mathrm{ft}$ and propped fracture conductivity is taken as $2000 \mathrm{md}-\mathrm{ft}$. Both overburden and underburden thickness are taken as $80 \mathrm{ft}$ each. The formation depth is $1970 \mathrm{ft}$ with the targeted heated interval of $110 \mathrm{ft}$ approximately. The top of the heated 
interval is at $1780 \mathrm{ft}$ depth. The simulation input parameters are same as mentioned in case of ExxonMobil Electrofrac process. The grid area is same as that Shell ICP case of hexagonal heater pattern with $20 \mathrm{ft}$ heater spacing at $600{ }^{0} \mathrm{~F}$.

Super-heated steam is injected at the rate of 200 STB /Day cold water equivalent (CWE) at $600{ }^{0} \mathrm{~F}$ and $300 \mathrm{psi}$ through transverse fracture created from horizontal injector well (HZ-I). In contrast to the model by Thoram and Ehlig-Economides (2011) model which only considered the time to heat the formation to the target temperature, in this case the pressure in the production well is low enough to flowback the converted hydrocarbons through a horizontal producer well (HZ-P) during steam injection.



Figure 44: TAMU MTFH simulation model developed using CMG

As shown in Figure 45 and Figure 46, the total cumulative recovery and production rates 
are compared with that of Shell ICP case of hexagonal heater pattern operating at $600{ }^{0} \mathrm{~F}$ and $20 \mathrm{ft}$ spacing. The ultimate hydrocarbon recovery for both the Shell ICP and TAMU MTFH methodologies are similar though the former technique provides accelerated production. The peak oil and gas production rates are higher and appear earlier in case of Shell ICP at approximately 130 days which means radial conduction is working faster to linear conduction here. This is because in case of Shell ICP, all the heat being generated through downhole electric heaters, is imparted into the formation whereas in case of super heated steam injection, some of the heat is recovered through producer well due to hot fluid circulation i.e. steam.

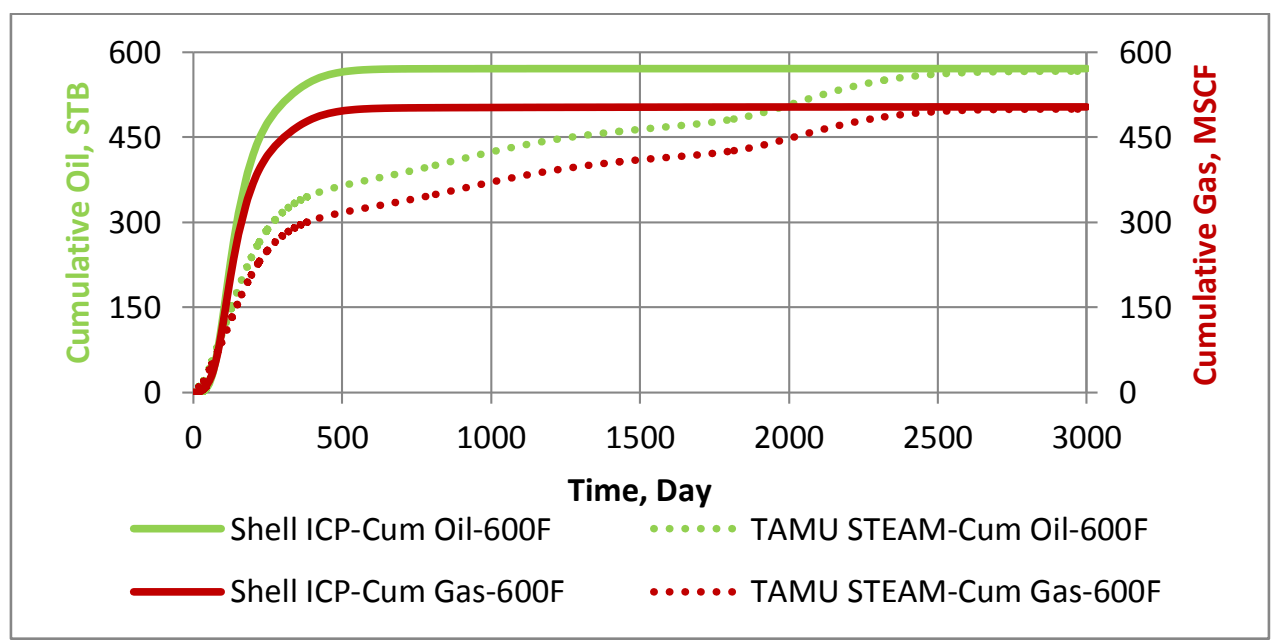

Figure 45: Comparison of Shell ICP and TAMU MTFH STEAM: cumulative oil and gas production 


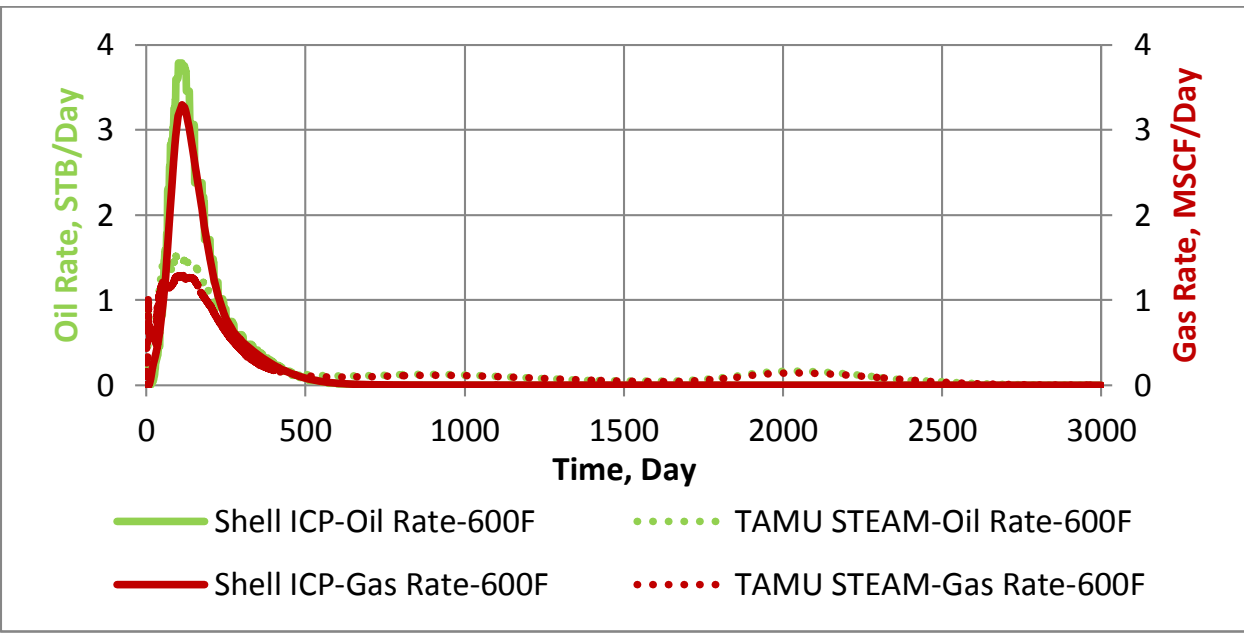

Figure 46: Comparison of Shell ICP and TAMU MTFH STEAM: oil and gas production rates

We have also compared the production profile of TAMU MTFH for steam and $\mathrm{CO}_{2}$ injection to ExxonMobil Electrofrac process for operating temperature of 600 ${ }^{0} \mathrm{~F}$. Hot $\mathrm{CO}_{2}$ gas is injected at the rate of $720 \mathrm{MSCF} /$ Day at $600{ }^{0} \mathrm{~F}$ and 300 psi through transverse fracture created from horizontal injector well (INJ-1). One thing to take into consideration is that both ExxonMobil Electrofrac and TAMU MTFH technologies require creation of transverse vertical fractures which can be achieved at deep formations. From Figure 47, it can be seen that ultimate hydrocarbon recovery is similar whereas from Figure 48, it can be seen that peak oil and gas rates are always higher and achieved earlier in time for eletrofrac method as compared to super-heated steam or $\mathrm{CO}_{2}$ circulation. This is because in case of ExxonMobil Electrofrac, all the heat is imparted into the formation whereas in case of hot fluid circulation whether super heated steam or $\mathrm{CO}_{2}$, some of the heat is recovered at the surface through producer well though in all the cases fracture is acting as the linear conducting source. For super-heated steam or $\mathrm{CO}_{2}$ 
injecton, total hydrocarbon recovery remains the same but the peak oil and gas rates are approximately 1.5 STB/ Day and 1.5 MSCF/ Day respectively for super-heated steam injection which is almost thrice that of the rates obtained with $\mathrm{CO}_{2}$ circulation.

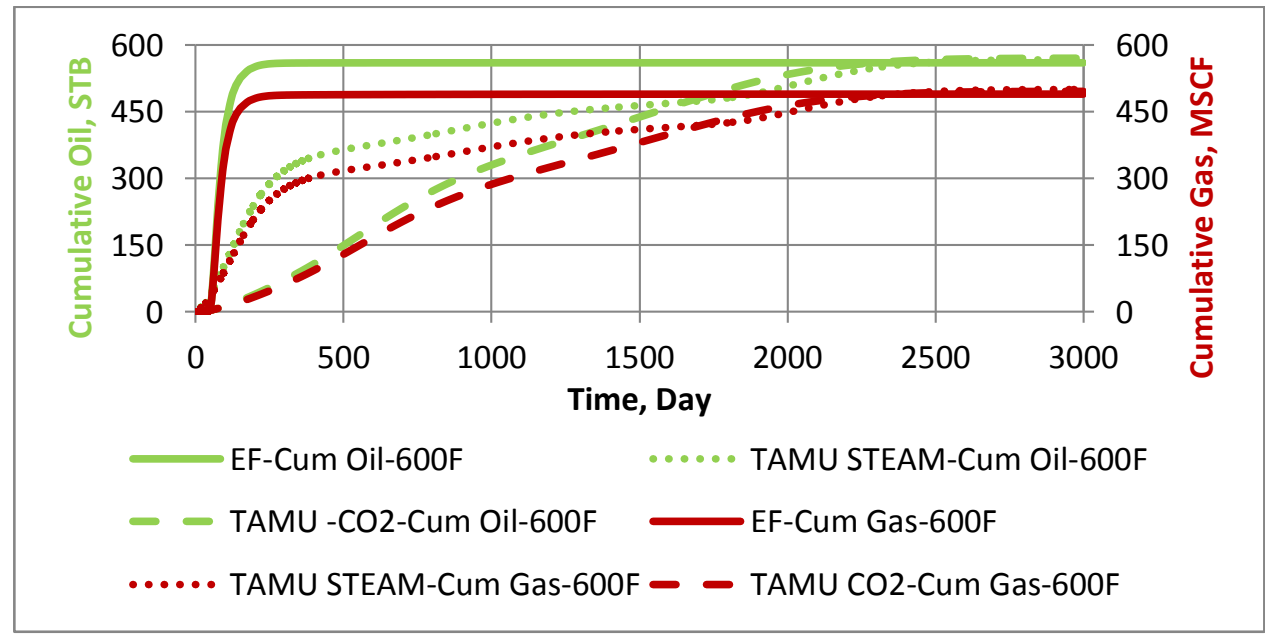

Figure 47: Comparison of EF and TAMU MTFH STEAM \& $\mathrm{CO}_{2}$ : cumulative oil and gas production

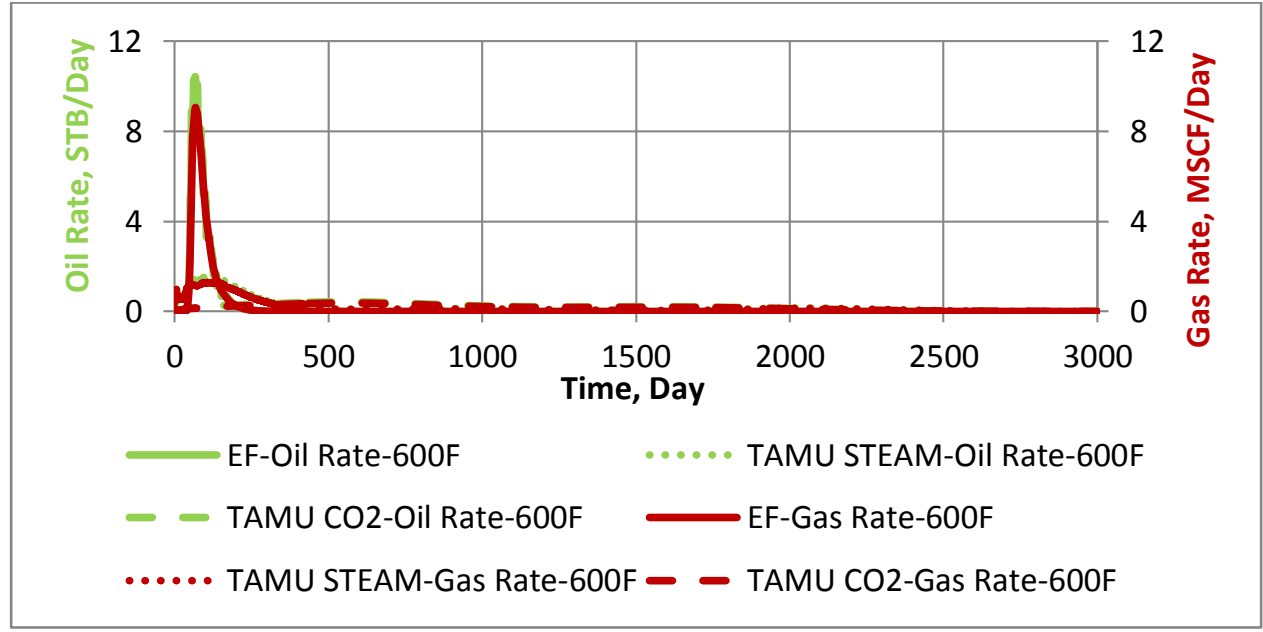

Figure 48: Comparison of EF and TAMU MTFH STEAM \& $\mathrm{CO}_{2}$ : oil and gas production rates 
Figure 49 shows the temperature profile of the heated formation excluding overburden and underburden for TAMU MTFH super-heated steam and $\mathrm{CO}_{2}$ vapor circulation being injected temperature of $600{ }^{\circ} \mathrm{F}$ and 300 psi for 100, 1000, 2000 and 3000 days respectively. One important thing to notice is that the formation temperature rises uniformly for $\mathrm{CO}_{2}$ injection, as the injection well is placed in the middle layer as compared to super-heated steam as gravity override occurs for latter. It is observed that for steam injection, formation temperature increases rapidly as compared to that of $\mathrm{CO}_{2}$ injection as unit mass of steam contains almost four times the enthalpy that of carbondioxide. In this case, to attain similar temperature profile and also to ensure that cumulative hydrocarbon recovery reaches the same value; $\mathrm{CO}_{2}$ is being injected at a rate five times of that of steam injection.

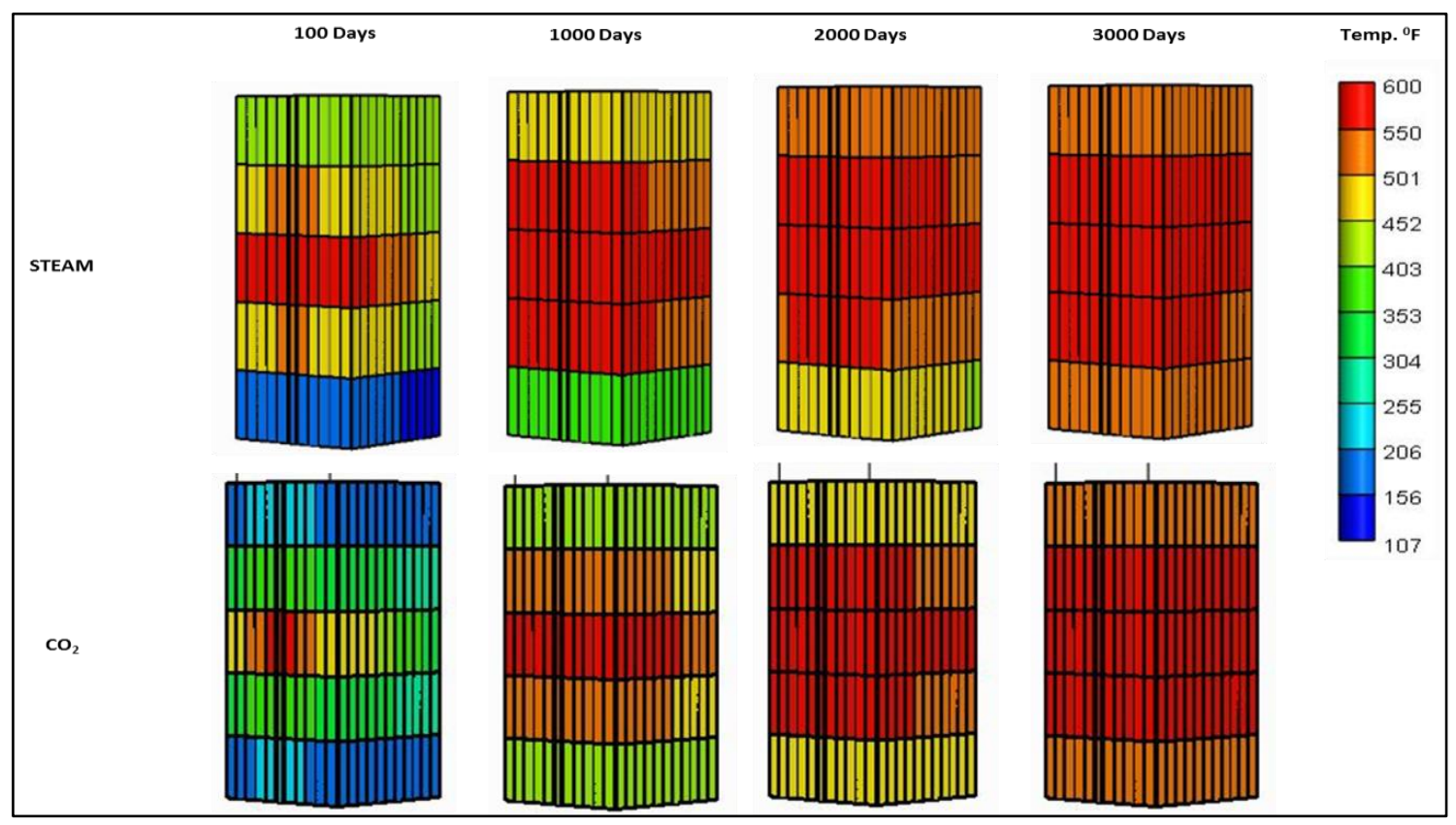

Figure 49: Formation temperature profile for TAMU MTFH STEAM \& $\mathrm{CO}_{2}$ injection 


\subsection{TAMU MTFH energy efficiency comparison}

We have also compared the relative energy efficiency of TAMU MTFH process for steam and $\mathrm{CO}_{2}$ injection at $600{ }^{0} \mathrm{~F}$ and 300 psi to that of ExxonMobil Electrofrac process when heaters are operated at $600{ }^{0} \mathrm{~F}$. In case of TAMU MTFH methodology, energy efficiency is defined as the ratio of total chemical energy content of recovered hydrocarbons with each barrel of oil equivalent yield $5.6^{*} 10^{6}$ btu and the net heat injected into formation from hot fluid circulation e.g. super-heated steam or $\mathrm{CO}_{2} \mathrm{~g}$, given by equation 3 .

The maximum efficiency is obtained when the cumulative oil production becomes constant with time. At this time the heaters could be turned off as all of the kerogen has been converted to oil and gas products, but the simulations actually kept the heaters and hot fluid injection on throughout. With continued heating, the efficiency actually drops, but this is not what we would expect the operator to do in practice. The maximum efficiency occurs when approximately $90 \%$ of the converted oil has been produced.

$$
\eta=\frac{E_{\text {out }}}{E_{\text {in }}}=\frac{\text { Chemical_Energy_HC }}{\text { Thermal_Energy_Fluid }}=\frac{\text { Tot_HC(boe })^{*} 5.6 * 10^{\wedge} 6}{\text { Cum_Enthalpy_inj }- \text { Cum_Enthalpy_prod }} \ldots . . . . .(\text { Eq.3 })
$$

From Figure 50, it is obvious that Electrofrac process has the highest efficieny of almost $140 \%$ whereas TAMU MTFH proposed technology has $150 \%$ efficiency for both steam and $\mathrm{CO}_{2}$ injection respectively. The slope of the graph indicates that highest 
efficiency is achieved much earlier for Electrofrac process, almost at 150 days as compared to 500 and 700 days for TAMU MTFH steam and $\mathrm{CO}_{2}$ injection processes. This ensures faster hydrocarbon recovery and expedited cash flow in case of the former heating method. The slightly lower efficiency of TAMU MTFH process can be understood as partial diffusion of heat from circulating hot fluid to the formation whereas in case of ExxonMobil Electrofrac process, total generated heat is directly injected into the formation. However, the choice of fluid circulation, $\mathrm{CO}_{2}$ vapor or super-heated steam; is incumbent on the commercial availability of natural $\mathrm{CO}_{2}$ source or an aquifer respectively in a close proximity to the oil shale deposits. The technoeconomical feasibility of hot fluid circulation project should be evaluated on the basis of required rates of $\mathrm{CO}_{2}$ and steam injection for similar hydrocarbon recovery from oil shales if both the sources are available or absent.

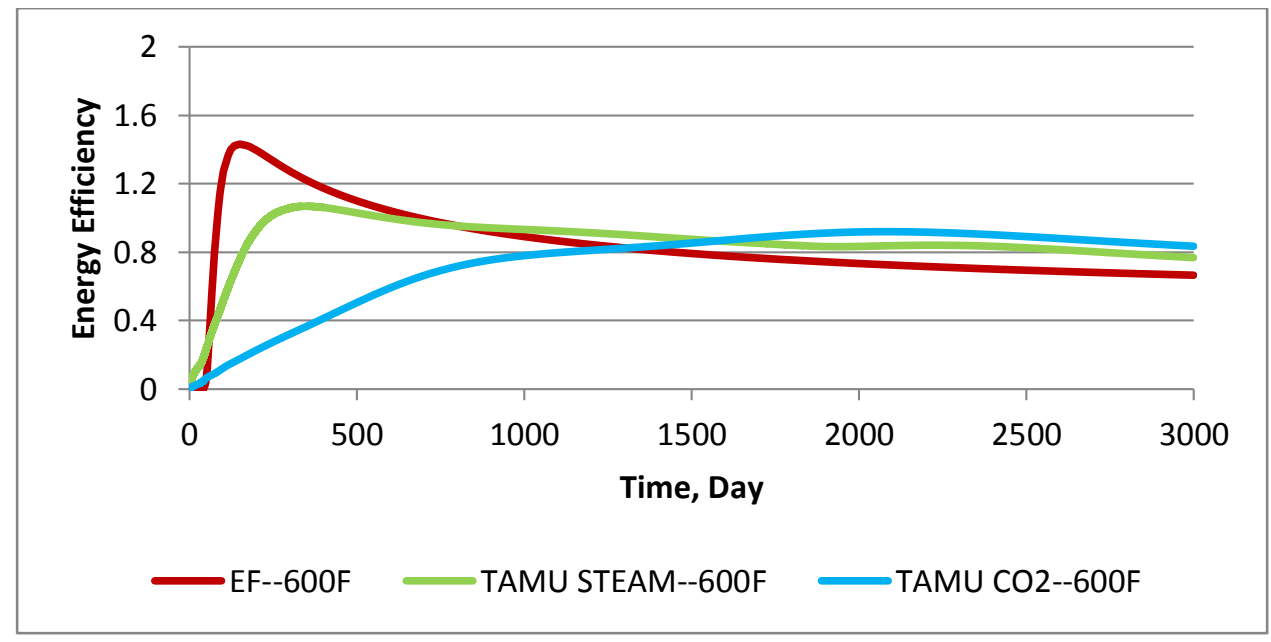

Figure 50: Electrofrac and TAMU MTFH Steam \& $\mathrm{CO}_{2}$ injection energy ratio comparison at temperature $=600^{\circ} \mathrm{F}$ 
This chapter summated one of the indirect heating techniques, TAMU MTFH approach for heating oil shale with steam or $\mathrm{CO}_{2}$ circulation through multiple transverse fractures created from horizontal well. Both ExxonMobil Electrofrac and TAMU MTFH technologies conduct heat into formation through planar source ie.e fractures and hence work on the basis of linear conduction which has lesser heat losses than radial conduction. ExxonMobil Electrofrac process has higher efficiency and expedited hydrocarbon recovery at $600{ }^{0} \mathrm{~F}$ as total generated heat is directly injected into the formation whereas in case of TAMU MTFH approach, partial diffusion of heat from circulating hot fluid to the formation is taking place. For similar hydrocarbon recovery, $\mathrm{CO}_{2}$ has to be circulated at higher rates as compared to super-heated steam as it contains lesser enthalpy. The next chapter describes another indirect heating approach, Chevron CRUSH based on application of heat from circulation of hot fluid, $\mathrm{CO}_{2}$ gas or steam through horizontal fractures originated from vertical wells in shallow oil shale deposits. A comparative study is done with Shell ICP methodology, a direct heating approach for oil and gas production performances accompanied with the effect of type of hot fluid on energy efficiency. 


\section{CHAPTER V}

\section{CHEVRON CRUSH TECHNOLOGY}

Chevron CRUSH process would be implemented in oil shale rich Mahogany zone in Piceance basin, Colorado for 200 feet thick formation. It proposes drilling vertical wells into the target formation with horizontal fractures created from them to circulate hot $\mathrm{CO}_{2}$ gas for heating and if necessary, explosives would be used to further rubblize the formation. Drilling of wells would be carried out in five spot pattern consisting of four injection wells with spacing of $100-300 \mathrm{ft}$ and one centered production well. The implementation of this technology will take place through a series of seven different phases initiating with core studies to thermal decomposition of kerogen to oil and gas.

\subsection{Simulation model description}

Our simulation model for Chevron CRUSH technology consists of Cartesian gridding with $11^{*} 11^{* 9}$ grids along $\mathrm{x}, \mathrm{y}$ and $\mathrm{z}$ directions. Heated interval of $110 \mathrm{ft}$ consisting of two horizontal fractures $35 \mathrm{ft}$ apart with fracture conductivity of $2000 \mathrm{md}$ $\mathrm{ft}$ is represented in Figure 51. We have modelled production performance of a five spot pattern with four injection wells and one centered production well for both $\mathrm{CO}_{2}$ and steam injection. The formation depth is $470 \mathrm{ft}$ and the top of the heated interval is at 200 $\mathrm{ft}$ depth. Both overburden and underburden thickness are $80 \mathrm{ft}$ each. The simulation input parameters are same as in case of TAMU MTFH process.

We have compared the production profile of Chevron CRUSH methodology for 
steam and $\mathrm{CO}_{2}$ injection to Shell ICP case of hexagonal heater pattern operating at 600 ${ }^{0} \mathrm{~F}$ and $20 \mathrm{ft}$ spacing as both these methods can be implemented at shallow depth. Hot $\mathrm{CO}_{2}$ gas and super-heated steam are injected at the rate of $360 \mathrm{MSCF} /$ Day and 100 STB/ Day cold water equivalent (CWE) at $600{ }^{0} \mathrm{~F}$ and 300 psi respectively through the horizontal fractures created from vertical wells (I-1, 2, 3, and 4). The simulation area is kept similar to other heating methodologies at $1369 \mathrm{ft}^{2}$.

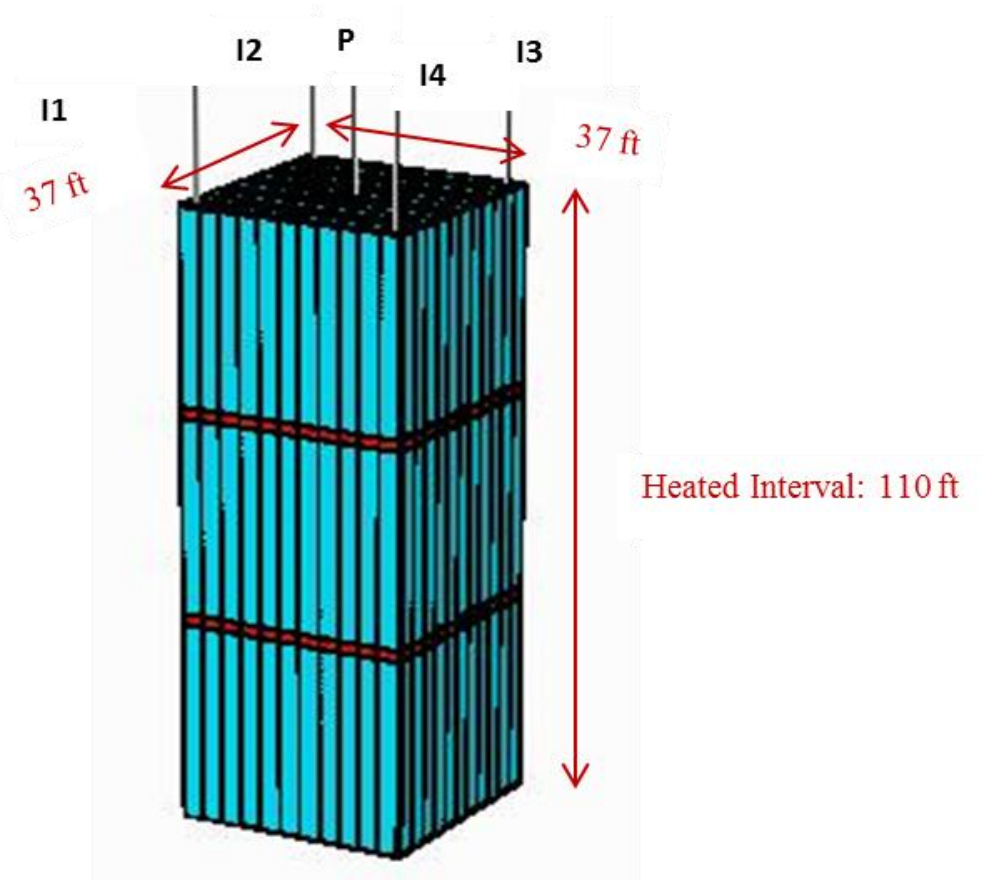

Figure 51: Chevron CRUSH simulation model developed using CMG

From Figure 52, it is inferred that ultimate hydrocarbon recovery is similar whereas from Figure 53, it can be seen that peak oil and gas rates are always higher and achieved earlier in time for Shell ICP as compared to super-heated steam or $\mathrm{CO}_{2}$ circulation for 
chevron CRUSH. This is because in case of Shell ICP, all the heat is imparted into the formation whereas in case of hot fluid circulation whether super heated steam or $\mathrm{CO}_{2}$, some of the heat is recovered at the surface through producer well. For super-heated steam injection, peak oil and gas rates are approximately 2 STB/Day and 2 MSCF/Day respectively and is twice of that of the $\mathrm{CO}_{2}$ injecton; though the cumulative hydrocarbon recovery remains the same for both hot fluid injections. Peak production rates always occur earlier for steam injection as compared to $\mathrm{CO}_{2}$ circulation for Chevron CRUSH method.

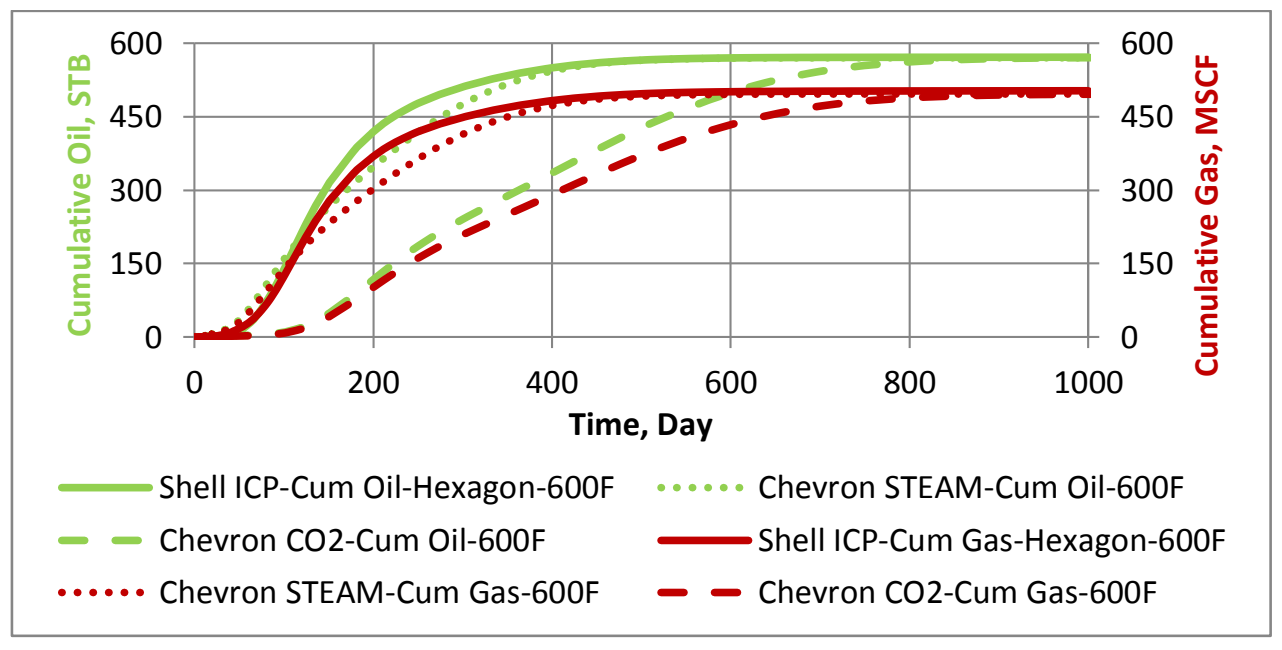

Figure 52: Comparison of Shell ICP and Chevron CRUSH STEAM \& $\mathrm{CO}_{2}$ : cumulative oil and gas production 


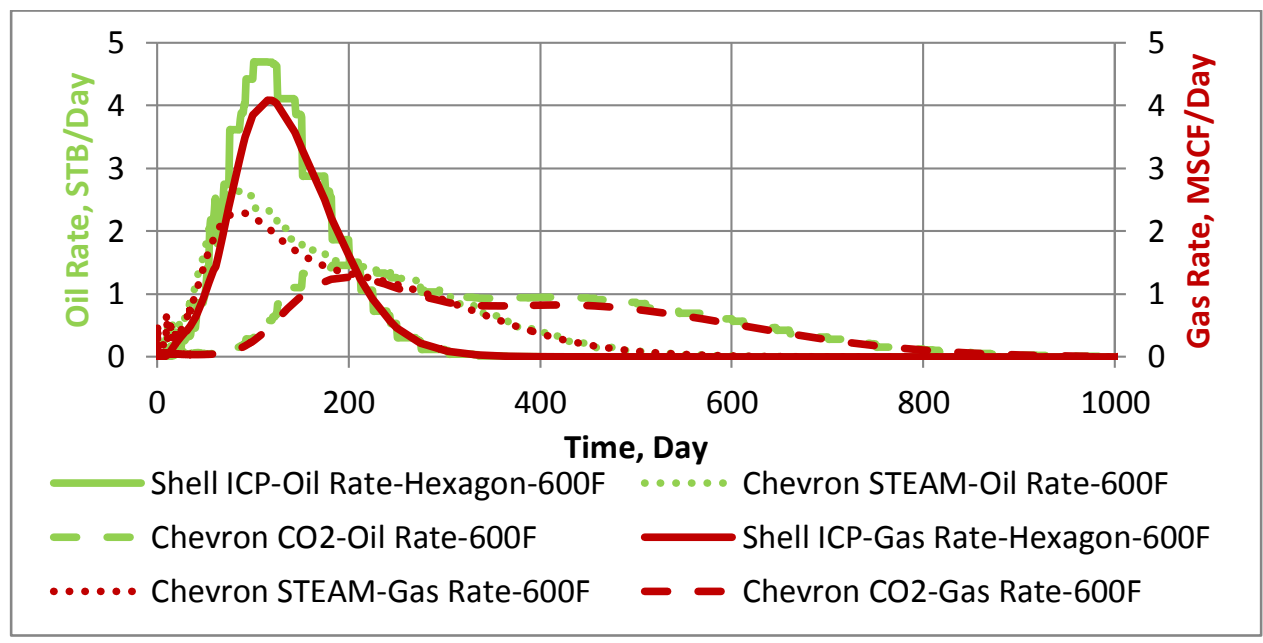

Figure 53: Comparison of Shell ICP and Chevron CRUSH STEAM \& $\mathrm{CO}_{2}$ : oil and gas production rates

Figure 54 shows the temperature profile of the heated formation for Chevron CRUSH super-heated steam and $\mathrm{CO}_{2}$ vapor circulation being injected temperature of $600{ }^{0} \mathrm{~F}$ and 300 psi for $200,400,600$ and 800 days respectively. It is observed that for steam injection, formation temperature increases rapidly as compared to that of $\mathrm{CO}_{2}$ injection as unit mass of steam contains almost four times the enthalpy that of carbondioxide. Similar to TAMU MTFH methodology, formation temperature rises uniformly for $\mathrm{CO}_{2}$ injection but slower as compared to super-heated steam where gravity override occurs leading to higher heating of the layers above the horizontal fractures. As the injection is continued for long time, the targeted formation will attain the window of pyrolysis temperature all throughout. 


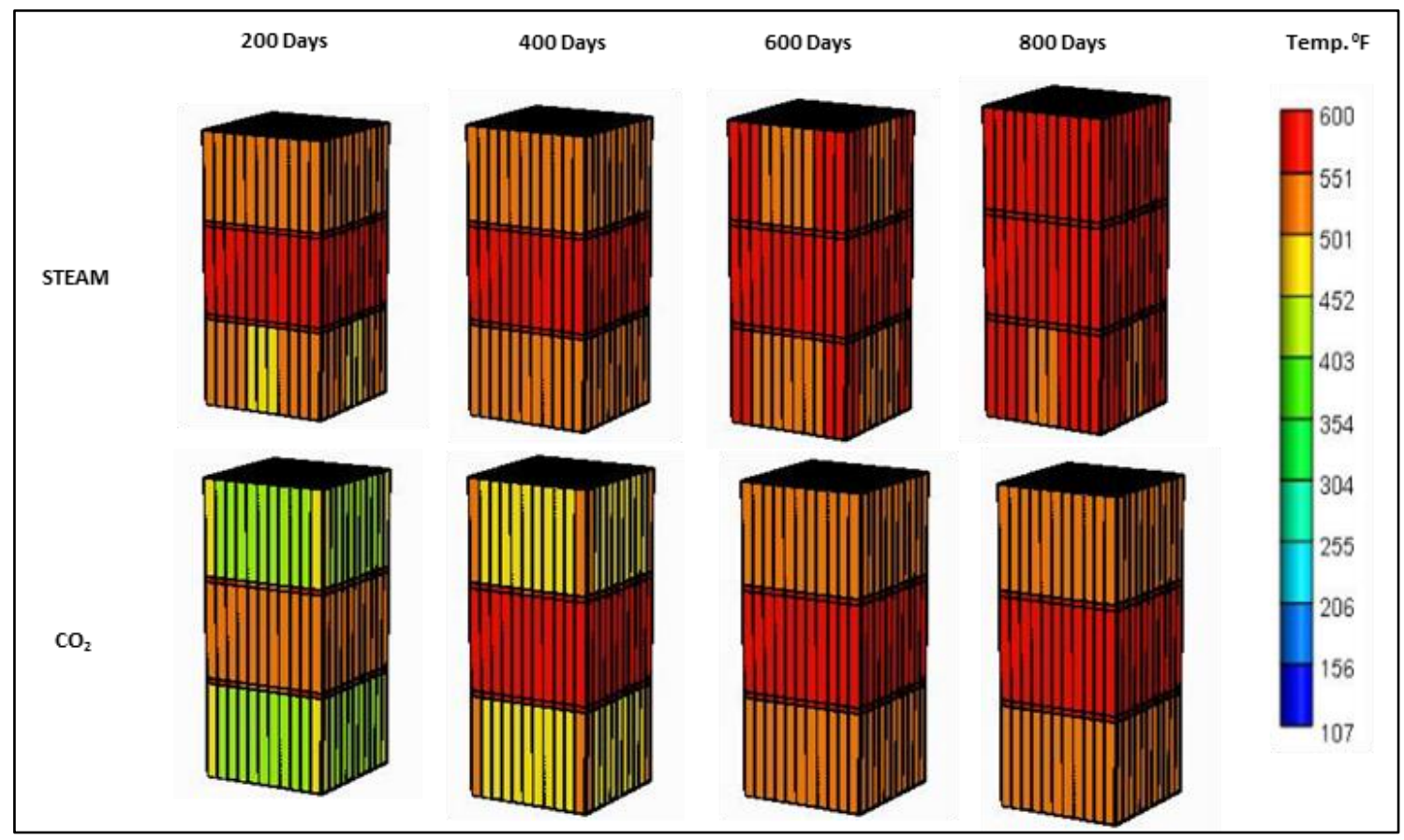

Figure 54: Formation temperature profile for Chevron CRUSH STEAM and $\mathrm{CO}_{2}$ injection

\subsection{Chevron CRUSH energy efficiency comparison}

We have compared the relative energy efficiency of Chevron CRUSH process for steam and $\mathrm{CO}_{2}$ injection at $600{ }^{0} \mathrm{~F}$ and 300 psi to that of Shell ICP case of hexagonal heater pattern operating at $600{ }^{0} \mathrm{~F}$ and $20 \mathrm{ft}$ spacing. The maximum efficiency occurs when approximately $90 \%$ of the converted oil has been produced after which the injection of hot fluid heaters could be discontinued as all of the kerogen has been converted to oil and gas products. With continued injection, the efficiency actually drops, that is not expected to be practiced. From Figure 55, it is inferred that Chevron CRUSH technology has the highest efficieny of almost $140 \%$ and $120 \%$ for both steam and $\mathrm{CO}_{2}$ injection respectively as compared to $120 \%$ of Shell ICP process. Nonetheless, 
the highest efficiency for Shell ICP is achieved earlier in time as compared to that of Chevron CRUSH that ensures faster hydrocarbon recovery and expedited cash flow. The higher efficiency of Chevron CRUSH process can be attributed to heat conduction from fractures that act as an efficient planar heat source, curtailing the need of radial heating from downhole electric heaters that result in excessive peripheral heat losses. When compared to Shell ICP process, Chevron CRUSH technolgy serves as a more energy efficient in-situ upgrading process for oil shale conversion.

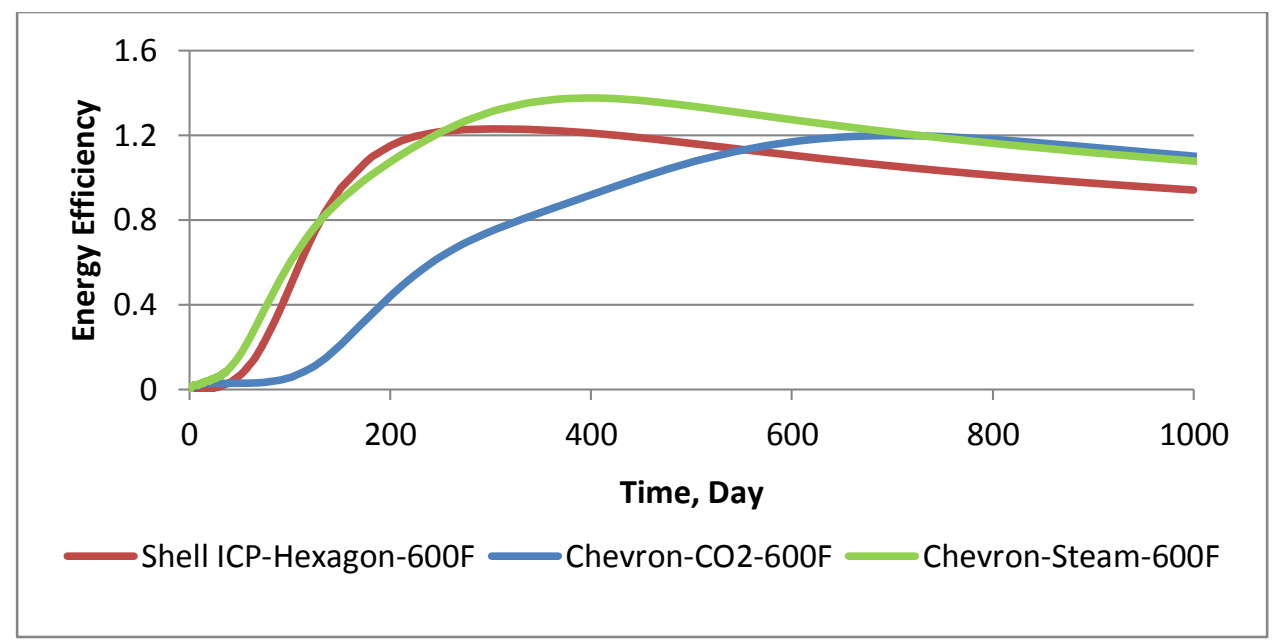

Figure 55: Shell ICP and Chevron CRUSH STEAM \& $\mathrm{CO}_{2}$ injection energy ratio comparison at temperature $=600^{\circ} \mathrm{F}$

This chapter explained Chevron CRUSH technology for hydrocarbon extraction based on indirect heating of oil shale, one of the indirect heating techniques. Both Shell ICP and Chevron CRUSH are implemented at shallow oil shale deposits, howver former method has expedited hydrocarbon recovery but lower efficiency due to heat losses from 
radial conduction. Similar to TAMU MTFH, for equal hydrocarbon recovery, $\mathrm{CO}_{2}$ has to be circulated at higher rates as compared to super-heated steam because of lesser heat content. 


\section{CHAPTER VI \\ DISCUSSION AND CONCLUSIONS}

This chapter sums up all the in-situ methods elaborated in this thesis along with conclusions and recommendations.

\subsection{Discussion}

This section categorizes all the heating methods discussed so far on the basis of depth of application. As some of these in-situ techniques require creation of vertical or horizontal fractures in the formation, a detailed stress studies on core samples from the formation is required to analyse the propagation of type of fracture in the subsurface. Also, TAMU MTFH and Chevron CRUSH methods are based on heating of oil shale by hot fluid circulation i.e. steam or carbondioxide respectively; generation of type of fluid is dependent on pressure and temperature.

The terms mentioned in Figure 56 are explained below.

- Stress line: A hypothetical critical depth of $1300 \mathrm{ft}$ is calculated using the parameters mentioned in (Economides et al. 2012), greater than which will facilitate creation of transverse vertical fractures in the formation as the vertical stress will be greater than the minimum horizontal stress.

- Steam quality: At $600{ }^{0} \mathrm{~F}$, super-heated steam can be generated to critical pressure of $\mathrm{p}_{\mathrm{c}, \mathrm{H} 2 \mathrm{O}}=1542 \mathrm{psi}$ which when assumed as hydrostatic pressure, $\mathrm{p}_{\mathrm{hyd}}$ and is converted to depth; approximately equals to $3600 \mathrm{ft}$. Greater than $3600 \mathrm{ft}$ or $\mathrm{p}_{\mathrm{c}, \mathrm{H} 2 \mathrm{O}}$, only saturated steam can be circulated in the formation at $600{ }^{\circ} \mathrm{F}$ which has a lower 
enthalpy. Similarly, for $\mathrm{CO}_{2}$ vapor circulation, critical pressure is $\mathrm{p}_{\mathrm{c}, \mathrm{CO} 2}=1100 \mathrm{psi}$ above which carbondioxide is generated in supercritical (sc) state.

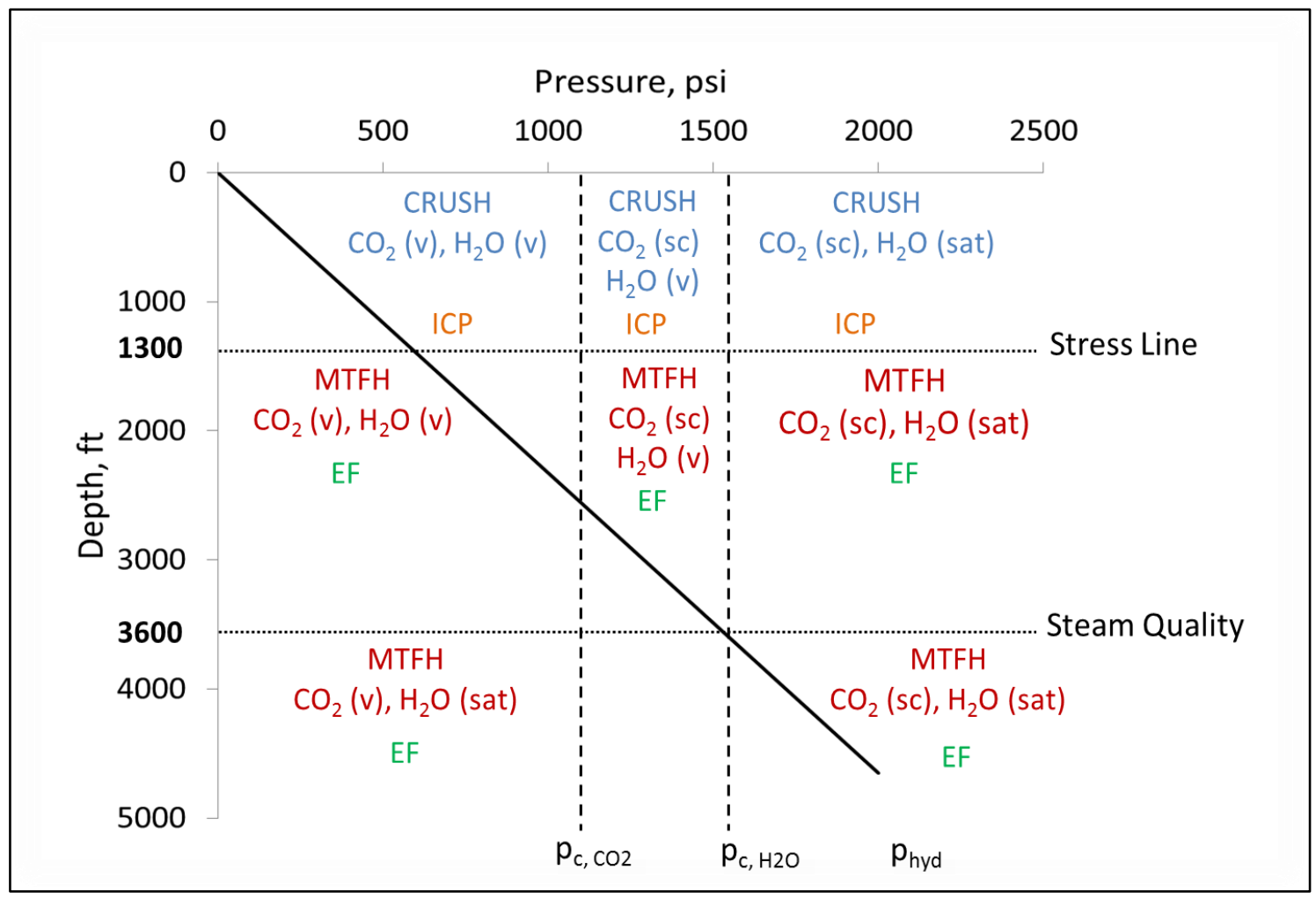

Figure 56: Depth of application of in-situ techniques @ $600{ }^{0} \mathrm{~F}$

It is observed that Shell ICP and Chevron CRUSH heating methodologies can be applied at shallow formation depth though the former can be applied in deeper formations but that could lead to excessive peripheral heat losses because of radial conduction. TAMU MTFH and Electrofrac (EF) processes can be implemented for deeper oil shale deposits that would promote creation of vertical transverse fractures for heating the formation. Since TAMU MTFH proposes circulation of steam through 
transverse vertical fractures, super-heated or saturated; choice of steam type is dependent on the depth of formation and the required pressure for a given temperature.

\subsection{Conclusions}

This study compared various approaches for heating and converting kerogen in oil shale to producible hydrocarbons. Both direct and indirect heating methods were studied. Direct heating methods included Shell ICP and ExxonMobil EF. The indirect heating methods included the TAMU MTFH steam injection method and the Chevron CRUSH technology.

- For all direct heating geometries, accelerated production occurs at the maximum temperature of $800{ }^{0} \mathrm{~F}$.

- For direct heating approaches, highest energy efficiency occurred with the ExxonMobil Electrofrac process at $600{ }^{0} \mathrm{~F}$.

- For heating approaches operating at shallow formation depth, highest efficiency is obtained with Chevron CRUSH method for super-heated steam circulation at $600{ }^{0} \mathrm{~F}$.

- For heating approaches operating at deeper formation depth, highest efficiency is obtained with ExxonMobil Electrofrac at $600{ }^{0} \mathrm{~F}$.

- When operating on the same formation bulk volume, all of the heating geometries ultimately produce about the same cumulative hydrocarbon recovery, but closer spacing or increased heating rate will accelerate the production.

- Of the indirect heating approaches, greater efficiency is achieved for steam injection as compared to $\mathrm{CO}_{2}$ vapor. 


\subsection{Recommendations}

Following are the recommendations for making the simulation models more realistic:

- Better understanding of the petrophysics of oil shale.

- Accountance of pre-existing fracture system.

- Use of temperature dependent thermo-physical parameters instead of constant values.

- Modeling of reservoir parameters like porosity and permeability evolution during heating oil shale.

- Rigorous fine scale geological modeling for reservoir flow simulation.

- Economic analysis for each of the method based on capital expenditure (CAPEX) and operational expenditure (OPEX). 


\section{REFERENCES}

Biglarbigi, K., Crawford, P., Carolus, M. et al. 2010. Rethinking World Oil-Shale Resource Estimates. Paper presented at the SPE Annual Technical Conference and Exhibition, Florence, Italy. Society of Petroleum Engineers SPE-135453MS. DOI: 10.2118/135453-MS.

Biglarbigi, K., Dammer, A., Cusimano, J. et al. 2007. Potential for Oil Shale Development in the United States. Paper presented at the SPE Annual Technical Conference and Exhibition, Anaheim, California, U.S.A. Society of Petroleum Engineers SPE-110590-MS. DOI: 10.2118/110590-ms.

Biglarbigi, K., Dammer, A., Mohan, H. et al. 2008. Economics of Oil Shale Development in the United States. Paper presented at the SPE Annual Technical Conference and Exhibition, Denver, Colorado, USA . Society of Petroleum Engineers SPE-116560-MS. DOI: 10.2118/116560-MS.

Braun, R.L. and Burnham, A.K. 1990. Mathematical Model of Oil Generation, Degradation, and Expulsion. Energy \& Fuels 4 (2): 132-146. DOI: 10.1021/ef00020a002

Campbell, J.H., Koskinas, G.H., and Stout, N.D. 1978. Kinetics of Oil Generation from Colorado Oil Shale. Fuel 57 (6): 372-376.

Crawford, P., Biglarbigi, K., Dammer, A. et al. 2008. Advances in World Oil Shale Production Technologies. Paper presented at the SPE Annual Technical Conference and Exhibition, Denver, Colorado, USA. Society of Petroleum Engineers SPE-116570-MS. DOI: 10.2118/116570-ms.

Crawford, P.M., Biglarbigi, K., Dammer, A.R. et al. 2008. Advances in World Oil-Shale Production Technologies. Paper presented at the SPE Annual Technical Conference and Exhibition, Denver, Colorado, USA. 116570.

Das, K. 1989. Solvent and Supercritical Fluid Extraction of Oil Shale: A Literature Survey. USDOE Morgantown Energy Technology Center, WV (USA). 
Dow, W.G. 1977. Kerogen Studies and Geological Interpretations. Journal of Geochemical Exploration 7: 79-99.

Dyni, J.R. 2006. Geology and Resources of Some World Oil-Shale Deposits Original edition. ISBN.

Economides, M.J., Hill, A.D., Ehlig-Economides, C. et al. 2012. Petroleum Production Systems: Pearson Education. Original edition. ISBN 9780137033256.

Eseme, E., Urai, J., Krooss, B. et al. 2007. Review of Mechanical Properties of Oil Shales: Implications for Exploitation and Basin Modelling. Oil Shale 24 (2): 159174.

Fan, Y., Durlofsky, L., and Tchelepi, H.A. 2010. Numerical Simulation of the in-Situ Upgrading of Oil Shale. SPE Journal 15 (2): pp. 368-381. DOI: 10.2118/118958pa

Fowler, T.D. and Vinegar, H.J. 2009. Oil Shale Icp - Colorado Field Pilots. Paper presented at the SPE Western Regional Meeting, San Jose, California. Society of Petroleum Engineers SPE-121164-MS. DOI: 10.2118/121164-ms.

Hill, G.R. and Dougan, P. 1967. The Characteristics of a Low Temperature in Situ Shale Oil. Paper presented at the Annual Meeting of the American Institute of Mining, Metallurgical, and Petroleum Engineers, Los Angeles, California. Society of Petroleum Engineers SPE-1745-MS. DOI: 10.2118/1745-MS.

Leavitt, D.R., Tyler, A.L., and Kafesjian, A.S. 1987. Kerogen Decomposition Kinetics of Selected Green River and Eastern Us Oil Shales from Thermal Solution Experiments. Energy \& Fuels 1 (6): 520-525.

Miadonye, A., Singh, B., and Puttagunta, V. 1994. Modelling the Viscosity-Temperature Relationship of Alberta Bitumen. Fuel science \& technology international 12 (2): 335-350. 
Prats, M. and O'Brien, S. 1975. The Thermal Conductivity and Diffusivity of Green River Oil Shales. Journal of Petroleum Technology 27 (1): 97-106.

Symington, W.A., Olgaard, D.L., Otten, G.A. et al. 2006. Exxonmobil's Electrofrac ${ }^{\mathrm{TM}}$ Process for in Situ Oil Shale Conversion. In Proceedings of the 26th Oil Shale Symposium.

Thoram, S. and Ehlig-Economides, C.A. 2011. Heat Transfer Applications for the Stimulated Reservoir Volume (Srv). Paper presented at the SPE Annual Technical Conference and Exhibition, Denver, Colorado, USA. Society of Petroleum Engineers SPE-146975-MS. DOI: 10.2118/146975-ms.

Wang, Y., Rajeshwar, K., Nottenburg, R.N. et al. 1979. Thermophysical Properties of Oil Shale Minerals. Thermochimica Acta 30 (1): 141-151.

Wellington, S.L., Berchenko, I.E., De Rouffignac, E.P. et al. 2005. In Situ Thermal Processing of an Oil Shale Formation to Produce a Desired Product. In: Google Patents.

Wen, C.S. and Kobylinski, T.P. 1983. Low-Temperature Oil Shale Conversion. Fuel 62 (11): 1269-1273. 